Florida International University

FIU Digital Commons

7-1-2020

\title{
Measuring the Relationship Between Educational Administrators' and Teacher Leaders' Leadership Styles and School Culture
}

Kristina K. Garcia

kgarc030@fiu.edu

Follow this and additional works at: https://digitalcommons.fiu.edu/etd

Part of the Other Educational Administration and Supervision Commons

\section{Recommended Citation}

Garcia, Kristina K., "Measuring the Relationship Between Educational Administrators' and Teacher Leaders' Leadership Styles and School Culture" (2020). FIU Electronic Theses and Dissertations. 4473. https://digitalcommons.fiu.edu/etd/4473

This work is brought to you for free and open access by the University Graduate School at FIU Digital Commons. It has been accepted for inclusion in FIU Electronic Theses and Dissertations by an authorized administrator of FIU Digital Commons. For more information, please contact dcc@fiu.edu. 


\section{FLORIDA INTERNATIONAL UNIVERSITY}

Miami, Florida

\section{MEASURING THE RELATIONSHIP BETWEEN EDUCATIONAL ADMINISTRATORS' AND TEACHER LEADERS' LEADERSHIP STYLES AND SCHOOL CULTURE}

A dissertation submitted in partial fulfillment of the requirements for the degree of

DOCTOR OF EDUCATION

in

EDUCATIONAL ADMINISTRATION AND SUPERVISION

by

Kristina K. Garcia 
To: Dean Michael R. Heithaus

College of Arts, Sciences and Education

This dissertation, written by Kristina K. Garcia, and entitled Measuring the Relationship Between Educational Administrators' and Teacher Leaders' Leadership Styles and School Culture, having been approved in respect to style and intellectual content, is referred to you for judgment.

We have read this dissertation and recommend that it be approved.

$\begin{array}{r}\hline \text { Teresa Lucas } \\ \hline \text { Mido Chang } \\ \hline \text { Thomas Reio } \\ \hline \text { Peter J. Cistone, Major Professor }\end{array}$

Date of Defense: July 1, 2020

The dissertation of Kristina K. Garcia is approved.

Dean Michael R. Heithaus

College of Arts, Sciences and Education

Andrés G. Gil

Vice President for Research and Economic Development and Dean of the University Graduate School

Florida International University, 2020 
(C) Copyright 2020 by Kristina K. Garcia

All rights reserved. 


\section{DEDICATION}

This dissertation is dedicated to the memory of Dr. Joanne Sanders-Reio, who always advised me to reflect critically, to explore opposing perspectives, to think deeply, but to write simply. Thank you for all of your support and your encouragement.

I also dedicate this dissertation to my three lovely daughters; Jordan Nicole, Lilianne Elizabeth, and Emma Grace. Throughout this process, you have been a constant source of motivation, support, and encouragement. You have exercised eternal patience with the endless late nights, banishment to the park so that I could write papers, and simple (and sometimes late) dinners so that I could accomplish all that I have. You have been my biggest cheerleaders though plenty of challenges. There were times when I doubted, but I never quit and that is because of you. As I always tell you, nothing worth doing is ever easy. You can accomplish anything in life, if only you have the will to see it through. I hope that you are able to read this and understand that I have done all of this for you. I love you all. 


\section{ACKNOWLEDGMENTS}

I would like to acknowledge Dr. Daniel Saunders, whose endless patience and support have helped me to get over this finish line. You have gone above and beyond to help me achieve my goals. Thank you for all of your words of wisdom, petitions, and assistance.

I would also like to acknowledge my committee members, Dr. Teresa Lucas, Dr. Mido Chang, and Dr. Thomas Reio, whose tolerance and advice have been instrumental to helping me to complete of this project. Without your patience and perseverance, I would not have been able to complete my program. I thank you.

I would like to say thank you to Victoria Dobbs, Nicole Berge-MacInnes, and Joseph Eberhard for allowing me to work with your faculty and for your willingness to show yourselves for the exemplary leaders you are.

Finally, I would like to acknowledge my major professor, Dr. Peter J. Cistone. Throughout this process, you have been a cheerful and constant source of encouragement. The challenges that I have had to face in order to complete this project and this program have been many; however, it is your direction and guidance that have helped me through all of them. Your excellent teaching and guidance have helped to shape me into the leader that I am. I truly enjoyed our classes, our discussions, and our debates. Thank you for everything. 


\title{
ABSTRACT OF THE DISSERTATION \\ MEASURING THE RELATIONSHIP BETWEEN EDUCATIONAL ADMINISTRATORS' AND TEACHER LEADERS' LEADERSHIP STYLES AND SCHOOL CULTURE
}

by

\author{
Kristina K. Garcia
}

Florida International University, 2020

Miami, Florida

Professor Peter J. Cistone, Major Professor

The purpose of my study was to examine the relationship between educational administrators' and teacher leaders' leadership styles, and school culture and sought to measure the correlation between the perceived leadership styles of formalized leaders and school culture. The theoretical framework of the study was derived from the Bass and Avolio (1985) Full Range Leadership Model describing the transactional to transformational leadership continuum.

Data for the study were collected using the Multifactor Leadership Questionnaire (MLQ-5X Short Form), a survey containing 45 questions on a Likert type scale. The purpose of the survey is to examine the degree to which leadership behaviors fit along the continuum as a function of the leader and followers' perceptions. The second instrument, the Organizational Description Questionnaire (ODQ) is a survey containing 28 questions designed to evaluate an organization's culture profile.

The data were analyzed using One-Way Analysis of Variance (ANOVA) to ascertain whether there was a significant difference between the primary leadership style 
of administrative leaders, teacher leaders, and followers perception of leadership style; to discover whether a significant difference exists between the perceived school culture profiles; and the relationship that exists between leadership styles and school culture. The study confirmed a difference between administrative leaders' and teacher leaders' leadership styles. It also demonstrated that there is a significant difference between the participants' perceived organizational culture and the transactional profile, which verified that the schools demonstrate significant transformational characteristics. The study confirmed that there is no significant difference between the transformational characteristics of leaders and that of school culture. An analysis of the characteristics found that the predominant combination of styles and culture was TF Moderately Four I's (Highly Developed) combined with TF Idealized Influence (Attributes), both highly transformational.

My study's findings illustrate that leaders who demonstrate transformational characteristics also demonstrate a significant amount of transformational culture characteristics. These conclusions elucidate the practices within the organization that there is, in fact, a relationship between educational administrators' and teacher leaders' transformational leadership style and transformational school culture. 


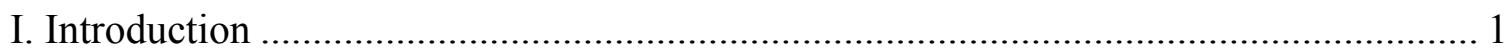

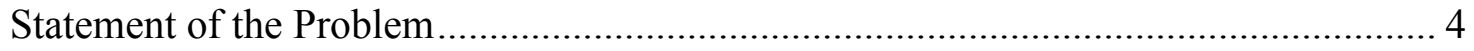

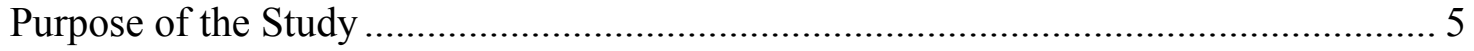

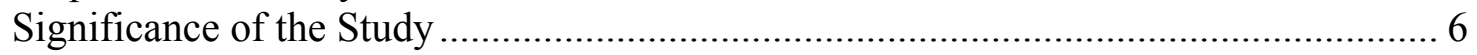

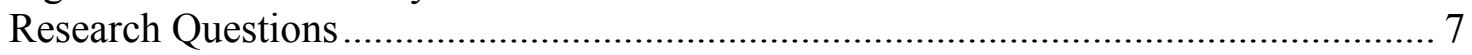

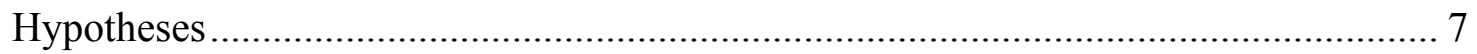

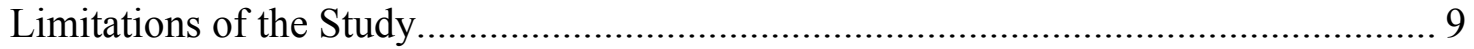

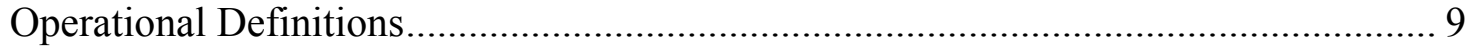

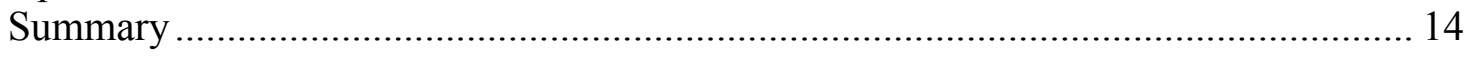

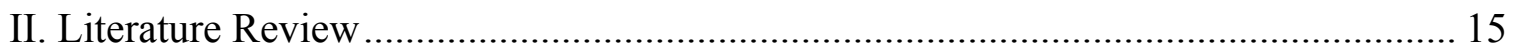

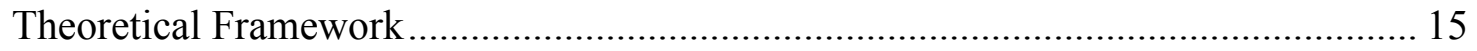

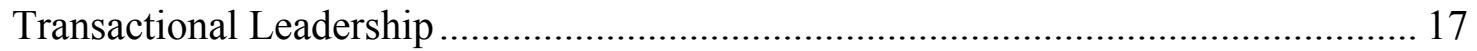

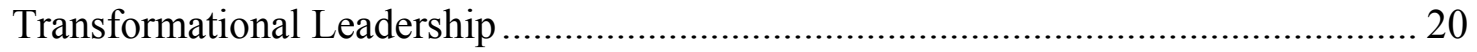

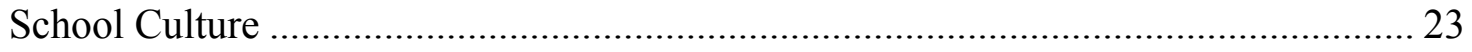

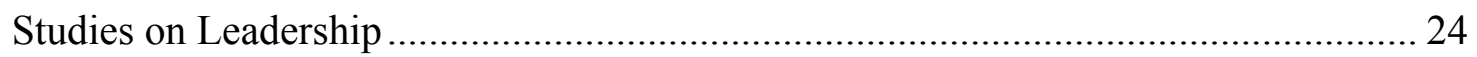

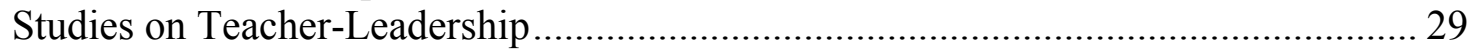

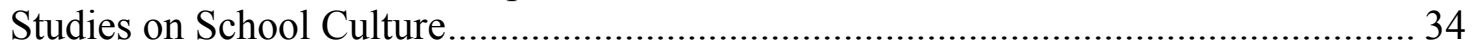

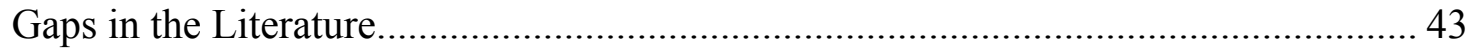

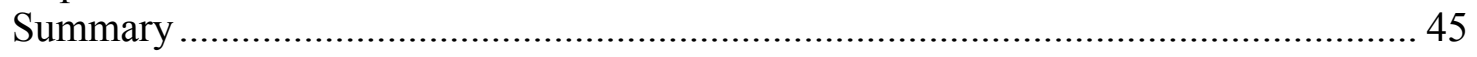

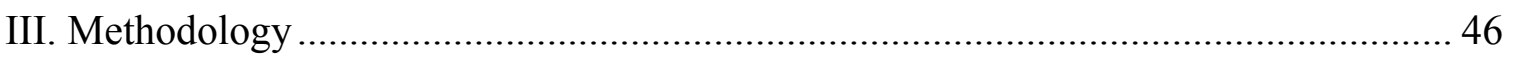

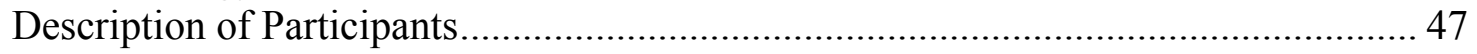

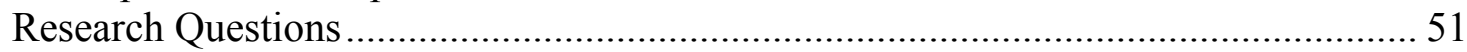

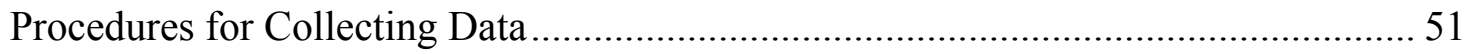

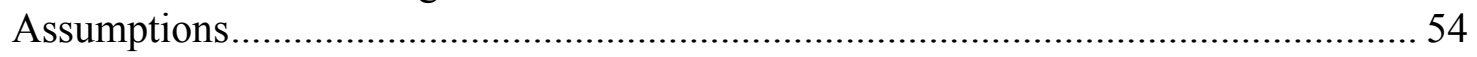

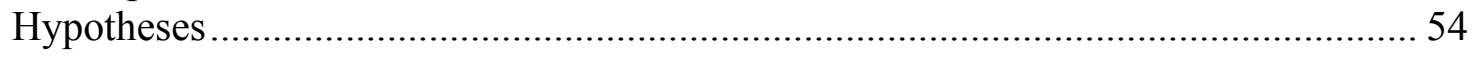

Statistical Analysis Procedures .......................................................................... 56

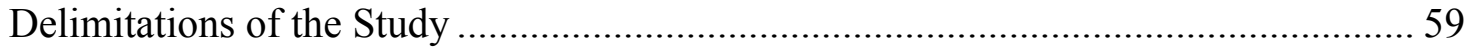

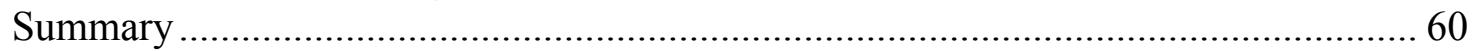

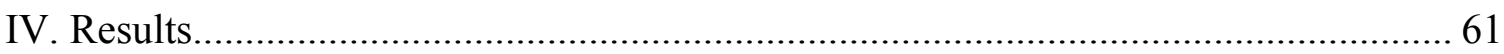

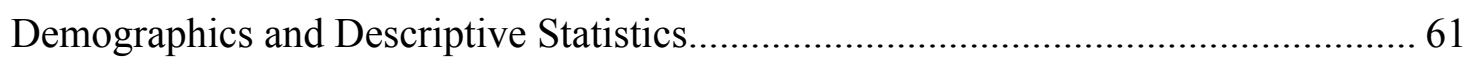

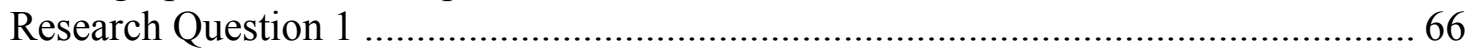

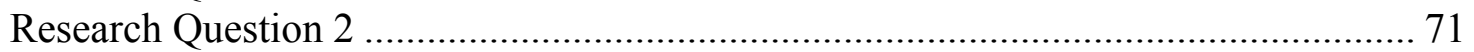

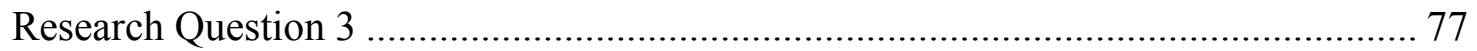

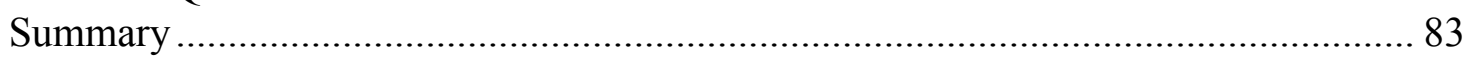

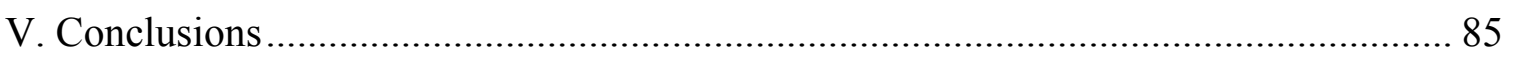

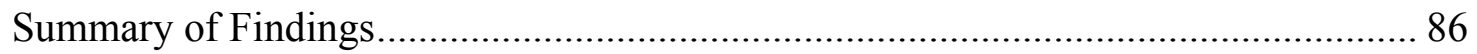

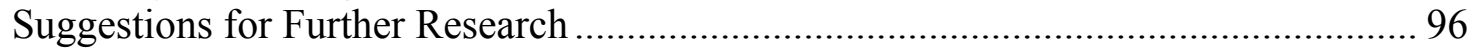

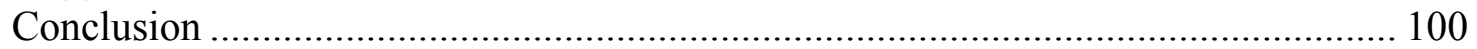

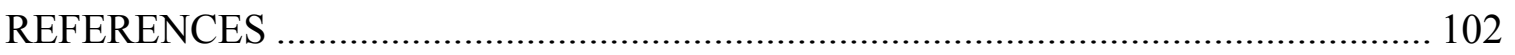




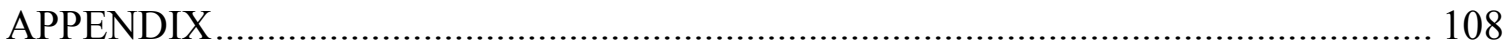

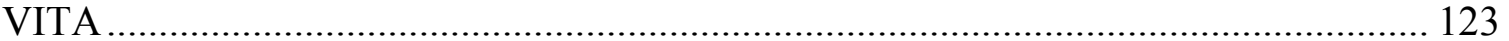




\section{LIST OF TABLES}

TABLE

PAGE

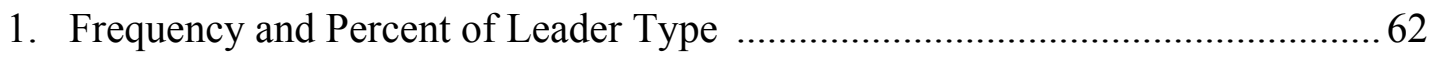

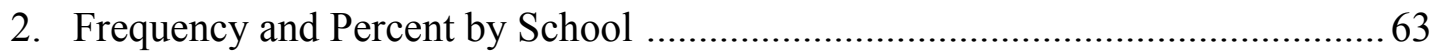

3. Frequency and Percent, Number of Participants by Leader ..............................64

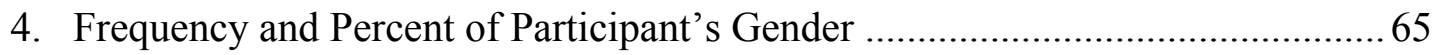

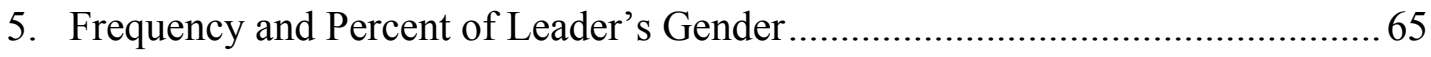

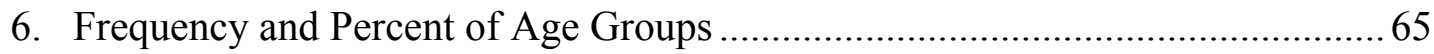

7. Frequency and Percent of All Participants' Degree Levels ...............................66

8. Frequency and Percent of Leader's Degree Levels .......................................6 66

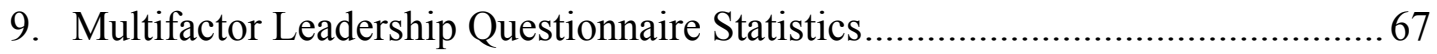

10. Frequency and Percent of Predominant Leadership Characteristic .................... 68

11. MLQ Predominant Characteristic Descriptive Statistics ................................69

12. Multifactor Leadership Questionnaire ANOVA..........................................6 69

13. Multifactor Leadership Questionnaire Multiple Comparison ............................. 70

14. Organizational Description Questionnaire Statistics ................................... 72

15. Frequency and Percent of ODQ Predominant Culture Profile........................... 73

16. Organizational Description Questionnaire Descriptive Statistics ..................... 75

17. Organizational Description Questionnaire ANOVA ….................................. 76

18. MLQ and ODQ Descriptive Statistics. ................................................. 78

19. MLQ and ODQ Predominant Characteristic Cross Tabulation Part 1............... 79

20. MLQ and ODQ Predominant Characteristic Cross Tabulation Part 2................ 80

21. ODQ Mean and Standard Deviation Descriptive Statistics ............................. 82 


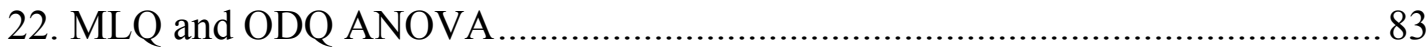




\section{CHAPTER I. Introduction}

The United States is currently embroiled in an educational revolution. The history of the education system in the United States is often contentious, containing several positions through which to view reform strategies that are employed in an attempt to rectify the perceived failings of public education. Many theories drive reform activities and differing views of what constitutes leadership and student learning often confound the problem of how to improve our education system. As tensions increase between the government and educational institutions, the role that leaders play is becoming increasingly important and increasingly scrutinized as a measure of the health of an organization and its participants within that system. Therefore, in recent years, the focus of research has turned towards leadership perspectives and the improvement of leadership styles with an eye on gaining an understanding of the needs of both leaders and followers in an attempt to facilitate achievement and goal attainment for that organization. Chapter I introduces the study and will discuss the statement of the problem, the purpose of the study, operational definitions, and the theoretical framework for transactional leadership, transformational leadership, and school culture.

One of the most important elements to any educational institution is the school's culture. School culture influences all aspects of a school, from expectations of student achievement, to staff buy-in, and commitment to learning objectives. However, school culture is often overlooked as a crucial piece of school environment and is discounted in successful educational efforts (Peterson \& Deal, 1998). Culture is an amalgamation of the values, traditions, behavioral norms, and beliefs that are perpetuated within a school and are used to establish collaboration and influence decision-making to professionals and 
leaders (Northouse, 2018). School culture is an intangible and often difficult to gauge unspoken agreement between all stakeholders that drives improvement efforts and goal setting activities.

The Full Range Leadership Model can best be viewed as a spectrum of leadership. At one end of the spectrum lies Laissez Faire leadership followed by Management-byException (Passive and Active), to transactional leadership, and at the other end lies transformational leadership. The Full Range model contains several components that are necessary for a complete understanding of leadership styles. These components are the Full Range Leadership Model, the behavioral components of transactional leadership, the leadership culture profile, and school culture. The Full Range Model of Leadership research focuses on educational administration and their perceived theoretical framework in regards to their own leadership style in conjunction with their leadership style as perceived by their subordinates within their school site. The synergy that arises from the comingling of skillsets from leaders and followers is essential to the idea of effective leadership.

My study looked at a number of principals, teacher-leaders, and followers within high schools, middle schools, and elementary schools in Miami Dade County Public Schools. These leaders assessed their own leadership style using the Multifactor Leadership Questionnaire Self (MLQ- Form 5X Short) form developed by Bass and Avolio (1997). This questionnaire consists 45 Likert type questions. The instrument assessed the leader on two accounts: What they actually do in practice, and what they think they should do in terms of leadership activities. For my study, the two types of 
leaders that were surveyed are school administrative leaders and teacher-leaders that hold a formal title such as test chair, athletic director, activities director, and department chair.

The second part of my study is the follower portion, which evaluated the congruence between leaders' perceived styles, and the perceptions of their followers. For the purposes of my study, followers were defined as teachers and other school site instructional personnel not in a formalized leadership position, such as school guidance counselors, and paraprofessionals. Each leader was evaluated by several raters using the Multifactor Leadership Questionnaire Rater form (MLQ- Form 5X Short; Bass \& Avolio, 1993). The survey requested the follower to report observed behaviors along the continuum in terms of the specific behaviors of each of the leaders scrutinized. The form evaluated the discrepancy between the leaders' perceptions and that of their subordinates. Leaders' answers in conjunction with those of their subordinates was used to evaluate their leadership style and predominant leadership characteristic along the transformational/ transactional spectrum.

In addition, a second instrument was used to evaluate the organization's culture. Each of the participants and their raters was surveyed with the Organizational Description Questionnaire (ODQ), an instrument designed to measure the culture of the school as an organization (Bass \& Avolio, 1992). The instrument consists of 28 True/False/? answers designed to identify an organization's perceived culture as primarily transformational or transactional based upon both leader's and follower's responses.

The organizations were evaluated and categorized along a continuum of Maturing, Highly Developed, High Contrast, Loosely Guided, Coasting, Formal, Garbage Can, Pedestrian, or Bureaucratic. The outcome of both of these analyses were then 
correlated with the outcome of the Multifactor leadership questionnaire predominant leadership style in order to ascertain a relationship between these two factors: leadership style and school culture.

\section{Statement of the Problem}

Spurred by the report published in 1983 entitled A Nation at Risk, the education system has been enduring a plethora of reform strategies that rarely exhibit the increased outcomes that are anticipated (National Commission on Excellence in Education, 1983). The scrutiny endured by the education system has persisted despite many reform efforts aimed at improving the student learning. Empirical studies, though, have shown that administrators' leadership styles are imperative to their practice as educators and can have a profound influence on the institution and subordinate colleagues (Leithwood \& Jantzi, 1997). Theoretical leadership is idealized leadership in that leaders are often aware of good theory, yet are imperfect at transferring theory into practice.

The leaders' perceptions of their leadership abilities and styles often vary from the perceptions of their followers, which can have a negative effect on school culture and on subordinates, ultimately impacting school and student achievement. There is a growing need to align these perceived leadership styles between leaders and followers in a manner that allows for a greater symbiotic relationship to flourish between them. Creating a mutually beneficial connection enhances the organization's collaborative efforts by allowing each individual to feel that he or she is an integral and valued member of the system, which in turn enhances the morale and culture of the school. My study attempted to establish the degree to which administrative leaders and teacher-leaders are perceived 
as transformational or transactional leaders by their subordinates and the relationship between the leaders' style and school culture.

The potential implications for my study are the fostering and development of practices, relationships, and styles within organizations and can assist in placing administrative leaders and teacher-leaders into organizations in which they will be most effective. In addition, my study helps build an understanding of the relationship between leadership style and school culture. The ramifications of my research may assist school districts in assigning administrators where appropriate and to the greatest degree of efficiency. The results of my study can also potentially improve practices and influence change in the training and assessment of educational administrators and teacher-leaders for the betterment of school culture.

\section{Purpose of the Study}

My study surveyed current educational administrators and teacher-leaders in order to ascertain their leadership styles as well as to discover what they consider to be important in leadership functions and the relationship between that and school culture. The relationships and perceptions that exist between educators and their administrators and teacher-leaders is the focal point of my study in order to ascertain the leadership styles of administrative leadership and the teacher leaders that hold formal titular positions at that school. My study examines the predominant leadership style of current educational administrators and teacher leaders in order to assess that relationship between their approaches to leadership and how that relationship interacts with the culture of the educational institution. 
There were three parts to the research. First, educational administrators and teacher-leaders were surveyed to ascertain their primary theoretical leadership perspective in terms of their perceived functions in actual practice and they evaluated themselves on what they felt they should do as a separate function from actual practice. Second, a rater group of subordinates that work directly with those administrators and teacher-leaders was provided with a survey to ascertain which actions they perceived the leader actually exhibits in characteristics along the Full Range Leadership continuum. Third, both leaders and followers were surveyed to measure the perceived existing culture of the school and whether or not the existing school culture correlates with the leadership styles of both administrators and teacher-leaders.

\section{Significance of the Study}

My study will help determine the relationship between administrative leaders, teacher leaders, and school culture. In our current shifting of educational norms and ideologies, my study seeks to shed light on the role that educational leaders play in maintaining a school culture that is creative, open, and conducive to the changes needed for success. Student attainment and teacher efficacy are tied to several factors of school leadership and school culture and my study will shed some light on how those connections are forged within schools (McCormick 2003; Mangin 2007).

While the connection between educational leaders and success is documented, it is only now that we are beginning to understand the pivotal role that teacher leaders play in shaping and maintaining a healthy environment within a school. Their daily roles are crucial to the success of their individual departments; therefore, the organization's health and culture as a whole. My study will assist in highlighting that role, and will show the 
need for greater attention to and development of leadership practices for teacher leaders so that they can play a greater role in cultivating a healthy school culture than is currently practiced within educational institutions at the current time.

\section{Research Questions}

My study sought to answer three questions with my research. They were the administrators' and teacher-leaders' predominant leadership characteristic, and followers' perceptions of the administrators' and teacher-leaders' leadership style; the leaders' and followers' perceived culture of the school; and the degree to which that predominant style affects school culture.

- RQ 1: What is the primary demonstrated leadership style of the administrator and teacher leader as determined by the leader's scores combined with the follower's scores on the Multifactor Leadership Questionnaire 5X Short Form (MLQ-5X)?

- RQ 2: What is the school culture profile as determined by the leaders' and followers' scores on the Organizational Description Questionnaire (ODQ)?

- RQ 3: Is there a connection between the leadership style of educational administrators and teacher-leaders and school culture as determined by an analysis of variance between leader and follower scores on the MLQ-5X and the ODQ?

\section{Hypotheses}

The purpose of the study demonstrates that there is a need understand leadership style from the perceptions of followers. In addition, the need to clarify the relationship between these styles on school culture leads to several hypotheses that were tested. The 
following are the three hypotheses that were tested to determine the relationship between leadership style and school culture.

H1. There will be a significant difference between administrative leaders' and teacher-leaders' predominant leadership style as measured by the leaders' and followers' scores on the Multifactor Leadership Questionnaire for Research (MLQ-5X Short Form).

H1.0- Null- There will be no significance difference between administrative leaders' and teacher leaders' leadership characteristics as measured by the leaders' and followers' scores on the Multifactor Leadership Questionnaire for Research (MLQ-5X Short Form).

H2. There will be a significant difference between transactional and transformational predominant school culture profile as measured by the leaders' and followers' scores on the Organizational Description Questionnaire (ODQ).

H2.0- Null- There will be no significant difference between transactional and transformational predominant school culture profile as measured by the leaders' and followers' scores on the Organizational Description Questionnaire (ODQ).

H3. There will be a significant difference between administrative leaders' and teacherleaders' predominant leadership style and school culture profile as measured by the leaders' and followers' scores on the Multifactor Leadership Questionnaire (MLQ-5X Short Form) and the Organizational Description Questionnaire (ODQ).

H3.0- Null- There will be no significant difference between administrative leaders' and teacher-leaders' predominant leadership style and school culture profile as measured by the leaders' and followers' scores on both the Multifactor 
Leadership Questionnaire (MLQ-5X Short Form) and the Organizational

Description Questionnaire (ODQ).

\section{Limitations of the Study}

The limitations of my study are conditions or influences that limit the scope of the research, data, or participants. It is important to note that these limitations are outside of the control of the researcher; however, they may influence the results of the research. The following are limitations of the study being conducted here.

1. The culture of a school is influenced by many factors and is constantly in flux. Although this study seeks to illuminate the relationship between a principal's leadership style and its relationship to school culture, the outcome may be limited by external factors of school culture other than administration and as such, may be outside of the scope of control of the administrator.

2. As a consequence of the cyclical nature of the school calendar year, the study was limited to those participants that were able to complete the survey within the specified time period for data collection to maintain consistency of the data for the school site.

3. There may be external factors that affect the leadership style of administrators and teacher leaders and may affect the outcome of the measurement of leadership style.

\section{Operational Definitions}

Throughout the course of this study, these terms will be used according to the following operational definitions. 
Administrative Leadership-School leaders who hold administrative positions such as Principal, Assistant Principal, Activities Director, and Athletic Director.

Coasting Organization- Organizational culture in which the organization acts moderately, exhibiting neither strong transactional nor transformational attributes. Characterized by an organization that maintains the status quo (Avolio, Bass, \& Jung, 1999).

Contingent Reward- Leadership that develops "exchanges and agreements" with their followers in an attempt to convey the a reward system in which the follower will receive something in exchange for task completion (Bass \& Avolio, 1993, p 112).

Culture- The organization's setting in which the participants act within a set or norms and behaviors. Culture is symbiotic in which the participants act to create changes in culture while the culture in part dictates actions of the participants (Hinde, 2004). Bass and Avolio (2006) characterize culture using nine factors to create a profile of organizational culture: Predominantly Four I's (Maturing), Moderately Four I's (Highly Developed), High Contrast, Loosely Guided, Coasting, Garbage Can, Pedestrian, Moderately Bureaucratic (Formal) or Predominantly Bureaucratic based on a scale of transformational and transactional components.

Full Range Leadership Model Components of Transformational Leadership- The Four I's of active transformational leadership in which leaders exhibit characteristics of one or more of the following traits. These characteristics are Idealized influence (attributes and behaviors), Inspirational Motivation, Intellectual Stimulation, and Individualized Consideration (Avolio, Bass, \& Jung, 1999). 
Garbage Can Organization- Culture in which a lack of leadership is the main component and individuals have little internal cooperation and are often unclear about common goals and visions for the organization (Avolio, Bass, \& Jung, 1999).

High Contrast Organization- Both highly transactional and transformational culture that contains elements of attention to processes and vision setting (Avolio, Bass, \& Jung, 1999).

Idealized Influence (Attributes)- Leadersship in which leaders seek to instill a sense of pride in the organization and will forego self interest for the good of the group. Often display a sense of confidence and power (Avolio, Bass, \& Jung, 1999). Idealized Influence (Behaviors)- Leadership that works to create a shared sense of purpose for the work in the organization. Leadership that encompasses strong moral and ethical decision making skills (Avolio, Bass, \& Jung, 1999).

Individualized Consideration- Leadership style in which leaders devote efforts to the individual needs and growth of their followers. Leaders who coach other and help them to realize success (Antonakis et al., 2003).

Inspirational Motivation- Leadership in which leaders seek to motivate others through their own actions and accomplishments and are able to articulate a clear vision for followers, expressing confidence and power (Avolio, Bass, \& Jung, 1999).

Intellectual Stimulation- Leadership that asks followers to question assumptions, processes, and paradigms for innovative problem-solving. Focuses on creativity and innovation to reframe problems (Avolio, Bass, \& Jung, 1999).

Laissez Faire Leadership- Characterized by the absence or avoidance of leadership (Bass \& Avolio, 1993). 
Loosely Guided Organization-Culture in which individuals are guided by their own independent ideals and are highly unstructured (Avolio, Bass, \& Jung, 1999). Management by Exception (Active)- An active style of leadership in which leaders oversee the actions of the organization and take action when results differ from the expected (Avolio, Bass, \& Jung, 1999).

Management by Exception (Passive)- A passive style of leadership characterized by reactive action rather than active participation (Avolio, Bass, \& Jung, 1999).

Moderately Bureaucratic (Formal)- Few transformational characteristics, with higher transactional activities that take precedence. Self interest is more important than the good of the group (Avolio, Bass, \& Jung, 1999).

Moderately Four I's (Highly Developed)- Culture in which the shared vision and values are moderated by some consensus of formalized agreements. An increase in transactional behaviors leads to greater balance in the organization (Avolio, Bass, \& Jung, 1999).

Multifactor Leadership Questionnaire (MLQ-5X Short)- A survey instrument developed for the purpose of measuring leadership styles according to the transactional, transformational, and passive/avoidant leadership styles. (Antonakis et al., 2003). Organizational Description Questionnaire (ODQ)- A survey instrument developed for the purpose of measuring effective culture within an organization that provides a Leadership Culture Profile in which the organization is categorized as Maturing, Highly Developed, High Contrast, Loosely Guided, Coasting, Formal, Garbage Can, Pedestrian, or Bureaucratic (Bass \& Avolio, 2006). 
Pedestrian-Very formal culture in which structure is the main component of the work. Individuality is lacking, as is a personal commitment to the organization (Avolio, Bass, \& Jung, 1999).

Predominantly Four I's (Maturing)- Culture in which vision, purpose, and values are the driving force. May lack transactional processes and have few formalized agreements; internalized trust becomes essential with informal agreements (Bass \& Avolio, 1993).

Predominantly Bureaucratic-Culture which is an "internal marketplace where much is negotiated according to the "rules of the game'". Focuses on processes with little discretion for followers (Avolio, Bass, \& Jung, 1999).

Teacher-Leadership- Instructional personnel within a school site that hold leadership positions, facilitate a community of learners, and "translate ideas into sustainable systems of action" (Ackerman \& Mackenzie, 2007, p. 53). Within the context of this study, teacher-leadership is defined as those that hold formal titles, such as Department Chair, Grade Level Chair, Athletic Director, Magnet Lead, Instructional Coach and Activities Director.

Transactional leadership- A leadership style in which leaders "develop exchanges or agreements with their followers, pointing out what the followers will receive if they do something right as well as wrong" (Bass \& Avolio, 1993, p. 112). These leaders exhibit contingent rewards and management by exception leadership styles in which the leader wields his power to both reward and punish the followers for real and perceived successes and failures (Avolio, Bass, \& Jung, 1999). 
Transformational leadership- Leadership in which the leaders "integrate creative insight, persistence and energy, intuition and sensitivity to the needs of others" to create a culture of vision and achievement of objectives (Bass \& Avolio, 1993 p. 112).

Transactional leaders seek to engage followers to encourage participation in improvement efforts of the system in which they work in symbiosis (Moujaes et al., 2012).

\section{Summary}

My study sought to illustrate the need to align leadership styles between leaders and followers in a manner that allows for a more effective relationship to flourish between leaders, followers, and organizational culture. My study aims to examine the extent to which subordinates perceive their administrators and teacher-leaders as either transformational or transactional leaders and how that influences school culture. My research examines the Full Range Model of Leadership and the focus of educational administrators' practice. The study focused on the predominant leadership characteristics demonstrated by the administrative leaders and teacher-leaders. It also focused on the chief culture characteristics present in the schools. In addition, the study sought to understand the connection between these two important facets of education in a system in which both of these issues are becoming ever more critical. 


\section{CHAPTER II. Literature Review}

The increasing tension in education has paved the way for a wealth of research into educational leadership and the needs of the educational system to develop and employ techniques for effective leadership within districts and school sites all over the

country. The result has been that many leadership styles have emerged as significantly answering to the needs of the system. One of the foremost styles is that of the Full Range Leadership model, or the transformational to transactional leadership continuum as elucidated by James MacGregor Burns (1978), Bernard M. Bass (1985) and Bruce J. Avolio (1989). It is this theory that is the focus of this research, and will be used in examining the leadership styles of both principals and assistant principals within the Miami Dade County Public school district.

This chapter will provide an overview of the theoretical framework upon which this study is based. It will also provide a review of the current literature and discuss studies on leadership, teacher-leadership, and school culture. In addition, this chapter will demonstrate that there are gaps that exist within the literature and will illuminate the need for this study as it pertains to creating a connection between school culture and the Full Range Model of Leadership.

\section{Theoretical Framework}

This study focused on two theoretical frames: the Full Range Model of Leadership and school culture. It is imperative to have an understanding of these frames as well as understanding the leadership expectations of each of them. This section will focus on an examination of the theories, their history, and the implications each has had for educational leadership practices. 
Currently, one theory on leadership that has emerged as the frontrunner in the debate is the Full Range Leadership Model as conceived and developed by James Burns (1978), Bernard Bass (1985), and Bass and Bruce Avolio (1989). Traditionally, transactional leadership uses terminology such as "exchange", "reward", and "punishment" in order to describe the methods of leadership and assessments taking place (Burns, 1978, pp. 258, 372). In the present paradigm the standard by which we evaluate students, teachers, and educational administrators is highly transactional, focusing on standardized testing and data driven decision making as a means through which to shore up the existing paradigm in the education system. Educational policy and its administration have focused on a transactional approach, concentrated on the achievement of specified goals, which is currently evaluated through standardized test taking and data measurements.

However, a disconnect arises because current concepts of learning focus rather on the conceptual understanding, meaning making, and collaboration that is associated with transformational leadership. Transformational leadership embodies concepts that are grounded in "participative decision making", "facilitative power", and "collaborative culture" (Leithwood, 1992, pp. 9, 10). One of the main tenets of transformational leadership is the relationship that exists between the leader and follower in a collaborative partnership for the mutual benefit of both parties.

Educational administrators, though, are expected to act in transactionally managerial leadership roles, overseeing the product of student learning in terms of increased expectations of data analysis, prescribed outcomes, and sequential curriculum planning (Giese et al., 2009). However, leadership is much more organic in nature than 
creating spreadsheets and data disaggregation as nothing more than a function of expectations. The culture contained within any organization as a living entity is affected by the leadership practiced and is influenced by the role and relationships between subordinate and leader. Therefore, in order to better understand an organization's goals and vision, it is imperative to understand the connection between leadership and culture, and how transactional or transformational leadership theoretically affects the culture itself.

\section{Transactional Leadership}

One of the facets of the Full Range Model of Leadership is transactional leadership. The first known mention of the terms transactional and transformational leadership were written by J.V. Downton (1973) and provided a conceptual foundation for further theoretical development. However, the theory itself was elucidated by James MacGregor Burns in 1978 as he developed his study on leadership theory and leadership styles and was later expounded upon by Bass's (1985) six-factor leadership model based on his leadership observations of 198 U.S. Army field grade officers (Avolio, Bass, \& Jung, 1999). The terms transactional and transformational were described as a means of exchange between leaders and followers and a description of the types of exchange that were necessary to enact effective leadership. According to Burns (1978), transactional leadership is based on an "exchange of valued things," whether economic, political, or psychological. In terms of educational leadership, these valued things are often defined as educational outcomes of student achievement and organizational goal attainment.

Transactional leadership is based on a reward or punishment system that is evaluated according to a set of behavioral or performance standard of expectations. This 
reward system most often takes the form of pay, advancement, power, or increased benefits. The punishment system consists of a loss of wages, advancement opportunities, or power within the organization. These rewards and punishments are devised and disseminated according to the culture of the system in which they operate (Bass \& Avolio, 1993).

Transactional leadership is the paradigmatic system upon which our capitalistic society is based, and is the cornerstone tenet of work. According to DenHartog, Muijen, and Koopman (1997), it is this cost-exchange system that drives the fundamental relationship between leaders and followers. Motivating factors arise from an understanding of the system of rewards or punishments that is operational within the organization. In this manner, those driven by a need for reward are allotted the opportunity to earn those rewards; likewise, those who operate under threat of punishment are obliged to comply to expectations, clarification of goals, and task completion (Hinkin \& Tracey, 1999). Therefore, transactional leadership reaches all members of the organization, as each person has the need to operate within the reward/ punishment system that is the foundation of transactional leadership. The leader has the authority and power to enact these rewards and punishments in a manner that is consistent with his or her goals for the organization. However, according to Amar (2001), transactional leadership is inconsequential to the achievement of organizational goals and increased production.

While Burns (1978) espoused transactional leadership as one of the two sides of the leadership coin, others expanded on the theoretical framework and added several new dimensions to the theory and created a continuum of contingent rewards and punishments 
(Bass, Avolio, Jung, \& Berson, 2003). However, research demonstrated that these compliance contingencies were only effective insofar as the personal reward or punishment was aligned with the missions and visions of the organization (Barnett, McCormick, \& Connors, 2001).

Bass, Avolio, Jung, \& Berson (2003) have categorized corrective leadership as transactional in nature, based on a punishment system. The exchange system requires that corrective action be taken for a job not completed satisfactorily or to specification. According to Avolio \& Bass (2004) there are several types of transactional leadership; the first is laissez-faire leadership, which is characterized as a lack of leadership action altogether. This type of transactional leader demonstrates an avoidant role in goal setting, problem solving, and standard attainment.

The second type of transactional leadership is contingent reward "managementby-exception," of which there are two types (Bass et al., 2003). First, there is active management by exception in which the leader proactively outlines the expectations for the assigned task, and the rewards or consequences for successes or failures. In this manner, the subordinate is fully aware of the importance of the task at hand and the outcomes for performance standards. Thus, active management by exception is closely monitored, employing corrective action, as the occasion requires (Bass et al., 2003).

The second type of management-by-exception is passive avoidant (Bass et al., 2003). By its nature, passive management by exception is reactionary in nature, lacking a systematic problem solving technique designed to avoid problematic areas. The passivity with which this type of leader allows problems to develop before taking action is indicative of a lack of planning and implementation of specified agreements. The passive 
avoidant leader typically avoids clarifying expectations, objectives, and standards to be achieved by the followers (Bass et al., 2003).

\section{Transformational Leadership}

The other end of the spectrum from transactional leadership is transformational leadership. Recently researchers have demonstrated that leadership functions are more than the simple completion of the leader/follower transactions of organizations.

Transformational leaders work to understand the culture of their organization and to work within those constructs as a means of achieving the shared vision and mission of the organization's goals (Den Hartog, Van Muijen, \& Koopman, 1997). Transformational Leadership is the cornerstone of a movement in leadership style that emphasizes the need for leaders to create a relationship between themselves and their subordinates that integrates the needs of others, the organization's goals, and the existing culture. They foster relationships between themselves and their followers, and emphasize the growth and development for the good of the organization. In addition, transformational leaders foster leadership

Avolio, Bass \& Jung (1999) and Antonakis (2001) have identified the 4 I's of transformational leadership: idealized influence, inspirational motivation, intellectual stimulation, and individualized consideration. Leaders who exhibit mentoring skills and display "socialized charisma", power, and confidence, all characteristics of idealized influence (Antonakis et al., 2003, p. 264). By exhibiting idealized influence (attributes and behaviors), the transformational leader models moral and ethical standards of conduct for the follower to emulate and assimilate (Northouse, 2018). Inspirational motivation, however, refers to the leaders' ability to motivate followers to meet higher 
organizational standards of performance and achievement (Antonakis et al., 2003). The inspirational motivator projects the organizational mission as attainable and idealized realities while embodying the high standards expected of the followers (Antonakis et al., 2003). Intellectual stimulation refers to the leaders' ability to facilitate the development of the follower's logical and analytical skills by encouraging and fostering a sense of creative problem solving and critical processing (Antonakis et al., 2003). Finally, individualized consideration refers to the leaders' ability to understand the needs of the followers and to facilitate development of their leadership skills and abilities as a function of the job (Antonakis et al., 2003).

According to Quantz, Rogers, \& Dantley (1991), empowerment and symbiotic cooperation are the main precepts of leadership, which is the cornerstone of transformational leadership. These collaborative efforts are inherent in the operations of schooling functions and are imperative to the achievement of school goals, both organizational and educational. "Transformational leadership is the process whereby a person engages with others and creates a connection that raises the level of motivation and morality in both the leader and the follower" (Northouse, 2018, p. 186). Therefore, the transformational relationship between followers and their leaders is essential to organizational success.

Wilmore and Thomas (2001) asserted, "In this process, all individuals are afforded opportunities to make many of their own choices in life. People, in these settings, develop an awareness of their abilities to modify and even play significant, positive roles in reconstructing the work and social environment" (p. 117). This process provides several aspects of organizational life that had previously been absent from 
transactional leadership. First, the leader is able to act as facilitator rather than authoritarian. The sense of agency that arises from a relationship based on mutual respect and understanding allows both the follower and the leader to enact necessary change in a proactive manner. In addition, the followers and leaders alike are able to develop their skills and to build a sense of efficacy in their work and professional environment in a symbiotic relationship.

Edwards (1992) elaborates, "symbiotic leaders commit to new cultural norms in which shared values or belief systems recognize mutual contribution" (p. 28). Collaboration, motivation, and trust are three components of transformational leadership that create a profound relationship that underscores the mutually obligatory relationship between the leader and his or her followers.

Transformational leadership focuses on the development of leaders in a hierarchical fashion, the leader acting as model and exemplar while attempting to raise awareness of the goals of the organization and to foster achievement in followers (Hampton, 2010). However, this assumption depends upon the idea of the leader as being worthy of example. In reality, if the leader is less than the idealized influence, or the inspirational motivator that Northouse (2018) describes, the ideology collapses. Rather, leaders must continue to refine their leadership style, improve their ethical constructs, and align their personal professional goals with those of the organization. Transformational leaders acknowledge the value of individual contribution, and apply those contributions for the growth of the individual and leader alike, for the benefit of the organization.

The theoretical foundations of the Full Range Leadership Model are inclusive of several leadership styles that encompass many facets of leadership. The theory stands to 
define these styles in a manner that allows for a deeper understanding of many of the types of leadership that we see in practice within organizations today. While many organizations outside of education are studying the theory for its practical implications within their fields, education has a critical need to employ theoretically sound leadership practices in order to remediate the current perceived failings of the system in which we currently preside. By seeking a greater understanding of transformational leadership, we are able to envision improved leadership practice throughout all levels of leadership in education. Transformational leadership has several factors whose purpose is to explain leadership behaviors that are evident in successful leaders, including the ability to build a positive school culture.

\section{School Culture}

Increasingly, we see a strong connection between leadership efforts and school culture. Leadership is proving to be essential to building and maintaining a healthy culture and to repairing unhealthy cultures. As Bass \& Avolio (1993) assert, "there is a constant interplay between culture and leadership" (p. 113). The leader has a responsibility to create opportunities for culture building activities to improve the morale and development of the staff to ensure that the goals of the institution remain student learning centered and focused on improvement efforts. According to Peterson \& Deal, even successful schools can possess toxic subcultures in which negativity, resistance, and hopelessness dominate conversation surrounding leadership efforts (1998). Strong leadership that is theoretically sound and research based can have a profound effect on the culture of a school; however, leaders must also have an understanding of the school and its stakeholders (Lahtero \& Risku, 2013). A leader who has an appreciation of the 
existing school culture will be able to effectively lead transformational efforts to improve the achievement and goals of the school.

School culture has gained the spotlight over the last few years as studies into leadership highlight the need to create a more complete understanding of the effects of culture on long-term achievement and success for the school. In the discussion about the importance of school culture, Sergiovanni (1996) asserts that, "The heart and soul of school culture is what people believe, the assumptions they make about how schools work, and what they consider to be true and real" (pp. 2-3). It is this perceived reality that is at the heart of the current discussion about education and the need for drastic reforms and changes to the paradigm for enhanced learning, shared values, and improvement goals.

\section{Studies on Leadership}

Studies on leadership have sought to understand what characteristics compose an effective leader within an organization. Throughout the conversation on research several studies have sought to identify specific traits and behaviors to create a range of leadership styles that allow for leaders to be placed along a continuum that has become the Full Range Leadership (Avolio, Bass, \& Jung, 1999). A review of the literature demonstrates the evolution of leadership along this continuum.

While the literature demonstrates an understanding of effective leadership and how it operates, the integration of this leadership into practice is the next step of the process of effective leadership and how the followers are impacted by the leadership functions that act upon them. Avolio's (2007) study for leadership found that the previous studies excluded important processes such as the follower and the context through which 
leadership functions would be exercised. That is to say, Avolio's claim that leadership became a set of characteristics or skillsets in a vacuum operating regardless of the context or situational awareness of these processes (2007). He contends that whether a follower decides to follow a leader is a more active process and that the perceptions of the follower towards the leader may play just as important a role, if not moreso, than that of the characteristics or qualifications of the leader (2007). While he does not discount the traits of effective leaders, he states that it is imperative to move into a more active context for recognizing what makes a good leader and what promotes positive change within an organization.

The question, then, becomes one of measurement. How is it possible to measure these contexts and styles in a manner that allows for us to gain a unique understanding of the organization and its leaders? The literature outlines the Multifactor leadership questionnaire (MLQ) as a measurement of leadership style. Bass (1985) identified the factors of transformational and transactional leadership: charisma, inspirational, intellectual stimulation, individualized consideration, contingent reward, and management-by-exception, and laissez-faire, or the absence of leadership. The MLQ, however, combined charisma and intellectual stimulation into the six factors that are most well known today (Avolio, Bass, \& Jung, 1999). However, throughout the literature, there have been analyses of this six factor model that have recommended several changes including adding subsets of factors into the model as a more complete adaptation of the model and included passive and active participation in management by exception (Den Hartog, Van Muijen, \& Koopman, 1997). However, the construct of the model has remained relatively complete. 
In 2004, Avolio and Bass reexamined their model for these constructs and concluded that the six factor model provided a comprehensive model that best identified leadership styles, but made accommodations for the passive and active management that were identified by Den Hartog, et al. (1997). This iteration of the model provided the Full Range model of leadership that are split into three leadership styles that identify a leader as either transactional, transformational, or laissez faire. In this model, charisma has become idealized influence separated into two components, idealized attributes and idealized behaviors. Inspiration has been renamed inspirational motivation as the third component. Intellectual stimulation and individual consideration are the fourth and fifth factors. All of these five factors make up transformational leadership. Transactional leadership is now includes contingent reward, management-by-exception active, and management-by-exception passive. The final component is laissez faire, which is its own factor for a total of nine components for the three styles (Avolio \& Bass 2004). Antonakis et al., (2003) conducted a study in which they confirmed the validity of this most current model. This study sought to use the full range model of leadership that is represented in the most current adaptation of the MLQ-5X.

Throughout the literature, there have been many studies that have sought to investigate one specific factor of the full range model of leadership. For example, Barnett and McCormick (2003) investigated idealized influence in a qualitative study and examined its effect on teacher motivation and the school vision. In this study, they concluded that leadership is contingent upon an individual's ability to not only share vision, but also to entice others to follow the vision. They also concluded that successful leadership is characterized by relationships and the effective use of those relationships to 
encourage and support the vision of the school. This study exposed three attributes of school vision; collaboration, a shared sense of responsibility and accountability to carrying out the vision, and the principal as the leader of the process. It is essential to note that these three characteristics relates to idealized behaviors and idealized attributes from Avolio and Bass’ MLQ-5X (2004).

In another study, researchers used a meta analysis to determine the connection between charismatic leadership style and leadership effectiveness (DeGroot, Kiker, \& Cross, 2000). Their main concern in this study was to assess subordinate satisfaction, effort, and commitment as it relates to the leaders' style of leadership. Their results, though differ from that of the Barnett and McCormick (2003) in that they found that at the individual level, the relationship between charisma and effective leadership is weaker than previous studies had found it to be when measured at the individual level $(r=0.31)$ than was found at the group level $(r=0.49)$ (DeGroot, Kiker, \& Cross, 2000). The implications of this study concluded that while charismatic leadership can increase group performance, it has less influence over individual performance. This meta analysis revealed lower correlations than had been anticipated; therefore, the implications for transformational leadership were found to be that charismatic leadership may be effective on some level but still lacks the ability to significantly affect the performance of subordinates outside of the group performance level. It is interesting to note that as a group, performance is enhanced rather than reverting to the mean.

Other research has been aimed at analyzing other factors on the transformational leadership scale in an attempt to determine if the behaviors of principals within schools could be linked to staff turnover, staff perceived job satisfaction, and school performance 
(Griffith, 2004). They studied data from elementary principals, staff, students, and disaggregated standardized test scores in order to determine the correlation between effective leadership and these variables. They concluded that while no statistically significant effects were found on staff turnover or on achievement test scores, they did find that staff job satisfaction was impacted by principal leadership behaviors. In addition, they also found that higher job satisfaction levels correlated directly to smaller achievement gaps between minority and non-minority students (Griffith, 2004). The implications of this study were interpreted to mean that while leadership behaviors did not directly affect achievement, they did affect job satisfaction, which in turn had an impact on achievement scores. This study implied that while transformational leadership practices were secondary in significance, they still played a pivotal role in the execution of educational practice.

Furthermore, Griffith's (2004) study concluded that the principal's leadership styles were categorized by three components of transformational leadership: idealized influence, individualized consideration, and intellectual stimulation. Therefore, those principals that exhibited behaviors consistent with transformational leadership were more likely to be able to have a direct impact on staff job satisfaction; and therefore, were able to reduce the achievement gap.

However, another study by Thoonen et al. (2011), claims that although transformational leadership practices were essential to engaging teacher motivation and commitment, the real predictor of effective teaching was professional development activities and the extent to which the teachers engaged in learning predicated upon improving their craft. The team surveyed 502 teachers from 32 elementary schools in the 
Netherlands and concluded that transformational leadership had an indirect impact on effective teaching and pedagogical practices. According to the researchers, there was a direct connection between fostering these learning activities and the transformational leadership practices of the administrators in motivating these practices (Thoonen et al., 2011).

\section{Studies on Teacher Leadership}

Educational systems and the research that examines the principles of leadership have downplayed the importance of teacher-leadership in schools and the impact that they have on the ability of a school to achieve their vision. While research has increasingly pointed to a need for more effective transformational leaders to steer education forward and to reduce the number of failing schools, it is becoming more and more apparent that the need for teachers who have leadership skills and capacities can assist in bridging the gap between school site administration, classroom teachers, and students (Angelle \& Schmid, 2007; Camburn, 2009; Shelton, 2014).

The research has begun to highlight the impact that teacher leaders have on students, student achievement, and the efficacy of the school as a whole. Mangin (2007) examined the conditions under which school site administrators are best able to support the efforts and initiatives of teacher-leaders in order to better facilitate learning structures and achievement. Her study examined principals, teacher-leaders, and their supervisors to determine the scope and role of these teachers in their capacity as leaders. Mangin's 2007 study concluded that there existed a link between those teacher-leaders who worked under principals who understood and facilitated their initiatives and efforts to better the curriculum and student achievement in the school. According to Mangin, the implications 
for this study illuminate the underlying relationships that exist between teacher-leaders and their principals that allows for open communication and trust to develop (2007). From this study, we can see that effective principals and teacher-leaders demonstrate traits of transformational leadership in practice. The Wallace Foundation's research found that distributing leadership between administrators and teachers assists with developing stronger relationships between principals, teacher-leaders, and teachers and leads to higher student achievement (Leithwood et al., 2011).

Not all of the research agrees that teacher-leadership is the panacea to the problem of education, though. Research questions the wisdom of removing or distracting those teachers that are most highly qualified to teach from the classroom and allocating their talents to functions that are for purposes other than teaching (Camburn, 2009). In fact, Camburn states, "Placing such teachers in leadership positions supports school improvement initiatives, but it can also pull valuable teaching resources from the classroom" (2009). Indeed, throughout his study, he found that consistently, teachers in a position of leadership had "substantially more postsecondary training and teaching experience than do nonleaders" (Camburn, 2009). While he does admit that the scaffolding and leadership functions can assist in training, modeling, and adaptive behaviors and practices, the research clearly demonstrates that the loss of these teachers in the classroom has a negative effect.

Furthermore, several studies also demonstrate the need for teacher-leaders' contributions to the organization as a means of improving school and student achievement (Jackson \& Marriot, 2012). They argue that while these leaders are imperative to improving the functions of schools, they disagree about what constitutes a 
school leader. The debate continues throughout the literature as to whether a teacher must be formally recognized as a leader, i.e. a department chair, in order to be considered in a leadership position. Their study is grounded in the concept of leadership being an inherent function of teaching and is not tied to "specific functions or roles" within the organization itself (Jackson \& Marriot, 2012). This idea is intriguing in that it implies that all teachers lead and contribute to the organization for the betterment of the vision of the school and its students.

Another study found that not only do these roles matter, but the educational levels were significant as well. The study found that whether the teacher leader was an elementary or middle/high school teacher, whether they held a bachelor's degree or graduate degree, and whether they held formal positions as teacher-leaders or were teachers with no leadership position all made a significant difference in the perception of their leadership ability by other teachers (Agnelle \& DeHart, 2011). This quantitative study collected data across 43 schools in seven states and found that these relationships informed the effectiveness of the teacher-leader was predicated upon other teacher's perceptions, which were affected by these indicators. The ability of the teacher to lead in an effective manner and affect change within the organization depended upon the context of that leader.

Agnelle and DeHart (2011) claim that researchers have failed to look at teacherleadership from the perceptions of these teacher leaders. Their study investigated the teacher-leaders themselves and asked whether their perceptions differed according to their background and the educational level at which they implemented their practice. Indeed, they found a significant disparity between those at the elementary level from 
those at the middle/high school level, and those that has earned a bachelor's degree from those that has earned a graduate degree (Angelle \& DeHart, 2011).

The perceived efficacy of these teacher-leaders is inherent on their ability to recognize their own agency in supporting school-wide initiatives, their own perceived value, and the facilitative power they hold as leaders whether formal or informal. According to another study, the idea that teacher-leaders were more adept at wielding this agency and influencing their peers whether formalized or not (Bowman, 2004). Bowman's concept that teacher-leaders contain "adaptive capacity" to engage in multiple ways and to use their relationships has created a system in which the teacher-leader is able to navigate social variances in order to achieve the vision and goals of the organization (2004). The claim that learning this skill is necessary for a teacher to becoming a leader in which they are able to create and sustain a culture of achievement for both their organizations and their students. This emergence is deemed a "powerful process" and enables a shift in perception between teacher and leader (Bowman, 2004). Another researcher, Brosky (2011) discusses this very idea in his research in which he focuses on the micropolitics of teacher-leadership. He posits that it is the knowledge of strategic positioning, influential power, and relationship building that creates active leadership within the school community. He agrees with Bowman's (2004) assertion that the use of influence by these teacher leaders was essential in gaining and maintaining leadership power. While the microcosm of politics plays out within the school, the personal goals and needs of the individual are at a constant interplay and work to shape the organization. He states that those who have the most influence are most likely to be able to mold the goals and vision of the organization to that which is most 
beneficial. Brosky claims that the theoretical world of leadership that we see in the literature and that which is experienced in the real world is drastically different (2011). However, it is the ability to navigate this difference that creates effective leadership for teacher leaders. In effect, the ability to manipulate relationships is transformational in nature. By balancing and leveraging the needs of the subordinates against that of the organization, effective teacher-leaders are able to elicit cooperative efforts in which leaders and followers are able to work in a symbiotic relationship.

This process was underlined in a study that examined the transformational teacher-leadership prototypes seen in rural schools in Canada. Anderson (2008) studied the fluidity of rural schools in which there were fewer restrictions and allowed more creativity to innovate and therefore were free to develop more transformational practices. The research determined that in schools that has less restrictive environments, teacherleaders were a considered a "source of creativity" and therefore able to develop unique leadership styles and relationships because of their ability to operate outside of traditional leadership roles typically seen and perpetuated by larger school districts in more urban settings (Anderson, 2008).

The implications for Anderson's (2008) study of teacher-leadership as it pertains to transformational leadership is that the mutual influence necessitated by smaller schools that have fewer administrators allows for distributive leadership, higher levels of shared decision making, and greater collaborative participation in the components that make up transformational leadership. Therefore, a case can be made for less rigid control of school administration and more facilitative power to allow for schools to adopt innovative and creative ideas so as not to "exclude valuable sources of leadership" (Anderson, 2008, p. 
16). This increased participation hints at improved morale, and ergo, improved school culture, as they also found this type of shared responsibility to be the norm rather than the exception. The teacher-leadership being displayed in these rural settings, while not formalized, as is our study, demonstrates the need for administration to incorporate creativity and allow for development of a transformational culture of innovation.

\section{Studies on School Culture}

One of the frontrunners in the conversation about leadership is Bernard Bass and Bruce Avolio. In 1993, their work on the connection between and organization's culture and its leaders demonstrated that a leaders' impact on the values, beliefs, and practices of an organization were imperative for the health of an organization's culture. They posited that while organizations required strategic and tactical leaders, they also had a need for leaders who could understand the undertones and traditions of a school in order to support the vision of the organization and create a culture of understanding and problem solving in which the leaders are able to trust and depend upon their subordinates at all levels to contribute meaningfully to the achievement of shared goals (Bass \& Avolio, 1993). In addition, a school's culture is essential to the effectiveness of the learning that takes place at that school (Bolman \& Deal, 2006).

Another study sought to reach beyond the cultural boundaries of the educational paradigm in the United States to understand whether transformational leadership practices had an effect on school in Hong Kong (Yu et al., 2002). Their study attempted to determine whether transformational leadership carried an effect on teacher's commitment to change, and other variables such as school culture, school structure, and school environment. Their research found significant disparities in the perceptions of 
transformational practices between cultures, but also found that the variables were influenced significantly (Yu et al., 2002).

The researchers found that while there were many factors that influence school culture, school structure, and school environment, these were all significantly impacted by transformational leadership practices. In effect, the leadership style changed the variable conditions at the school. However, the study also found that there was only a very weak connection between transformational leadership practices and teacher's commitment to change (Yu et al., 2002). Further, researchers claim that there is a disparity in the cultural traditions that underscore personal interactions in the workplace between Chinese and American leadership roles, which affects the effectiveness of the leadership tactics in practice (Fu \& Yuk1, 2000).

The implications for this study are that the cultural contexts through which the school operates are indicative of the effect that transformational leadership practices may have on the school culture itself. For example, Yu et al. (2002) found that the highest mean rating was the item that the principal set high expectations for ongoing teacher development and growth $(\mathrm{M}=4.36, S D=1.13)$. Interestingly, while studies are being conducted in many cultures and across many traditional educational paradigms, it seems that transformational leadership affects many aspects of school culture regardless of geographic culture.

Another study looks at job satisfaction and teacher performance as it relates to teacher competence, motivation, and culture. The study collected data from 117 teachers and conducted an SEM analysis to see if competence, motivation and school culture had an influence on teacher job satisfaction and performance. Their study determined that 
there was a significant positive relationship between job motivation and job satisfaction; however, the results demonstrated that there was not any significant effect on teacher performance. This means that job motivation creates more satisfaction at the workplace, but not necessarily better performance at that job. The study did find, however, that competence and job satisfaction did affect teacher performance. Therefore, and indirect relationship between job motivation and performance did exist. The research also demonstrated that the culture of an organization had an affect on job satisfaction (Arifin, 2014).

This study highlights to complex relationship between competence, motivation, job satisfaction, and performance as it relates to the culture of an organization. Increasingly, studies have begun to uncover the intricate web that creates a culture of an organization as it pertains to schools and the performance of its teachers. While the research illuminates the need for a better understanding of how organizational culture evolves and is shaped by those within it, we also must come to a better understanding of how the culture affects those that operate within those systems. Additionally, Arifin (2014) suggests that schools can increase motivation by allowing greater accountability, encouraging creativity, and allowing teachers to develop professionally, which are behaviors associated with transformational leadership. By encouraging an improved school culture, we are able to increase job satisfaction and thereby improving performance (Arifin, 2014).

Dininno (2012) identifies what she calls "promoters" to leadership practices. Her study found certain identifiers for promoting healthy leadership practices. Among those was the use of distributive leadership to foster decision making accountability, building a 
trusting culture, creating time for collaboration, administrator availability for mentorship and skill building, and differentiated professional development. The study concluded that the encouragement factor in a culture that provided these promoters was pivotal in supporting leadership initiatives among teacher leaders. This study implies that school leaders can support a positive school culture by strategically employing these identifiers or "promoters" of teacher-leadership (Dininno, 2012).

In fact, another study illustrates the need to improve school culture to create a culture of high achievement within the school. The Aspen Institute (2014) studied high performing institutions and found that the role that culture plays is essential to the success of the school. The study found that while the school has a strong record of achievement, their leaders scored very low on instructional leadership practices, but high on cultural leadership practices. The implications of this study demonstrate that although a leader may lack some leadership traits, fostering a culture of achievement may assist leaders in achieving organizational goals (Aspen Institute, 2014).

This study has implications for the field of school culture in that it is imperative that schools work to assess and reassess the effectiveness of their culture in terms of goal setting and vision. The leaders in an organization are strategically responsible for building a culture of achievement and success regardless of their leadership role. They found that a shared sense of community and responsibility produces achievement, and concluded that teacher leaders have a significant impact on the culture of the school. The study also concluded that teacher leaders were better positioned to enact change in culture (Aspen Institute, 2014). 
Indeed, Turan and Bektas (2013) found that creating a positive culture in a school was dependent on leadership practices that supported cohesiveness and shared objectives. The study concluded that there was appositive and significant relationship between leadership practices both of teachers and of educational leaders and the school's culture. The research determined that certain leadership practices such as guidance, questioning, encouragement, and vision setting all had a huge impact on the variance of school cultures (Turan \& Bektas, 2013). The importance of this study underlines the specific practices that leaders can use to engage their followers in creating a positive school culture.

A study conducted in 2013 posited that the more positive a school's culture, the more teacher-leaders would develop and learn leadership practices in order to strengthen that school's culture further (Wang \& Zepeda, 2013). The symbiotic relationship that they posited found a link between school culture, positive teacher-leadership, and school improvement. By comparing their data, they were able to confirm that a positive culture fostered improved leadership development in teacher-leaders, and also helped to create a collaborative culture within the school; thereby, encouraging increased leadership roles and willingness to learn and take on increased responsibilities (Wang \& Zepeda, 2013).

Conversely, Wang and Zepeda also found that a negative school culture of distrust and disenfranchisement led to a difficulty in developing teacher-leaders and had an adverse impact on the ability of existing teacher-leaders to effectively enact change. They found that negative or unhealthy school culture was detrimental to efficiency and achievement of school wide goals and impeded a teacher-leaders' ability to impact educational practice and their peers (Wang \& Zepeda, 2013). 
The implications of this study to shed light on the cyclical relationship between teacher-leadership and school culture in a manner that demonstrates that school culture is a result of the functions of leadership, but still impacts leadership efficacy and efficiency throughout the organization. A Chinese study found similar results in their survey of 1318 teachers that found that fostering a culture of virtue and kind deeds could predict teacher efficacy and commitment (Cheng, 2012). The study found a cumulative effect on teacher and leaders and reaffirms the relationship between positive culture and effective leadership practices as a symbiosis of one another. The ability of a leader to effect change on an organization's culture is one that is longitudinal in nature, changing an organization over time.

In fact, several studies have determined that it is possible to improve the culture of a school by using transformational leadership practices such as the type discussed by the Aspen Institute (2014). The type of job satisfaction that is inherent in school with a healthy school culture are considered to be an affirmation of positive transformational leadership (Springer et al., 2012). Their longitudinal study followed a school's transformation from a negative culture to a positive one through the use of transformational leadership being used to build trust and employee satisfaction leading to increased achievement and performance. They describe the need to empower employees to be creative and the efforts of the school leaders to help build a shared vision within the organization through open communications and collaborative processes to generate change (Springer et al., 2012). These transformational practices worked to shift the perceptions of those stakeholders and to build a culture of empowered trust. According to Springer et al., "Organizational culture is a determining factor in the efficacy of 
organizations" (2012). Their study links transitions in school culture as a result of transformational leadership.

Another case study found similar significance in the role that leaders take in assisting to shape school culture through transformational leadership practices (Veiseh et al., 2014). They found a "meaningful" relationship between a school's culture and transformational leadership practices such that several factors of transformational leadership have a significant effect on culture. Although the found that intellectual encouragement had no significant influence on organizational culture, they found that inspirational motivation, personal observations, and hopeful influence were positively correlated with organizational culture. In fact, they describe the influence that transformational leadership has on the role of culture as "remarkable" (Veiseh et al., 2014).

While the majority of the research seems to concur that transformational leadership significantly changes the climate, culture, and achievement of a school, not all researchers agree that this information is being utilized in a manner that allows for this type of successful change in the educational paradigm. Researchers Moujaes et al (2012) claim that policymakers fail to enact reforms based on solid research verified practices. They claim that while those leaders who have the power to enact significant change in the way education is led, they themselves are not transformational leaders capable of developing leaders with the capacity to effect real needed reform. Moujaes et al (2012) urge these top tier leaders to become transformational leaders themselves in order to be able to work with their leaders for the betterment of the educational paradigm. 
Moujes et al (2012) introduce a three-part framework that identifies leaders capable of making significant transformational change within education. First, they identify leaders who are visionary, capable of thinking strategically in order to meet future expectations and needs of the school system. Second, they are able to work within the existing system in order to affect change from within. Third, they are leaders who are able to lead by engaging stakeholders and subordinates during transition in a manner that allows for supportive behaviors. Their research looked at specific case studies in many regions of the world such as Abu Dhabi, Finland, South Korea, and Canada and found that while all of these places had different educational systems, they were very similar in their management of these systems: transactional rather than transformational (Moujaes et al, 2012).

Other research suggests that while these studies are imperative to the field of education, that they also have far reaching implications for all leadership roles. Davis and Macauley (2011) outlines the need for leaders to create cultures of leadership in which all leaders take their roles personally in an effort to transform the organization from within through all levels of leadership which in turn impacts school culture.

However, not all of the research confirms that transformational leadership positively impacts school learning culture. Barnett, McCormick, and Connors (2001) conducted a study that concluded that the use of transformational leadership is no more effective than transactional leadership in terms of its impact on school culture. Their research determined that while transformational leadership does have a positive impact on teacher outcomes such as job satisfaction, commitment, and teacher's perceptions of leadership effectiveness, it had a negative impact on student learning culture. The 
implications of this study were significant because it implies that the relationship between leadership and achievement or those factors that influence achievement may be much more complex than first noted. Their research surveyed 124 teachers using the Multifactor leadership questionnaire (MLQ-5X) instrument to measure the characteristics of transformational leadership. Barnett, McCormick, and Connors research conclusions indicated that elements of transactional leadership were critical to building and maintaining a culture of learning within the school (2001).

Interestingly, studies have now expanded from contained school culture to educational culture outside of the school. Leithwood and Patrician (2015) discuss the need for educational culture to include stakeholders in the home and community to improve school culture and to foster a culture of achievement. In fact, their study presents a "multi-dimensional" concept of school culture that includes parental engagement, instructional support, and leadership as a necessary component to building beneficial educational cultures at school (Leithwood \& Patrician, 2015). Tavares-Silva and Pessanha (2012), on the other hand, discuss the implications of school culture on curriculum and educational management and conclude that the culture of an organization is both historical and political in nature, and that the education efforts reach outside of school boundaries to deeper sociological issues.

Bernard Bass and Bruce Avolio originated the Organizational Description Questionnaire in 1992 as a means of exploring the correlation between a leaders' leadership style and that of the culture of an organization (Bass \& Avolio 1993). This instrument measures transformational leadership culture and transactional leadership culture. This instrument has been used in order to evaluate the culture of an organization 
as either transformational in which the organization seeks to build a culture of trust and mutual purpose for growth and change in both the individual and the organization itself; or transactional in which supportive environments are in favor of a productive organization outside of the needs of the individual (Inabinett \& Ballero, 2014). The instrument contains 28 survey items, which are half transformational and half transactional in nature in order to frame a culture for the organization. The instrument allows for an organization to be able to accurately assess their culture in terms of their commitment to transformational or transactional leadership.

\section{Gaps in the Literature}

A review of the literature shows a considerable amount of research being conducted in the area of transformational leadership. The Full Range Leadership Model demonstrates a comprehensive overview of leadership styles that are in evidence in both schools and in other types of organizations. The components of the model are compelling to the study of leadership practices and their impact on culture and collaborative practices. Examining school culture as a result of leadership yields a wealth of research that effectively determines a positive relationship between building a healthy school culture and transformational leadership.

There is also a great deal of research being conducted on teacher leadership and its impact on achievement and on school culture. The literature is comprehensive in providing insight into the need for effective teacher-leaders and the practices that encourage effective leadership. Throughout the literature, studies have demonstrated that having effective leaders within an organization influences culture. 
However, a gap persists in making a connection between teacher-leadership and transformational leadership. Very few studies have been made that effectively study the need for teacher-leaders to demonstrate the transformational practices that educational administrators have been shown to need. While teacher-leadership is essential in an effective culture, and transformational leadership is also pivotal to building that culture, the logical evolution in research would lead to the need for studies in transformational teacher-leadership.

In addition, there exists a gap in the literature for practical application. While the research hints at usage of transformational practice, the existing research fails to uncover a methodology for employing teacher-leadership or transformational leadership in a manner that allows for greater achievement of organizational goals and personal vision. The research has implications for practical usage, but seems to stop short of creating an impetus for actual change within organizations. The implied applications are essential for making actual and workable improvements to educational paradigms. The research must produce conditions under which form and function become practice.

The study being conducted here seeks to fulfill the purpose of highlighting the transformational leadership being practiced in schools that have healthy cultures. The need for this study becomes apparent when we view the literature as a means of building useful practice within the school site for achieving organizational goals and for the betterment of the school functions. Teacher-leadership has proven an indispensable asset to the vision of schools that have few administrators and even fewer resources. The research demonstrates that these leaders have a wealth of untapped ability, but fails to connect that resource to transformational practices. 


\section{Summary}

A review of the literature demonstrates that the Full Range Model of Leadership's nine components are well tested for reliability and validity and are both accurate and robust tests for leadership styles. The improvement efforts of the education system are becoming increasingly dependent on having effective leadership that is aware of leadership styles and its impact on school culture. By examining the literature, we are able to see a clear need to continue in our efforts to understand the cyclical influence culture has on leadership and that leadership has on culture.

Additionally, the research demonstrates that attention to understanding leadership styles has had an impact on improvement practices in leadership throughout a wide range of industries and cultures. Our understanding of administrative leadership, teacher leadership, and school culture are ever changing and ever evolving. The literature reviewed demonstrates this evolution and continued exploration of not only how to understand leadership styles, but also on their impact on the organization as a whole. 


\section{CHAPTER III. Methodology}

My research study examined the predominant leadership styles of educational administrators and teacher-leaders and the relationship between those styles and the culture of the school in which they work. A quantitative study was conducted in three layers. My study attempted to determine what type of leadership style the leader demonstrated and that relationship to school culture. First, the leaders themselves evaluated their own leadership style along the Full Range Leadership Model by answering survey questions on the Multifactor Leadership Questionnaire Self (MLQ-5X Short Form). Second, followers evaluated their perceptions of their leaders' actual leadership style on the Multifactor Leadership Questionnaire Rater (MLQ-5X Short Form). Third, all participants will evaluate their organizational culture on the Organizational Description Questionnaire (ODQ).

Chapter III includes include the following sections:

1. A description of the participants of the study including an explanation of the selection process for identifying participants.

2. Research instruments and studies examining validity

3. Research questions

4. The procedures for collecting data

5. Assumptions

6. Hypotheses

7. Statistical analysis procedures

8. Delimitations of the study 


\section{Description of Participants}

The participants in the study were educational administrators and teacher-leaders currently employed in the Miami Dade County Public School system. The participants were drawn from a population of approximately 460 administrators, approximately 3000 teacher-leaders, and all staff at participating schools in the Miami Dade County Public School System. The administrative leaders and teacher-leaders participated in the selfrater portion of the Multifactor Leadership Questionnaire (MLQ-5X). Data collected from the staff at participating schools were collected using the MLQ-5X Rater survey and the Organizational Description Questionnaire (ODQ).

During the data collection process, the study surveyed 139 participants. Sixteen of the surveys were discarded because of an unsigned consent form or incomplete survey data. In addition, three completed surveys had to be discarded because the leader to which they were assigned did not participate.

The final sample included one hundred and twenty participants.. Of those surveyed, twenty-four of the participants were leaders. Seven of these leader participants were administrative leaders, 17 of them were teacher-leaders. In addition, the research surveyed 96 followers, each of whom rated one of the 24 leaders in a randomized assignment.

These leaders and followers were surveyed from three different schools throughout Miami Dade County Public School System. At the time of the study, there were a total of 17 administrative leaders, and 42 teacher-leaders within those three schools. There were a total of 205 faculty members in the three schools at the time of my 
survey. All leaders and faculty members were provided the opportunity to participate in the study.

The average demographic participant's age, gender, racial-ethnic identity, and SES was determined by the leaders and followers that chose to participate in the study. It is assumed that the demographic sample is representative of the population based on the ethnic makeup of Miami Dade County. Participation in the study was on a volunteer basis after inviting participation to each school. As a result of the limited number of educational administrators and teacher-leaders in Miami Dade County Public School system, the participant pool was chosen from the existing administrators in the Miami Dade County Public Schools system and the formalized teacher-leadership pools in those schools that chose to participate. The pool of teacher-leaders consisted primarily of department and grade level chairs, instructional coaches, and other formalized instructional positions.

\section{Research Instruments and Studies Examining Validity}

The study that was conducted consisted of two research instruments that measured the two components of leadership and school culture. The first research instrument was used to measure whether the educational administrators and teacherleaders actually practice transformational, transactional, or passive/avoidant leadership as defined by Bass and Avolio (1997). For the purposes of this study the most recent form of the Multifactor Leadership Questionnaire, the MLQ-5X short form was used (Bass \& Avolio, 2006).

Those participants who are leaders were provided the Multifactor Leadership Questionnaire (MLQ-5X) self-rater form, a survey that determined the leaders' 
perception of their own predominant leadership style. The MLQ-5X survey contained a 5-point Likert type scale with 45 items and was used to determine the leaders' predominant leadership characteristics as determined between the leaders' perception and their followers perceptions of their leadership practices.

Several studies have been able to examine the validity of the MLQ-5X short form. Antonakis et al. (2003) examined several factors of the Multifactor Leadership Questionnaire and determined that the underlying structure of the MLQ-5X is best represented by the nine-factor analysis used in the most recent form. There have been concerns expressed about the validity of the six-factor model; therefore, the nine-factor model was developed to respond to those criticisms and is the model used here (Antonakis et al., 2002). These nine factors are Laissez Faire, Management by Exception (Passive), Management by Exception (Active), Contingent Rewards, Idealized Influence (Attributes), Idealized Influence (Behavior), Inspirational Motivation, Intellectual Stimulation, and Individualized Consideration. Judge and Piccolo (2004) found strong case for overall validity $(r=.44)$ for the MLQ-5X, and found that transformational leadership had a more strongly correlated relationship than did transactional leadership. In addition, the five transformational components had a high average inter-correlation factor $(r=.064, p<0.01)$ demonstrating that the nine-factor form contains much higher validity than the six-factor model (Eshbach, 2008).

The second instrument used in the study was the Organizational Description Questionnaire (ODQ). An examination into the validity and reliability of the ODQ instrument found the transformational scale to have both reliability and consistency as 
well as theoretically comprehensive. According to Parry and Proctor-Thomson (2001), the Organizational Description Questionnaire demonstrates adequate internal reliability ( $r=0.88$ for transformational culture and $r=0.77$ for transactional culture). They also found, however, that the transactional and transformational scales do negatively correlate with one another $(r=-0.61, p<0.001)$ (Parry \& Proctor-Thomson, 2001).

The ODQ contains a true/false type survey whose purpose was to obtain data on organizational culture. My survey contained 28 items based on a choice of "true," "false," or "?." Each answer was provided a point value, and the organization was given a mean score that represents the degree to which the culture type manifests itself in the organization (Parry \& Proctor-Thompson, 2007).

There are nine types of organizational culture defined within the ODQ by Bass and Avolio (1994) creating a leadership culture profile. These nine types are: garbage can, pedestrian, bureaucratic, loosely guided, coasting, formal, maturing, highly developed, and high contrast. These nine types were split into transformational and transactional components. Parry \& Proctor-Thomson (2007) conducted a validity study on the ODQ and concluded that the scale correlated positively with transformational culture $(r=0.39, p<0.001)$. The study also concluded that transactional culture correlated negatively with organizational effectiveness at $(r=-0.34, p<0.001)$. However, a study conducted by Nader et al. (2006) found "good levels of internal consistency for both dimensions", transformational and transactional (p. 152). While the Organizational Description Questionnaire has not been developed further than the original iteration of the survey, it demonstrates both valid and reliable results that measure the organizational culture with consistency. 


\section{Research Questions}

There are several questions that this study sought to answer throughout the course of the research. All of them have potential implications on leadership style and teacherleadership and the relationship between that and school culture. These questions are:

- RQ 1: What is the primary demonstrated leadership style of the administrator and teacher leader as determined by the leader's scores combined with the follower's scores on the Multifactor Leadership Questionnaire 5X Short Form (MLQ-5X)?

- RQ 2: What is the school culture profile as determined by the leaders' and followers' scores on the Organizational Description Questionnaire (ODQ)?

- RQ 3: Is there a connection between the leadership style of educational administrators and teacher-leaders and school culture as determined by and analysis of variance between leader and follower scores on the MLQ-5X and the ODQ?

\section{Procedures for Collecting Data}

The procedures for gathering the sample group were to recruit participating schools by first sending electronic correspondence requesting participation, followed by mailed letters to each of the approximately 460 principals in 464 schools in Miami Dade County Public School System. The purpose of this letter was to explain the nature and reasons for the research being conducted and to request participation in the survey. There were three schools that chose to participate in the research and had the principals, administrative leaders, and teacher-leaders surveyed. In addition, all faculty and instructional members at the school site were invited to participate in both survey instruments. 
The data collection period was ten weeks long, beginning with the initial contact between the researcher and principal. Once contact was made, the researcher made arrangements to meet with the participants at the school during faculty meetings as the ease of communication and the least intrusive time on campus. The data were collected at the next convenient meeting date for collection with those participants.

Prior to the meeting, the researcher prepared two types of survey packets for leader and follower participants. Also, prior to the meeting, the researcher requested s information from the school such as the number of faculty members, the types of leadership, and the number of participants in each department in order to assure randomization. The researcher had no control over the number or type of administrative leader that participated in the study, nor the followers that would choose to participate, which makes this a random sample. The assignment was provided in sealed envelopes per department and was randomly distributed to the members of that department.

The surveys were randomized according to the school and department in which the leader and follower worked. In each department, the packets were prepared for the number of followers in the department as well as the number of leaders in the school. In addition, the sampling was further randomized per department, with some of the members of the department being surveyed about the educational administrator, some about the department chair, and some about other administrative leaders or teacherleaders within the school such as the test-chair, athletic director, or the activities director. Half of the follower packets contained surveys for the department chair, and the other half contained surveys for the additional leaders at the school. The packets were marked only with "Leader" or Follower" and were separated by department. The follower survey 
packets were not marked in any other fashion and were distributed blindly according to each department only. It is unknown which follower participant received which leader to evaluate. The leader packets were assigned a "leader number" in order to preserve anonymity for the leader.

During the meeting, prior to collecting the data, the researcher provided information to the principals, teacher-leaders, and staff about the purpose of the study, the random selection process, the confidentiality of the results, and the potential uses for the results. The survey included a portion that provided informed consent to all participants.

Those who did not wish to participate in the study had the opportunity to decline participation. The participants were provided an envelope that contained an informed consent form, a short demographic section, the Multifactor Leadership Questionnaire Self or Rater (MLQ-5X Short Form), and the ODQ. The followers were given a survey for the leader that they were assessing, which was randomized. It is of note that the followers assessed the principal, one of the other administrative leaders, their department chair, or any other teacher-leaders and assessed only one of these leaders. In addition, each participant was given the ODQ, which only has one iteration.

At the conclusion of the meeting, the researcher set a due date for the data at the next faculty meeting during which a specified leader would collect the sealed packets and return them to the researcher. At the conclusion of the ten-week time period, the data collection period was closed and any data collected up to that time was used. Late surveys were not used in the data analysis.

The procedures for data collection included a survey for the participants to complete. The survey was a 20-30 minute survey given in a paper format. The survey 
will had two parts: first, was be the Multifactor Leadership Questionnaire (MLQ-5X) self or rater form, depending on whether the participant was a leader or a follower.

The second part of the data collected was the Organizational Description Questionnaire (ODQ), and was distributed to all participants in the study both leaders and staff members. The purpose of the Organizational Description Questionnaire was to determine the culture of the school and was used in conjunction with the MLQ-5X short form to answer the research questions.

\section{Assumptions}

There are several assumptions that underlie this study. First, no difference exists between school site administrators and teacher-leaders on the MLQ-5X form. The instrument is a measurement of leadership; therefore, the questions posed to the two levels of leadership are the same for both. Second, for the purposes of my study, only administrative leaders that hold formal titles were used for data collection. Third, the Full Range Model of Leadership as defined by Burns (1978), Bass (1985), and Avolio (1989) was used to define the leaders' style of leadership in the MLQ-5X. Fourth, School Culture was measured using the Organizational Description Questionnaire (ODQ). Fifth, the sample was representative of the demographic makeup of Miami Dade County. Seventh, Transactional and Transformational leadership styles define leadership differently.

\section{Hypotheses}

The hypotheses posed in the study are aimed at discovering a connection between leadership style, school administrators, teacher-leaders, and school culture. As indicated in Chapter I, there were three hypotheses that were tested in the course of the research. 
The following are the hypotheses that were tested throughout the course of the study being conducted and the assertions made by these hypotheses were the focal point of the research. The data collected from the three different surveys were focused on testing the hypotheses posed here.

H1. There will be a difference between administrative leaders' and teacher-leaders' predominant leadership style as measured by the leaders' and followers' scores on the Multifactor Leadership Questionnaire for Research (MLQ-5X Short Form).

H1.0- Null- There will be no difference between administrative leaders' and teacher leaders' leadership characteristics as measured by the leaders' and followers' scores on the Multifactor Leadership Questionnaire for Research (MLQ-5X Short Form).

$\mathrm{H} 2$. There will be a difference between transactional and transformational predominant school culture profile as measured by the leaders' and followers' scores on the Organizational Description Questionnaire (ODQ).

H2.0- Null- There will be no difference between transactional and transformational predominant school culture profile as measured by the leaders' and followers' scores on the Organizational Description Questionnaire (ODQ).

H3. There will be a difference between administrative leaders' and teacher-leaders' predominant leadership style and school culture profile as measured by the leaders' and followers' scores on both the Multifactor Leadership Questionnaire (MLQ-5X Short Form) and the Organizational Description Questionnaire (ODQ).

H3.0- Null- There will be no difference between administrative leaders' and teacherleaders' predominant leadership style and school culture profile as measured by 
the leaders' and followers' scores on both the Multifactor Leadership

Questionnaire (MLQ-5X Short Form) and the Organizational Description

Questionnaire (ODQ).

\section{Statistical Analysis Procedures}

The data for this study were gathered using three groups of participants: the educational leader, both administrative leaders and teacher-leaders, and the followers, each coded differently for statistical measurement purposes. The Multifactor Leadership Questionnaire (MLQ-5x) self-form was provided to each educational leader and teacher leader in participating institutions. The MLQ-5X rater form was provided to each follower at participating schools. Every participant in the study was provided with the Organizational Description Questionnaire (ODQ) in order to establish the culture at the school. Collection of these data permitted a comparative analysis of the predominant leadership style as defined by the Full Range Leadership Model and the nine factors of the MLQ-5X and its impact on school culture as defined by the ODQ.

Once the data were collected, the data were coded and entered into SPSS statistical software by hand and the raw data were evaluated. For the MLQ-5X, each of the 45 questions used the five-point Likert scale and was coded into a system in which each answer was assigned a number 0 through 4 , then transposed into the program for analysis as per the MLQ-5X instrument instructions (Avolio \& Bass 2004). For the ODQ, the 28 True/False/? Questions were coded as a "1" for "True", a "-1" for "False", and a "0" for "?" as per the Organizational Description Questionnaire (ODQ) instrument instructions (Bass \& Avolio 2006). 
The first seven demographics research questions were answered using descriptive statistics. The data were analyzed using mean and frequency analyses and the relationship between these descriptive statistics provided insight into the makeup of the participant population and will be discussed in the results section of my study.

The first analysis completed was for the MLQ-5X Rater and Self form which demonstrated the predominant leadership characteristic for each leader. After the data collection, data coding, and data entry, the initial analysis was conducted using descriptive statistics to examine the makeup of the participant responses.

The independent variable for this analysis was the leadership type: Administrative leader, teacher-leader, or follower. The dependent variable for this analysis was the predominant leadership characteristic demonstrated according to their scores on the MLQ-5X. A one-way analysis of variance (ANOVA) was conducted on the independent and dependent variable to test the hypothesis concerning the relationship between the educational leaders' self-perception of their predominant leadership characteristic and the followers' rating of those same leaders based using a comparison of their answers on the MLQ-5X. The mean difference between the item answers assisted in a determination of the predominant leadership style for each administrator.

The second research question concerning the participants' perceived culture profile for their school was examined in the same manner. The data were collected, coded, and entered into the statistical analysis program. The first analysis completed were descriptive statistics to determine the participant makeup and an evaluation of the culture profile. 
The independent variable for this analysis was the characteristics of school culture. The dependent variable for this study was the predominant culture scores transformational and transactional based on the participants' answers on the ODQ. A one-way analysis of variance (ANOVA) was conducted in order to test the hypothesis concerning the relationship between the educational leaders' and followers' perceptions of their school culture profile based on a comparison of their answers on the ODQ. The mean difference between the item answers assisted in a determination of the predominant culture profile.

The third research question examining a relationship between the leaders' predominant leadership style and the culture profile was examined by first using descriptive statistics to determine the mean and frequency of the participants' answers. In addition, a cross tabulation was completed to establish the frequency of the combinations of answers for both of the nine characteristic sets for the MLQ-5X and the ODQ. The results section illustrates those findings.

The independent variable in this analysis was the leaders' predominant leadership characteristic as determined by the participants' scores on the MLQ-5X. The dependent variable was the culture profile as evidenced by the participants' scores on the ODQ. Another one-way analysis of variance (ANOVA) was conducted to test the hypothesis concerning the relationship between administrative leaders' and teacher-leaders' predominant leadership style, and the predominant school culture characteristic. These statistics were examined to determine whether a disparity exists between administrative leaders' and teacher-leaders' leadership style and culture profile. The results are discussed in the following chapter. 
For each of the analyses in this study, the alpha level was set at .05, which is the typical alpha level for social science research. It has been determined that finding a significance level of $\mathrm{p}<0.05$ indicates a significant relationship between leadership styles and school culture.

\section{Delimitations of the Study}

This study has several delimitations that may have affected the scope and generalizability of the study and may have impacted the outcome of the study. These parameters were set by the researcher in order to maintain the feasibility of the study. The following are some of the delimitations of the study.

1. This study was limited and offered only to public school administrative leaders only in Miami Dade County Public School System due to their availability. Therefore, no assumptions should be made about the generalizability of this study to private, parochial, charter, alternative schools, or schools in other districts.

2. This research was also delimited to educational administrative leaders and teacher-leaders who hold formal titles. While a case can certainly be made for the inclusion of teacher-leaders that act in a leadership capacity without the authoritative position, this study sought to ascertain the leadership style of those endowed with formal authority to enact changes based on the school's organizational culture and goals.

3. Since this study contains a multi-part survey, the sample is limited to participants that completed all parts of the survey. The leadership styles of the educational administrators and teacher-leaders will be ascertained from the Multifactor Leadership Questionnaire Self (MLQ- Form 5X Short) (Bass, 1997). The 
perceptions of leadership style by subordinates and peers was ascertained using the Multifactor Leadership Questionnaire Rater (MLQ- Form 5X Short). The measurement of school culture was measured by all participants using the Organizational Description Questionnaire (ODQ). Any incomplete surveys were discarded.

\section{Summary}

The research conducted throughout this study was a randomized sample of educational administrators and teacher-leaders in Miami Dade County Public Schools that sampled twenty-four leaders and 96 followers to determine the educational leadership style as defined by the full range leadership model. In addition, the participants of the study were surveyed to determine the schools' predominant culture as defined by the Organizational Description Questionnaire. The study sought to answer to the relationship between educational leadership styles and school culture and to determine through statistical analysis whether there exists a correlation between leadership styles demonstrated in schools and school culture. 


\section{CHAPTER IV. Results}

This chapter contains the results of the quantitative research study conducted to ascertain the effects of school administrators' and teacher-leaders' leadership style on school culture. The research conducted attempted to answer the following research questions:

- RQ 1: What is the primary demonstrated leadership style of the administrator and teacher leader as determined by the leader's scores combined with the follower's scores on the Multifactor Leadership Questionnaire 5X Short Form (MLQ-5X)?

- RQ 2: What is the school culture profile as determined by the leaders' and followers' scores on the Organizational Description Questionnaire (ODQ)?

- RQ 3: Is there a connection between the leadership style of educational administrators and teacher-leaders and school culture as determined by and analysis of variance between leader and follower scores on the MLQ-5X and the ODQ?

After the surveys were collected and completed, the data was coded and entered into SPSS statistical analysis software. The first analysis completed was a demographic analysis.

\section{Demographics and Descriptive Statistics}

The sample from this study was taken from three schools in Miami Dade County Public Schools. The participants were limited to school administrative leaders, teacherleaders, and teaching faculty within those three schools. At the time of the study, there were a total of 17 administrative leaders, and 42 teacher-leaders within those three 
schools. There were a total of 205 faculty members in the three schools at the time of this survey. All leaders and faculty were provided the opportunity to participate in the study. Throughout the data collection process, a total of 139 surveys were completed. Of these, 16 of them were excluded due to an unsigned consent form or incomplete survey data. Three others were discarded due to because the leader they were assigned did not participate. Therefore, the total size of the number of participants was $N=120$. The research surveyed $n=24$ leaders. The subsample totals for the leader groups was administrative leaders $(n=7)$ and teacher leaders $(n=7)$. These leaders were surveyed from a total of three different schools throughout Miami Dade County. In addition, the research surveyed $n=96$ followers, each of whom rated one of the 24 leaders in a randomized assignment. Table 1 shows the survey percentages for the different leader types for the participants of the study.

Table 1. Frequency and Percent of Leader Type

Valid

\begin{tabular}{lcccc} 
& Frequency & Percent & Percent & Cumulative Percent \\
\hline Administrative Leader & 7 & 5.8 & 5.8 & 5.8 \\
Teacher Leader & 17 & 14.2 & 14.2 & 20.0 \\
Follower & 96 & 80.0 & 80.0 & 100.0 \\
Total & 120 & 100.0 & 100.0 & \\
& & & & \\
\hline
\end{tabular}

Of the three schools surveyed, the 120 total number of useable surveys completed varied by school due to school faculty size, and participation in the study. As Table 2 demonstrates, School 1 completed a total of 71 surveys, and accounted for $59.2 \%$ of the total number of surveys completed. School 2, however, completed 15 surveys and 
accounted for $12.5 \%$ of the completed surveys. School 3 completed 34 surveys, for a total of $28.3 \%$ of completed surveys.

Table 2. Frequency and Percent by School

\begin{tabular}{lcccc}
\hline & & & & Cumulative \\
Frequency & Percent & Valid Percent & Percent \\
\hline 1.00 & 71 & 59.2 & 59.2 & 59.2 \\
2.00 & 15 & 12.5 & 12.5 & 71.7 \\
3.00 & 34 & 28.3 & 28.3 & 100.0 \\
Total & 120 & 100.0 & 100.0 & \\
& & & & \\
\hline
\end{tabular}

The number of followers that surveyed each leader depended on the number of participants in each school. The research conducted provided an equal number of surveys for each leader to the expected participants; however, the number of surveys completed per leader varied by participation due to the fact that the participation was both random and voluntary. Therefore, the data demonstrates that the leaders do not have an identical number of follower ratings for each part of the survey. In addition, since several of the surveys completed were unusable due to incomplete answers or sections, the number of followers per leader varies.

Table 3 illustrates the number of leaders and the number of participants that rated the leaders. Within this distribution of surveys, 12 of the leaders originated from school 1, while schools 2 and 3 account for 6 leaders each. One leader did not participate; therefore, three follower surveys were also discarded, as they became unusable. Out of the 139 surveys completed, $86 \%(N=120)$ of the surveys were complete and contained usable data. Of the $14 \%$ that were not used 1 was a leader, and the rest were followers. 
Table 3. Frequency and Percent, Number of Participants by Leader

\begin{tabular}{|c|c|c|c|c|}
\hline & Frequency & Percent & Valid Percent & $\begin{array}{c}\text { Cumulative } \\
\text { Percent }\end{array}$ \\
\hline 1.00 & 6 & 5.0 & 5.0 & 5.0 \\
\hline 2.00 & 4 & 3.3 & 3.3 & 8.3 \\
\hline 3.00 & 5 & 4.2 & 4.2 & 12.5 \\
\hline 4.00 & 5 & 4.2 & 4.2 & 16.7 \\
\hline 5.00 & 4 & 3.3 & 3.3 & 20.0 \\
\hline 6.00 & 11 & 9.2 & 9.2 & 29.2 \\
\hline 7.00 & 6 & 5.0 & 5.0 & 34.2 \\
\hline 8.00 & 11 & 9.2 & 9.2 & 43.3 \\
\hline 9.00 & 8 & 6.7 & 6.7 & 50.0 \\
\hline 10.00 & 3 & 2.5 & 2.5 & 52.5 \\
\hline 11.00 & 2 & 1.7 & 1.7 & 54.2 \\
\hline 12.00 & 6 & 5.0 & 5.0 & 59.2 \\
\hline 13.00 & 4 & 3.3 & 3.3 & 62.5 \\
\hline 14.00 & 2 & 1.7 & 1.7 & 64.2 \\
\hline 15.00 & 3 & 2.5 & 2.5 & 66.7 \\
\hline 16.00 & 2 & 1.7 & 1.7 & 68.3 \\
\hline 17.00 & 2 & 1.7 & 1.7 & 70.0 \\
\hline 18.00 & 2 & 1.7 & 1.7 & 71.7 \\
\hline 19.00 & 6 & 5.0 & 5.0 & 76.7 \\
\hline 20.00 & 6 & 5.0 & 5.0 & 81.7 \\
\hline 21.00 & 6 & 5.0 & 5.0 & 86.7 \\
\hline 22.00 & 3 & 2.5 & 2.5 & 89.2 \\
\hline 23.00 & 3 & 2.5 & 2.5 & 91.7 \\
\hline 24.00 & 10 & 8.3 & 8.3 & 100.0 \\
\hline Total & 120 & 100.0 & 100.0 & \\
\hline
\end{tabular}

The gender distribution for the study was 86 female, comprising $71.7 \%$ of the participants. The male participant number was 34 and consisted of $28.3 \%$ of participants. The percentage of female to male participants is heavily weighted towards female. Table 4 shows the total distribution of male to female total participants, while table 5 demonstrates the number of male to female leaders that participated in the study. 
Table 4. Frequency and Percent of Participants' Gender

\begin{tabular}{lcccc}
\hline & & & & Cumulative \\
& Frequency & Percent & Valid Percent & Percent \\
\hline Female & 86 & 71.7 & 71.7 & 71.7 \\
Male & 34 & 28.3 & 28.3 & 100.0 \\
Total & 120 & 100.0 & 100.0 & \\
& & & & \\
\hline
\end{tabular}

Table 5. Frequency and Percent of Leaders' Gender

\begin{tabular}{lcccc}
\hline & Frequency & Percent & Valid Percent & $\begin{array}{c}\text { Cumulative } \\
\text { Percent }\end{array}$ \\
\hline Female & 19 & 79.2 & 79.2 & 79.2 \\
Male & 5 & 20.8 & 20.8 & 100 \\
Total & 24 & 100.0 & 100.0 & \\
& & & & \\
\hline
\end{tabular}

The age of the participants consisted of five ranges, $21-29,30-39,40-49,50-59$, and 60+. Table 6 illustrates that the youngest teachers, those between 21 and 29 made up $10 \%$ of the participants and $30-39 \%$ made up $15 \%$ of the participant pool. The teachers in the middle age range, those aged 40-49 and 50-59 made up the majority of the participant pool at $28.3 \%$ and $31.7 \%$ respectively. While the oldest teachers, aged 60 made up $15 \%$ of the participants. The distribution of age participation approximates a bell curve and is weighted towards the middle participant age range.

Table 6. Frequency and Percent of Age Groups

\begin{tabular}{lcccc}
\hline & & & & Cumulative \\
& Frequency & Percent & Valid Percent & Percent \\
\hline $21-29$ & 12 & 10.0 & 10.0 & 10.0 \\
$30-39$ & 18 & 15.0 & 15.0 & 25.0 \\
$40-49$ & 34 & 28.3 & 28.3 & 53.3 \\
$50-59$ & 38 & 31.7 & 31.7 & 85.0 \\
$60+$ & 18 & 15.0 & 15.0 & 100.0 \\
Total & 120 & 100.0 & 100.0 & \\
\hline
\end{tabular}


The education level demonstrated that the participants primarily held a Bachelor's degree level, with $40.8 \%$ of the participants having obtained an undergraduate degree as Table 7 demonstrates. Postgraduate degrees comprised $35.8 \%$ of the participants holding a Master's degree while $16.7 \%$ and $6.7 \%$ held a Specialist and Doctoral degree respectively. In terms of leaders, as Table 8 shows, only $12.5 \%$ of them hold a Bachelor's degree. Those leaders that held a Master's degree made up 54.2\% and 25\% of participants had a Specialist degree. Additionally, $8.3 \%$ of leaders held a Doctoral degree.

Table 7. Frequency and Percent of All Participants' Degree Levels

\begin{tabular}{lcccc}
\hline & & & & Cumulative \\
& Frequency & Percent & Valid Percent & Percent \\
\hline Bachelor's & 49 & 40.8 & 40.8 & 40.8 \\
Master's & 43 & 35.8 & 35.8 & 76.7 \\
Specialist & 20 & 16.7 & 16.7 & 93.3 \\
Doctorate & 8 & 6.7 & 6.7 & 100.0 \\
Total & 120 & 100.0 & 100.0 & \\
& & & & \\
\hline
\end{tabular}

Table 8. Frequency and Percent of Leaders' Degree Levels

\begin{tabular}{lcccc}
\hline & & & & Cumulative \\
& Frequency & Percent & Valid Percent & Percent \\
\hline Bachelor's & 3 & 12.5 & 12.5 & 12.5 \\
Master's & 13 & 54.2 & 54.2 & 66.7 \\
Specialist & 6 & 25 & 25.0 & 91.7 \\
Doctorate & 2 & 8.3 & 8.3 & 100.0 \\
Total & 24 & 100.0 & 100.0 & \\
\hline
\end{tabular}

\section{Research Question 1}

Research Question 1 explored the primary demonstrated leadership style of the administrator and teacher leader as determined by the leader's scores combined with the follower's scores on the Multifactor Leadership Questionnaire 5X Short Form (MLQ- 
$5 \mathrm{X})$. The purpose of the analysis was to determine the leadership style on the transactional to transformational continuum. The transformational characteristics on the continuum are Idealized Influence (Attributes), Idealized Influence (Behavior), Inspirational Motivation, Intellectual Stimulation, and Individualized Consideration. The transactional characteristics are Contingent Reward, Management-by-Exception (Active), Management-by-Exception (Passive), and Laissez Faire Leadership.

The independent variable in this study were the three types of participants; Administrative Leader, Teacher Leader, and Follower. The dependent variables in this study were the predominant characteristics as determined by the results of the scores on the MLQ-5X. The data was collected and first analyzed based on a frequency and mean according to the MLQ-5X (Avolio, Bass, \& Jung, 1999). In addition, an ANOVA was performed to study the relationship between the variances of the dependent and independent variable. The measure of transformational to transactional range was the dependent variable for answering this research question, which was the predominant characteristic demonstrated by the answers taken on the MLQ-5X Short form. The responses had a mean of 3.06 on a Likert type scale of $0-4$ with a standard deviation of 2.42 as shown in Table 9.

Table 9. Multifactor Leadership Questionnaire Statistics

\begin{tabular}{llr}
\hline & Valid & 120 \\
& Missing & 0 \\
\hline Mean & & 3.0583 \\
Std. Deviation & & 2.41944 \\
Skewness & .988 \\
Std. Error of Skewness & .221 \\
\hline
\end{tabular}


The results were coded on a scale of $1-9$ of the nine characteristics on the continuum of transformational to transactional leadership. The following measurements on the frequency Table 10 were the representation for each of the answers presented. A 1 $=$ Idealized Influence (Attributes); $2=$ Idealized Influence (Behavior); $3=$ Inspirational Motivation; 4= Intellectual Stimulation; 5= Individualized Consideration; $6=$ Contingent Reward; 7= Management-by-Exception (Active); 8= Management-by-Exception (Passive); 9= Laissez Faire Leadership. Table 10 illustrates that value 1, Idealized Influence (Attributes) accounts for the highest percentage of characteristics at $41.7 \%$ ( $n=$ 50), and values 2 and 3 Idealized Influence (Behavior) and Inspirational Motivation respectively account for $12.5 \%(n=15)$ and $15 \%(n=18)$. Value 4 , Intellectual Stimulation accounts for the lowest percentage at $1.7 \%(n=2)$. In addition, value 9 , Laissez Faire Leadership makes up 3.3\% $(n=4)$ of the characteristics.

Table 10. Frequency and Percent of Predominant Leadership Characteristic Valid Cumulative

$\begin{array}{llllll}\text { 1. Idealized Influence (Attributes) } & 50 & 41.7 & 41.7 & 41.7\end{array}$

2. Idealized Influence (Behavior) $\quad 15 \quad 12.5 \quad 12.5 \quad 54.2$

3. Inspirational Motivation $\quad \begin{array}{llll}18 & 15.0 & 15.0 & 69.2\end{array}$

$\begin{array}{lllll}\text { 4. Intellectual Stimulation } & 2 & 1.7 & 1.7 & 70.8\end{array}$

$\begin{array}{lllll}\text { 5. Individualized Consideration } & 12 & 10.0 & 10.0 & 80.8\end{array}$

$\begin{array}{lllll}\text { 6. Contingent Reward } & 10 & 8.3 & 8.3 & 89.2\end{array}$

7. Management-by-Exception $\quad 3 \quad 2.5 \quad 2.5 \quad 91.7$
(Active)

$\begin{array}{lllll}\text { 8. Management-by-Exception } & 6 & 5.0 & 5.0 & 96.7\end{array}$
(Passive)

$\begin{array}{lcccc}\text { 9. Laissez Faire Leadership } & 4 & 3.3 & 3.3 & 100.0 \\ \text { Total } & 120 & 100.0 & 100.0 & \end{array}$

Total 
A One-Way ANOVA was conducted on the MLQ-5X data set to ascertain the variance between the predominant characteristics demonstrated in comparison to the type of leadership. The descriptive results as illustrated in Table 11 show that Administrative Leaders had a mean=2.47 $(n=7)$ and a standard deviation of 0.192 . Teacher leaders had a mean score of $2.43(n=17)$ and a standard deviation of .279. Followers comprised a mean score of $2.05(n=96)$ and a standard deviation of .603 .

Table 11. MLQ 5X-Predominant Characteristic Descriptive Statistics

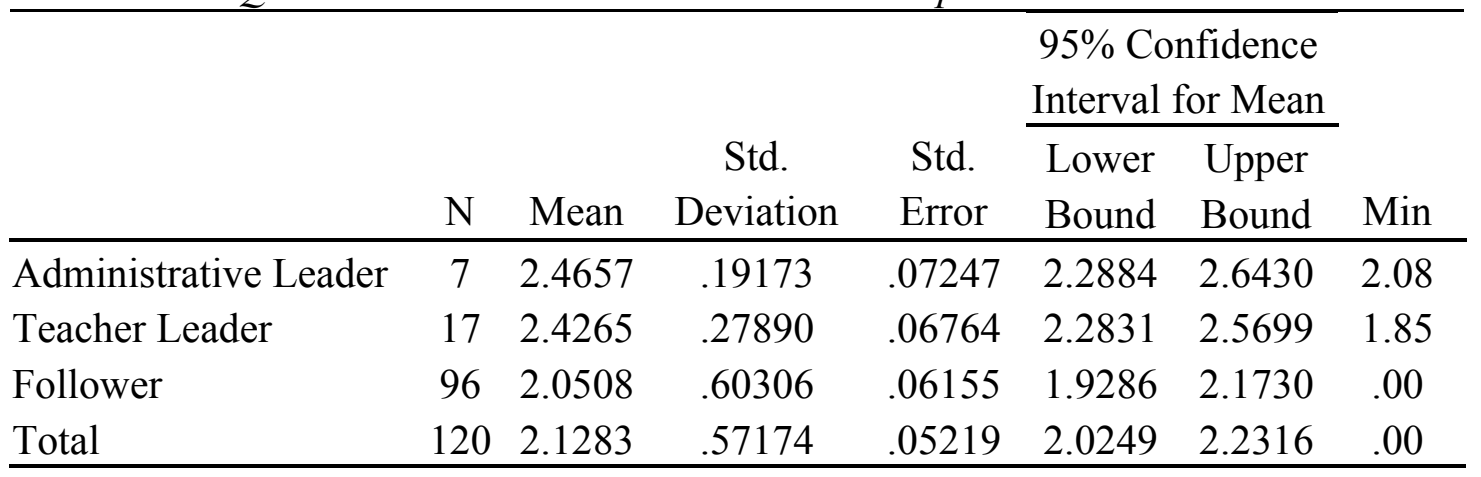

The ANOVA produced an $\mathrm{F}(2,117)=4.685, \mathrm{p}=.011$, which indicates that there is a significant difference between the Administrative Leader group average of $\mathrm{M}=2.47$ of the total MLQ-5X scores, the teacher leader's group's average of $M=2.43$, and follower average $M=2.05$. Table 12 illustrates the significance value between group differences.

Table 12. Multifactor Leadership Questionnaire ANOVA

\begin{tabular}{|c|c|c|c|c|c|}
\hline & $\begin{array}{l}\text { Sum of } \\
\text { Squares }\end{array}$ & $\mathrm{df}$ & Mean Square & $\mathrm{F}$ & Sig. \\
\hline Between Groups & 2.884 & 2 & 1.442 & 4.685 & .011 \\
\hline Within Groups & 36.014 & 117 & .308 & & \\
\hline Total & 38.899 & 119 & & & \\
\hline
\end{tabular}


A Tukey post hoc test was conducted and a multiple comparison analysis was completed to ascertain the between group differences. As Table 13 illustrates, the mean difference between groups and determined that the mean difference between administrative leaders and teacher leaders demonstrated no significant values at $\alpha=0.986$ $(\mathrm{M}=.0392, p>0.05)$. Additionally, the difference between the mean of administrative leaders and followers also demonstrated no significance with values of $\alpha=0.140$ (M= $.415, p>0.05)$. However, the test determined a significant difference between teacher leaders and followers with a significant value of $\alpha=0.030(\mathrm{M}=-.376, p<0.05)$. The results of this test illustrate that teacher leaders and followers demonstrate significantly different results on their total score in the Multifactor Leadership Questionnaire 5XShort Form, while the other groupings did not demonstrate significant differences.

Table 13. Multifactor Leadership Questionnaire Multiple Comparison

\begin{tabular}{lllccc} 
& & \multicolumn{4}{c}{ Mean } \\
& & & Difference & Std. & \\
& & & & \\
(I) Leadertype & $(\mathrm{J})$ Leadertype & $(\mathrm{I}-\mathrm{J})$ & Error & Sig. \\
\hline Tukey & Administrative & Teacher Leader & .03924 & .24916 & .986 \\
$H S D$ & Leader & Follower & .41488 & .21721 & .140 \\
& Teacher & Administrative Leader & -.03924 & .24916 & .986 \\
& Leader & Follower & $.37564^{*}$ & .14599 & .030 \\
& Follower & Administrative Leader & -.41488 & .21721 & .140 \\
& & Teacher Leader & $-.37564^{*}$ & .14599 & .030 \\
\hline
\end{tabular}

$*$ The mean difference is significant at the $p<.05$ level.

The null hypothesis for this research question held that there would be no statistically significance difference between administrative leaders and teacher leaders leadership characteristics based on the results of the MLQ-5X. The results of the study indicate that the null hypothesis is rejected, as there is a significant difference between 
the leadership characteristics of administrative leaders and teacher-leaders. The hypothesis for this research question was that there will be a statistically significant difference between administrative leaders' and teacher-leaders' predominant leadership style as measured by the leaders' and followers' scores on the Multifactor Leadership Questionnaire for Research (MLQ-5X Short Form). The hypothesis in this case is confirmed as is demonstrated by the results of the analysis conducted.

\section{Research Question 2}

Research Question 2 examined the primary school culture profile as determined by the leaders' and followers' scores on the Organizational Description Questionnaire (ODQ). The question focuses the fundamental leadership style that guides the culture of the school and how that culture is reflected on the transformational to transactional continuum. This research sought to understand how the culture of the school is manifested according to the perceptions of the stakeholders of the school. The research centered on the nine characteristics on the transformational to transactional organizational culture continuum. The transformational characteristics are Predominantly Four I's (Maturing), Moderately four I's (Highly Developed), High Contrast, Loosely Guided, and Coasting. The transactional characteristics are Moderately Bureaucratic (Formal), Predominantly Bureaucratic, Pedestrian, and Garbage Can.

The independent variables in this study were the nine characteristics of the school culture profile. The dependent variables were the transformational and transactional school culture as determined by the results of the Organizational Description Questionnaire. The data were collected and first analyzed based on a frequency and mean based on the ODQ (Bass \& Avolio, 2006). An ANOVA analysis was completed to study 
the relationship between the variances of the dependent and independent variable. The measure of transformational to transactional culture was the dependent variable for answering this research question, which was the predominant characteristic demonstrated by the answers taken on the Organizational Description Questionnaire. As Table 14 demonstrates, the responses had a mean of 2.88 and a standard deviation of 1.89 on a true or false survey. The data collected from the survey were coded according to Bass and Avolio’s Organizational Description Questionnaire instruction manual (1992) in which all "true" answers were coded with a "1", all "false" answers were coded with a "-1", and all "?" answers were coded with a "0". A sum total was calculated of those answers and the end results were entered into SPSS.

Table 14. Organizational Description Questionnaire Statistics

\begin{tabular}{lrr}
\hline & Valid & 120 \\
& Missing & 0 \\
\hline Mean & & 2.86 \\
Std. Deviation & & 1.87 \\
Variance & 3.56 \\
Skewness & 1.61 \\
Std. Error of Skewness & .22 \\
\hline
\end{tabular}

The results of the frequency table for the ODQ produced a culture profile for each participant based on the nine characteristics of organizational culture. Table 15, the frequency table illustrates that the transformational characteristic of Moderately Four I's (Highly Developed) accounts for the highest percentage of characteristics at $58.3 \%(f=$ 70), with the next closest characteristics of Predominantly Four I's (Maturing) at 10.8\% $(f=13)$ and High Contrast at $9.2 \%(f=13)$. The lowest percentage is Garbage Can at $0.8 \%$ $(f=1)$ followed by Predominantly Bureaucratic and Loosely Guided both at $2.5 \%(f=3)$. 
Table 15. Frequency and Percent of ODQ Predominant Culture Profile

\begin{tabular}{lcccc}
\hline & & & $\begin{array}{c}\text { Valid } \\
\text { Percent }\end{array}$ & $\begin{array}{c}\text { Cumulative } \\
\text { Percent }\end{array}$ \\
\hline $\begin{array}{l}\text { Predominantly Four I's } \\
\text { (Maturing) }\end{array}$ & 13 & 10.8 & 10.8 & 10.8 \\
$\begin{array}{l}\text { Moderately Four I's (Highly } \\
\text { Developed) }\end{array}$ & 70 & 58.3 & 58.3 & 69.2 \\
High Contrast & 11 & 9.2 & 9.2 & 78.3 \\
Loosely Guided & 3 & 2.5 & 2.5 & 80.8 \\
Coasting & 7 & 5.8 & 5.8 & 86.7 \\
Moderately Bureaucratic & 7 & 5.8 & 5.8 & 92.5 \\
$\begin{array}{l}\text { (Formal) } \\
\text { Predominantly Bureaucratic }\end{array}$ & 3 & 2.5 & 2.5 & 95.0 \\
Pedestrian & 5 & 4.2 & 4.2 & 99.2 \\
Garbage Can & 1 & .8 & .8 & 100.0 \\
Total & 120 & 100.0 & 100.0 & \\
& & & & \\
\hline
\end{tabular}

A One-Way ANOVA was conducted on the ODQ data set to ascertain the variance between the predominant transformational and transactional characteristics demonstrated in comparison to school culture profile. The ODQ Transactional scores were based on all odd numbered questions on the ODQ. The ODQ Transactional scores based on the nine characteristics had a total $\mathrm{N}=120$, and had a range of $n=70$ for the Moderately Four I's to $n=1$ for Garbage Can. Table 16 illustrates the mean and standard deviation for each of the nine characteristics and the transactional scores. Predominantly Four I's (Maturing) had an $\mathrm{M}=-3.54(n=13)$ on a scale of 0 to -14 and had a standard deviation of 4.99. Moderately Four I's (Highly Developed) had an $\mathrm{M}=-0.53(n=70)$ on a scale of 0 to -14 and had a standard deviation of 4.59. High Contrast had an M=3.91 ( $n=$ 11) on a scale of 0 to -14 and had a standard deviation of 5.79. Loosely Guided had an $\mathrm{M}=6.33(n=3)$ on a scale of 0 to -14 and had a standard deviation of 3.05. Coasting had 
an $\mathrm{M}=2.57(n=7)$ on a scale of 0 to -14 and had a standard deviation of 2.57. Moderately Bureaucratic (Formal) had an $\mathrm{M}=1.29(n=7)$ on a scale of 0 to -14 and had a standard deviation of 8.40. Predominantly Bureaucratic had an $\mathrm{M}=2.33(n=3)$ on a scale of 0 to 14 and had a standard deviation of 5.13. Pedestrian had an $\mathrm{M}=1.00(n=5)$ on a scale of 0 to -14 and had a standard deviation of 3.16 . Garbage Can had an $\mathrm{M}=8.00(n=1)$ on a scale of 0 to -14 and had no standard deviation. In totality, the transactional group had a total $\mathrm{M}=0.22(n=12)$ and a standard deviation of 5.24.

The Transformational scores on the ODQ were based on the even numbered of the survey. The ODQ Transformational scores also based on the same nine characteristics had a total N=120 and had a range of 70 for the Moderately Four I's to $n=1$ for Garbage Can. Table 16 also illustrates the mean and standard deviation for the transformational scores, in which the Predominantly Four I's (Maturing) had an $\mathrm{M}=10.62(n=13)$ on a scale of 0 to -14 and had a standard deviation of 5.61. Moderately Four I's (Highly Developed $)$ had an $\mathrm{M}=9.1(n=70)$ on a scale of 0 to -14 and had a standard deviation of 6.53. High Contrast had an $\mathrm{M}=7.82(n=11)$ on a scale of 0 to -14 and had a standard deviation of 8.80. Loosely Guided had an $\mathrm{M}=6.00(n=3)$ on a scale of 0 to -14 and had a standard deviation of 3.61. Coasting had an $\mathrm{M}=11.71(n=7)$ on a scale of 0 to -14 and had a standard deviation of 5.21. Moderately Bureaucratic (Formal) had an $\mathrm{M}=7.14$ ( $n=$ 7) on a scale of 0 to -14 and had a standard deviation of 6.69. Predominantly Bureaucratic had an $\mathrm{M}=2.33(n=3)$ on a scale of 0 to -14 and had a standard deviation of 12.50 . Pedestrian had an $\mathrm{M}=3.80(n=5)$ on a scale of 0 to -14 and had a standard deviation of 10.10. Garbage Can had an $\mathrm{M}=2.00(n=1)$ on a scale of 0 to -14 and had no standard 
deviation. The transformational group, on the other hand, had a total $\mathrm{M}=8.66(N=120)$ and standard deviation of 6.96 .

Table 16. Organizational Description Questionnaire Descriptive Statistics

$$
95 \%
$$

\section{Confidence}

Std. Std. Interval for

\begin{tabular}{|c|c|c|c|c|c|c|c|c|c|}
\hline & & \multirow{3}{*}{$\mathrm{N}$} & \multirow{3}{*}{ Mean } & \multirow{3}{*}{ Dev } & \multirow{3}{*}{ Error } & \multicolumn{2}{|c|}{ Mean } & \multirow[b]{3}{*}{ Min } & \multirow[b]{3}{*}{ Max } \\
\hline & & & & & & Lower & Upper & & \\
\hline & & & & & & Bound & Bound & & \\
\hline ODQ & Predominantly & 13 & -3.54 & 4.99 & 1.38 & -6.56 & -.52 & -10.00 & 6.00 \\
\hline TA & Four I's & & & & & & & & \\
\hline \multirow[t]{12}{*}{ Score } & Moderately & 70 & -.53 & 4.59 & .549 & -1.62 & .57 & -8.00 & 12.00 \\
\hline & Four I's & & & & & & & & \\
\hline & High Contrast & 11 & 3.90 & 5.79 & 1.74 & .02 & 7.80 & -4.00 & 12.00 \\
\hline & Loosely Guided & 3 & 6.33 & 3.06 & 1.76 & -1.26 & 13.92 & 3.00 & 9.00 \\
\hline & Coasting & 7 & 2.57 & 2.57 & .97 & .19 & 4.95 & .00 & 7.00 \\
\hline & Moderately & 7 & 1.29 & 8.40 & 3.18 & -6.48 & 9.06 & -10.00 & 15.00 \\
\hline & Bureaucratic & & & & & & & & \\
\hline & Predominantly & 3 & 2.33 & 5.13 & 2.96 & -10.41 & 15.08 & -2.00 & 8.00 \\
\hline & Bureaucratic & & & & & & & & \\
\hline & Pedestrian & 5 & 1.00 & 3.16 & 1.41 & -2.93 & 4.93 & -2.00 & 6.00 \\
\hline & Garbage Can & 1 & 8.00 & . & . & . & . & 8.00 & 8.00 \\
\hline & Total & 120 & .22 & 5.24 & .48 & -.73 & 1.16 & -10.00 & 15.00 \\
\hline ODQ & Predominantly & 13 & 10.62 & 5.81 & 1.61 & 7.10 & 14.13 & -6.00 & 14.00 \\
\hline $\mathrm{TF}$ & Four I's & & & & & & & & \\
\hline \multirow[t]{12}{*}{ Score } & Moderately & 70 & 9.10 & 6.53 & .78 & 7.54 & 10.66 & -14.00 & 14.00 \\
\hline & Four I's & & & & & & & & \\
\hline & High Contrast & 11 & 7.82 & 8.80 & 2.65 & 1.91 & 13.72 & -14.00 & 14.00 \\
\hline & Loosely Guided & 3 & 6.00 & 3.61 & 2.08 & -2.96 & 14.96 & 2.00 & 9.00 \\
\hline & Coasting & 7 & 11.71 & 5.22 & 1.9 & 6.89 & 16.54 & .00 & 14.00 \\
\hline & Moderately & 7 & 7.14 & 6.69 & 2.53 & .95 & 13.33 & -2.00 & 14.00 \\
\hline & Bureaucratic & & & & & & & & \\
\hline & Predominantly & 3 & 2.33 & 12.50 & 7.22 & -28.73 & 33.39 & -12.00 & 11.00 \\
\hline & Bureaucratic & & & & & & & & \\
\hline & Pedestrian & 5 & 3.80 & 10.11 & 4.52 & -8.75 & 16.35 & -8.00 & 14.00 \\
\hline & Garbage Can & 1 & 2.00 & . & . & . & . & 2.00 & 2.00 \\
\hline & Total & 120 & 8.66 & 6.96 & .63 & 7.40 & 9.92 & -14.00 & 14.00 \\
\hline
\end{tabular}


The ANOVA produced a $\mathrm{F}(8,111)=3.168, \mathrm{p}=.003$, for the transactional score, indicating that the transactional group average of $(M=0.2167)$ of the total ODQ scores for transactional leadership was significant. The transformational score which produced an $\mathrm{F}(8,111)=1.194, \mathrm{p}=.309$, group's average of $(\mathrm{M}=8.68)$ was not significant. Table 17 illustrates the significance value between group differences of transactional and transformational scores.

Table 17. Organizational Description Questionnaire ANOVA

\begin{tabular}{llrrrrr}
\hline & & Sum of & & Mean & & \\
& & Squares & df & Square & F & Sig. \\
\hline ODQ & Between Groups & 608.31 & 8 & 76.04 & 3.17 & .003 \\
Transactional & Within Groups & 2664.06 & 111 & 24.00 & & \\
Score & & & & & & \\
& Total & 3272.37 & 119 & & & \\
\hline ODQ & Between Groups & 456.23 & 8 & 57.03 & 1.19 & .309 \\
$\begin{array}{l}\text { Transformational } \\
\text { Score }\end{array}$ & Within Groups & 5300.77 & 111 & 47.76 & & \\
& Total & 5756.99 & 119 & & & \\
\hline
\end{tabular}

* The mean difference is significant at the $p<.05$ level

The null hypothesis for this research question was that there would be no statistically significant difference between the transactional and transformational predominant school culture profile as measured by the leaders' and followers' scores on the Organizational Description Questionnaire (ODQ). However, the results of the study indicate that there is a significant difference between the predominant school culture profile and the participants' transactional scores. The results of the ANOVA also demonstrate that there is no statistical difference in the predominant culture profile and transformational scores. Therefore, the null hypothesis is rejected and the hypothesis that there will be a statistically significant difference between transactional and 
transformational school culture profiles as measured by the leaders' and followers' scores on the Organizational Description Questionnaire (ODQ) is confirmed.

\section{Research Question 3}

Research Question 3 investigated a connection between the predominant leadership characteristics of educational administrators and teacher-leaders and school culture as determined by an analysis of variance between leader and follower scores on the Multifactor Leadership Questionnaire and the Organizational Description Questionnaire. The purpose of the study was to examine the relationship between the leaders' nine leadership characteristics and the school culture profile. My study sought to combine the previous two elements of leadership and culture and examined each of the nine characteristics of leadership and the nine characteristics of school culture. Therefore, this section also contains a cross tabulation of results in order to provide an overview of the relationship of the participants' characteristics of both leadership and culture.

The independent variable in this study was the MLQ Predominant Characteristic of leadership style. The dependent variable was the Culture Profile as evidenced by the leaders' and followers' scores on the ODQ. The data was collected and first analyzed based on a frequency and mean based on the MLQ and ODQ that produced identical results to the first two research questions and are exhibited in Tables 10 and 15. A second analysis, the cross tabulation, was completed in order to examine the combinations of variables and the relationship between them. Finally, an ANOVA analysis was completed to study the relationship between the variances of the dependent and independent variables and to determine whether there is a statistically significant relationship between school leadership and school culture. The ODQ Culture Profile produced an $\mathrm{M}=2.88$ with 
a standard deviation of $S D=1.89$, while the MLQ Predominant Characteristic produced a mean of $(\mathrm{M}=3.06)$ with a standard deviation of $S D=2.42$ as table 18 demonstrates.

Table 18. MLQ and ODQ Descriptive Statistics

\begin{tabular}{|c|c|c|}
\hline & $\begin{array}{c}\text { ODQ Culture } \\
\text { Profile } \\
\end{array}$ & $\begin{array}{c}\text { MLQ } \\
\text { Predominant } \\
\text { Characteristic }\end{array}$ \\
\hline Valid & 120 & 120 \\
\hline Missing & 0 & 0 \\
\hline Mean & 2.88 & 3.06 \\
\hline Median & 2.00 & 2.00 \\
\hline Std. Deviation & 1.89 & 2.42 \\
\hline Variance & 3.56 & 5.85 \\
\hline Skewness & 1.61 & .99 \\
\hline Std. Error of Skewness & .22 & .22 \\
\hline
\end{tabular}

The cross tabulation between the MLQ Predominant Characteristics and the ODQ Cultural Profile demonstrate the combination of leadership attributes combined with the cultural attributes. The table has been modified in two manners. First, although SPSS produces the information in one singular table, the cross tabulation table has been split into two different tables for use within this document and can be found in Tables 19 and 20. Second, for ease of interpretation the labels on both the $\mathrm{X}$-axis and the $\mathrm{Y}$-axis of the chart have been labeled with a TA signifying transactional characteristics, or a TF for transformational. The intent is to allow readers to understand the connection between the participants' answers on both of the instruments.

The cross tabulation results are indicated by the participants' scores who fall within a particular characteristic on the ODQ, and are cross-referenced with the same participants' score characteristic on the MLQ-5X. In total, there are 81 possible combinations, 44 of which do not have any singular participant that evidenced both 
characteristics. As is evidenced in Table 19, the most common combination was TF Moderately Four I's (Highly Developed) combined with TF Idealized Influence (Attributes) $(\mathrm{N}=30)$. The next most common combination was TF Moderately Four I's (Highly Developed) combined with TF Inspirational Motivation ( $N=13)$. Twenty of the combinations had an $\mathrm{N}=1$, and the remaining 15 had combinations ranging from $\mathrm{N}=2$ to $\mathrm{N}=6$. A total of 84 participants displayed transformational characteristics on both the Leadership characteristics and the culture profile.

Table 19. MLQ and ODQ Predominant Characteristic Cross Tabulation Part 1 ODQCultureProfile Moderately Predominantly Four I's

Four I's (Highly High Loosely
(Maturing) Developed) Contrast Guided

\begin{tabular}{|c|c|c|c|c|c|}
\hline MLQ & Idealized Influence & 3 & 30 & 5 & 1 \\
\hline Predominant & & & & & \\
\hline \multirow[t]{13}{*}{ Characteristic } & $\begin{array}{l}\text { Idealized Influence } \\
\text { (Behavior) }\end{array}$ & 5 & 5 & 0 & 1 \\
\hline & Inspirational & 0 & 13 & 2 & 1 \\
\hline & Motivation & & & & \\
\hline & Intellectual & 1 & 0 & 1 & 0 \\
\hline & Stimulation & & & & \\
\hline & Individualized & 1 & 6 & 2 & 0 \\
\hline & Consideration & & & & \\
\hline & Contingent Reward & 1 & 6 & 0 & 0 \\
\hline & $\begin{array}{l}\text { Management-by- } \\
\text { Exception (Active) }\end{array}$ & 0 & 3 & 0 & 0 \\
\hline & Management-by- & 1 & 5 & 0 & 0 \\
\hline & Exception (Passive) & & & & \\
\hline & Laissez Faire & 1 & 2 & 1 & 0 \\
\hline & Leadership & & & & \\
\hline \multicolumn{2}{|l|}{ Total } & 13 & 70 & 11 & 3 \\
\hline
\end{tabular}


As table 20 illustrates, twenty of the participants had characteristics that were on the transformational continuum for the culture profile, but were transactional on the leadership profile. Conversely, there were 13 participants that scored transactional on the school culture, but displayed transformational characteristics on the leadership continuum. There were 3 participants that displayed transactional characteristics for both the culture profile and the leadership continuum.

Table 20. MLQ and ODQ Predominant Characteristic Cross Tabulation Part 2

\begin{tabular}{|c|c|c|c|c|c|}
\hline & & Coasting & $\begin{array}{l}\text { ODQCu } \\
\text { Moderately } \\
\text { Bureaucratic } \\
\text { (Formal) }\end{array}$ & $\begin{array}{l}\text { ItureProfile } \\
\text { Predominantly } \\
\text { Bureaucratic }\end{array}$ & Pedestrian \\
\hline \multirow{11}{*}{$\begin{array}{l}\text { MLQ } \\
\text { Predominant } \\
\text { Characteristic }\end{array}$} & Idealized & 5 & 1 & 1 & 3 \\
\hline & Influence & & & & \\
\hline & (Attributes) & & & & \\
\hline & $\begin{array}{l}\text { Idealized } \\
\text { Influence } \\
\text { (Behavior) }\end{array}$ & 1 & 1 & 1 & 1 \\
\hline & $\begin{array}{l}\text { Inspirational } \\
\text { Motivation }\end{array}$ & 1 & 0 & 0 & 1 \\
\hline & $\begin{array}{l}\text { Intellectual } \\
\text { Stimulation }\end{array}$ & 0 & 0 & 0 & 0 \\
\hline & $\begin{array}{l}\text { Individualized } \\
\text { Consideration }\end{array}$ & 0 & 3 & 0 & 0 \\
\hline & $\begin{array}{l}\text { Contingent } \\
\text { Reward }\end{array}$ & 0 & 2 & 1 & 0 \\
\hline & $\begin{array}{l}\text { Management- } \\
\text { by-Exception } \\
\text { (Active) }\end{array}$ & 0 & 0 & 0 & 0 \\
\hline & $\begin{array}{l}\text { Management- } \\
\text { by-Exception } \\
\text { (Passive) }\end{array}$ & 0 & 0 & 0 & 0 \\
\hline & $\begin{array}{l}\text { Laissez Faire } \\
\text { Leadership }\end{array}$ & 0 & 0 & 0 & 0 \\
\hline Total & & 7 & 7 & 3 & 5 \\
\hline
\end{tabular}


The ANOVA examining the variance between the ODQ culture profile and the MLQ-5X predominant leadership characteristics, the results showed that the comparison had a total mean of $2.88(\mathrm{~N}=120)$ with a standard deviation of 1.89 . The transformational characteristic of Idealized Influence (Attributes) had a mean= $3.06(n=50)$ and a standard deviation of 2.01. The second characteristic of Idealized Influence (Behaviors) had a mean $=3.00(n=15)$ and a standard deviation of 2.39. Inspirational Motivation had a mean of $2.72(n=18)$ with a standard deviation of 1.56. Intellectual Stimulation had a mean of $2.00(n=2)$ and a standard deviation of 1.41. The last transformational characteristic of Individualized Consideration had a mean of $3.08(n=12)$ and a standard deviation of 1.83. The transactional characteristic of Contingent Reward had a mean of $3.20(n=10)$ and a standard deviation of 2.20. Management-by-Exception (Active) had a mean of $2.00(n=3)$ and a standard deviation of 0.00. Management-by Exception (Passive) had a mean of $1.83(n=6)$ with a standard deviation of 0.41 . Finally, the lack of leadership, Laissez Faire Leadership displayed a mean of $2.00(n=4)$ and had a standard deviation of 0.82 as is demonstrated in table 21 . The most predominant characteristic is Idealized Influence, in which the leader uses power, confidence and trust to gain the respect of followers. The least predominant characteristic was Laissez Faire Leadership in which the leader delegates heavily and allows followers to make decisions, rather than use the leadership role to guide decision making for the group. Laissez Faire Leadership is the leadership style in which the leader delegates authority and lacks leadership skills. This type of leader avoids making decisions and acts in a reactive role rather than proactively. 


\begin{tabular}{|c|c|c|c|c|c|c|c|c|}
\hline & \multirow[b]{2}{*}{$\mathrm{N}$} & \multirow[b]{2}{*}{ Mean } & \multirow[b]{2}{*}{ Deviation } & \multirow{2}{*}{$\begin{array}{l}\text { Std. } \\
\text { Error }\end{array}$} & \multicolumn{2}{|c|}{$\begin{array}{l}95 \% \text { Confidence } \\
\text { Interval for Mean }\end{array}$} & \multirow[b]{2}{*}{ Min } & \multirow[b]{2}{*}{ Max } \\
\hline & & & & & $\begin{array}{l}\text { Lower } \\
\text { Bound } \\
\end{array}$ & $\begin{array}{l}\text { Upper } \\
\text { Bound } \\
\end{array}$ & & \\
\hline $\begin{array}{l}\text { Idealized } \\
\text { Influence } \\
\text { (Attributes) }\end{array}$ & 50 & 3.06 & 2.01 & .28 & 2.49 & 3.63 & 1.00 & 9.00 \\
\hline $\begin{array}{l}\text { Idealized } \\
\text { Influence } \\
\text { (Behavior) }\end{array}$ & 15 & 3.00 & 2.39 & .62 & 1.68 & 4.32 & 1.00 & 8.00 \\
\hline $\begin{array}{l}\text { Inspirational } \\
\text { Motivation }\end{array}$ & 18 & 2.72 & 1.56 & .37 & 1.94 & 3.50 & 2.00 & 8.00 \\
\hline $\begin{array}{l}\text { Intellectual } \\
\text { Stimulation }\end{array}$ & 2 & 2.00 & 1.41 & 1.00 & -10.71 & 14.70 & 1.00 & 3.00 \\
\hline $\begin{array}{l}\text { Individualized } \\
\text { Consideration }\end{array}$ & 12 & 3.08 & 1.83 & .53 & 1.92 & 4.25 & 1.00 & 6.00 \\
\hline $\begin{array}{l}\text { Contingent } \\
\text { Reward }\end{array}$ & 10 & 3.20 & 2.20 & .70 & 1.63 & 4.77 & 1.00 & 7.00 \\
\hline $\begin{array}{l}\text { Management- } \\
\text { by-Exception } \\
\text { (Active) }\end{array}$ & 3 & 2.00 & .00 & .00 & 2.00 & 2.00 & 2.00 & 2.00 \\
\hline $\begin{array}{l}\text { Management- } \\
\text { by-Exception } \\
\text { (Passive) }\end{array}$ & 6 & 1.83 & .41 & .17 & 1.40 & 2.26 & 1.00 & 2.00 \\
\hline $\begin{array}{l}\text { Laissez Faire } \\
\text { Leadership }\end{array}$ & 4 & 2.00 & .82 & .41 & .70 & 3.30 & 1.00 & 3.00 \\
\hline Total & 120 & 2.88 & 1.89 & .17 & 2.53 & 3.22 & 1.00 & 9.00 \\
\hline
\end{tabular}

The ANOVA comparing MLQ-5X leadership characteristics as the independent variable and the ODQ culture profile as the dependent variable produced an $F(8,111)=$ $0.593, p=.782$, for the ODQ culture profile, which indicates that the ODQ culture profile is not significantly different than that of the Multifactor Leadership Questionnaire 
Leadership style. Table 22 illustrates the significance value between group differences of the ODQ culture profile and the MLQ-5X.

Table 22. MLQ and ODQ ANOVA

\begin{tabular}{lccccc} 
& Sum of Squares & df & Mean Square & F & Sig. \\
\hline Between Groups & 17.34 & 8 & 2.17 & .593 & .782 \\
Within Groups & 405.78 & 111 & 3.66 & & \\
Total & 423.13 & 119 & & & \\
& & & & & \\
\hline
\end{tabular}

* The mean difference is significant at the $\mathrm{p}<.05$ level

The null hypothesis for this research question is that there would be no statistically significant difference between the organizational culture profile and that of the leadership characteristics as measured by the leaders' and followers' scores on the Organizational Description Questionnaire and the Multifactor Leadership Questionnaire (5X Short Form). The research results indicate that there is no significant difference between the leaders' leadership style and the predominant school culture profile. Therefore the null hypothesis is confirmed, and the hypothesis that there will be a statistically significant difference between administrative leaders' and teacher-leaders' predominant leadership style and school culture profile as measured by the leaders' and followers' scores on both the Multifactor Leadership Questionnaire (MLQ-5X Short Form) and the Organizational Description Questionnaire (ODQ) is rejected.

\section{Summary}

This study was conducted on three research questions in order to seek an understanding of the relationship between the leadership style of school administrative leaders and teacher-leaders, and a school's culture. There were three distinct levels of study within the research. First was an examination of the leaders' leadership style and an 
examination of the difference between administrative leaders' and teacher leaders' styles of leadership. The second level of study was the leaders' and followers' perceptions of the culture of the school and an examination of where their perceived school culture falls on the school culture profile. The third was a cross examination of the leadership style and the school culture profile in order to ascertain whether or not there was a significant relationship between the two. The research demonstrated significant findings for two of the three research questions. The results of the study illustrate the connection between transformational and transactional characteristics of school leaders and their perception of the culture of their schools. 


\section{CHAPTER V. Conclusions}

The field of education is changing. The paradigms that, for centuries, were successful at educating our youth are no longer adequate to meet the rapidly changing needs of our students, our societies, and our global marketplace. Technology has seen advances in the availability of information and the speed with which we can access it. We have been forced to reimagine the educational system in a way that faces these new challenges head on and seeks to redefine the ways in which we teach our youth. So, too, have we had to redefine our leadership practices in order to address the needs of our teachers for improved pedagogy, differentiated instruction, technological education, standardized testing, standards mastery, and a myriad of other new ideologies. Like education, leadership has evolved into a collaborative relationship that is mutually beneficial to both leaders and followers.

This is the crux of transformational leadership; that it allows leaders to capitalize on the cumulative knowledge of followers while also being able to work with those followers to share in the increasing burdens of the educational paradigm. The roles between leaders and followers have shifted into a less transactional and dictatorial role, and into a role of shared work, shared responsibility, and shared success and achievement.

The purpose of this study was threefold. First, to discover whether or not administrative leaders and teacher leaders were leading in a manner conducive to this shared practice. The leaders and followers shared their impressions and opinions that allowed the researcher to understand the primary leadership characteristics that the leaders demonstrated to them and their followers. The second purpose was to uncover the 
schools' primary culture profile according to those leaders and followers. The schools' culture is pivotal in guiding tradition, motivation, and shared values and beliefs. Therefore, the aim of the second phase of study was to determine the culture profile according to the leaders and followers attitudes about the shared work. The third phase of the study sought to merge these two ideas to ascertain whether or not there was a connection between leadership and school culture. As the summary of findings will demonstrate, there were some significant findings within the three analyses that bear further discussion.

\section{Summary of Findings}

The research study contained three research questions and hypotheses designed to discover answers to those questions. The following is an overview of each of those questions and the findings that were discussed in the results section of the study. Three different research questions were the focus of the study and were answered throughout the course of the analysis. The investigation found significant results for two of the questions. The following is a summary of the findings.

The first research questions sought to illustrate the primary demonstrated leadership style of the administrator and teacher leader as determined by the leaders' scores combined with the follower's scores on the Multifactor Leadership Questionnaire 5X Short Form (MLQ-5X). The results demonstrated that there was a significant difference between the predominant leadership characteristics between administrative leaders and teacher-leaders. This demonstrates that leadership differs between formalized leaders and peer leaders and there is a significant difference between administrative leaders' and teacher-leaders' predominant leadership characteristics. Further, the 
predominant characteristics are transformational in nature, demonstrating that leaders prefer the types of activities that follow from transformational leadership.

The predominant characteristics shown in Figure 1 clearly illustrate Idealized Influence (Attributes) to be the most common of the leadership styles and Intellectual Stimulation to be the least common of the types of leadership styles.

Figure 1. Predominant Full Range Model Characteristic

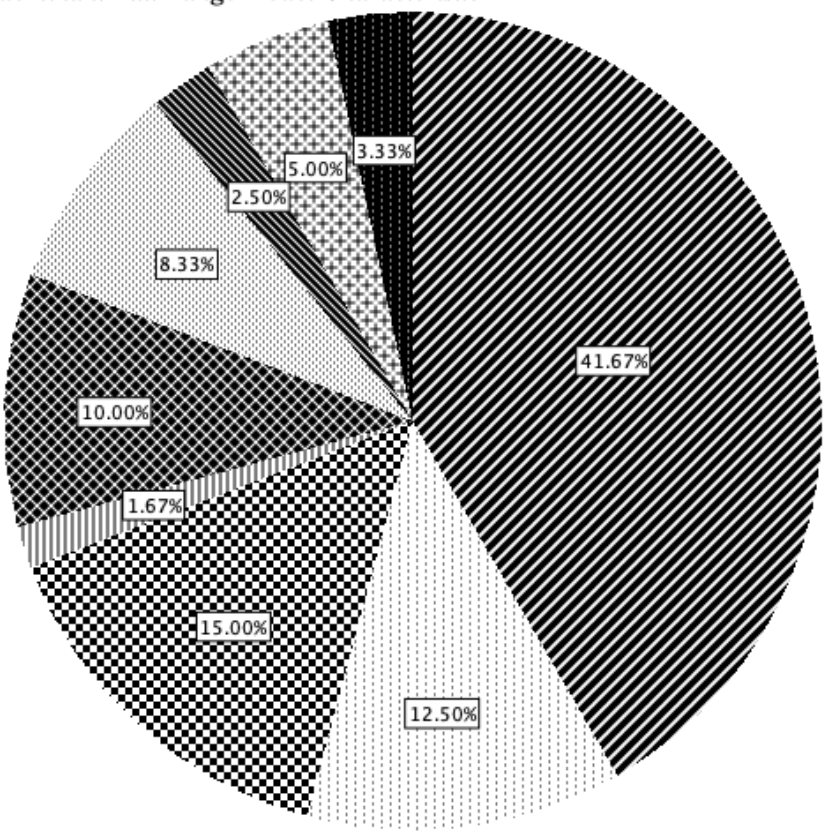

PredominantCharacteristic

Z Idealized Influence (Attributes) Idealized Influence (Behavior)

Inspirational Motivation

|II| Intellectual Stimulation

\& Individualized Consideration Contingent Reward

Management-by-Exception

$\mathbb{N}$ (Active)

$\Phi$ Management-by-Exception

(Passive)

B. Laissez Faire Leadership

Of note, both Idealized Influence and Intellectual Stimulation fall within the transformational range, meaning that they encourage input and value a collaborative style of leadership. Idealized Influence (Attributes) is characterized by a willingness to make sacrifices for the good of the group, a charisma in which the followers believe. Those who display Idealized Influence (Attributes) characteristics are often considered to be confident and powerful, instilling a sense of reassurance in their followers. $41.67 \%$ of the leaders were found to have this characteristic as their predominant leadership style. 
Intellectual Stimulation, on the other hand, the characteristic, which the fewest leaders displayed, is leadership that encourages followers to problem-solve using nontraditional methods, to think creatively, and to reexamine assumptions for problem solving. This type of leadership examines perspectives and the premises upon which those assumptions are made, and calls upon the followers to problem solve in new and unique ways. The results of this study suggest that followers do not interpret their leadership to have these types of factors present. The findings suggest that the followers do not feel that they are encouraged to problem-solve in creative ways that challenge the traditional paradigm.

The other factors that had the most common characteristics were Inspirational Motivation (15.00\%), Idealized Influence (Behavior) (12.50 \%), and Individualized Consideration. Interestingly, those attributes that demonstrated the highest percentage of participants are three of the four I's. The results of the study clearly reveal the value of transformational leadership. The activities of leadership that are displayed throughout these characteristics have shown themselves to be critical in creating positive leadership practices.

Research question 2 identifies the school culture profile as determined by the leaders' and followers' scores on the Organizational Description Questionnaire (ODQ). The results of the research indicate that the predominant characteristic demonstrated was Moderately Four I's (Highly Developed) as shown in Figure 2. A Moderately Four I's culture is one in which the purpose, vision, and values of the organization is the main driving force of the work. Though primarily transformational, this characteristic is marked by a lack of transactional characteristics, which also demonstrates that there can 
be a lack of formalized agreements about this work (Turan \& Bektas, 2013). The least demonstrated culture profile was that of Garbage Can, in which the participant perceives that the organization lacks leadership and a clear vision for the school. Garbage Can cultures tend to lack unity and purpose and may not have contractual rules, roles, or obligations (Bass and Avolio, 1993).

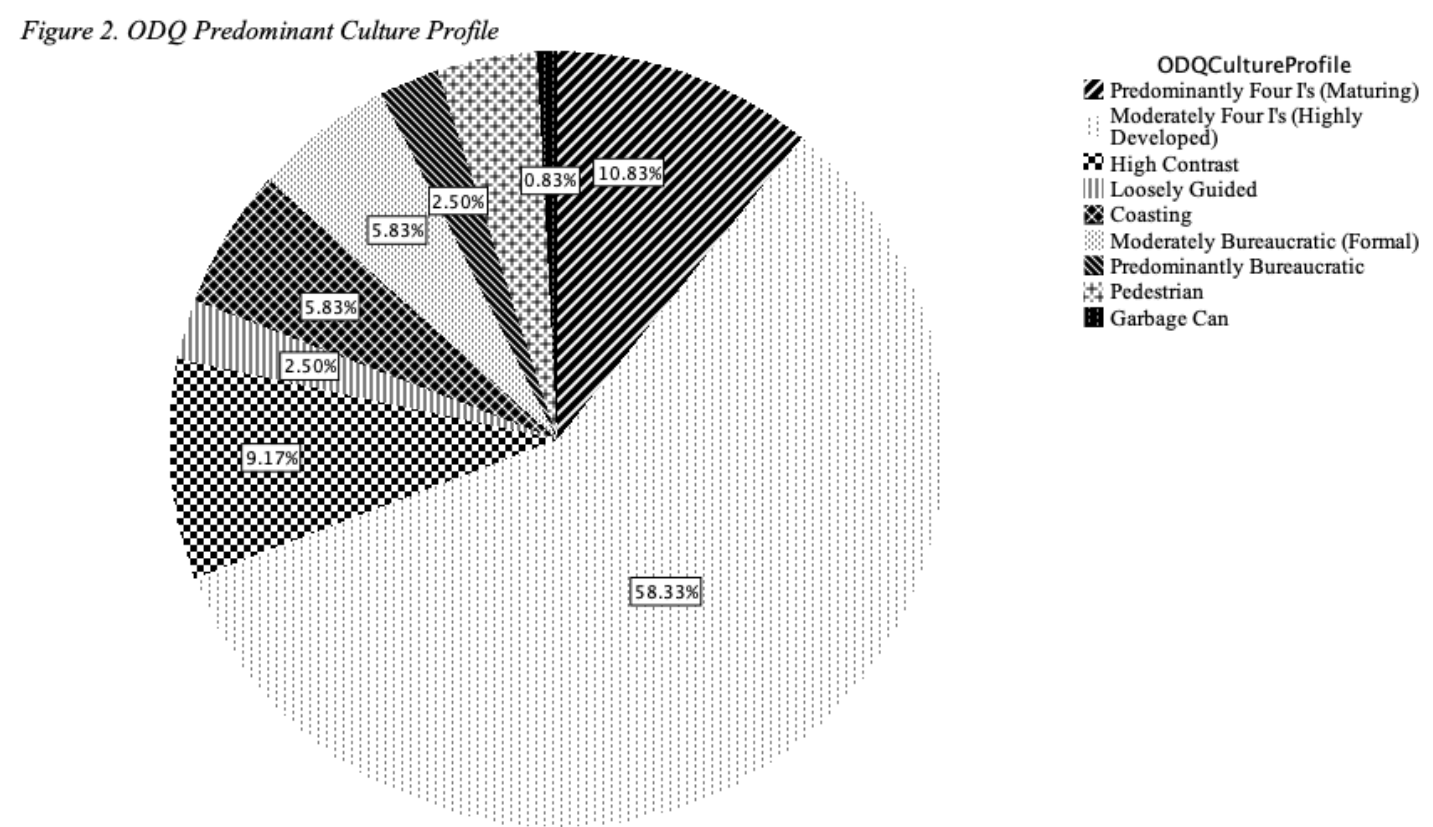

The analysis of variance revealed that there is a statistical significance between the scores of the participants on the transactional section of the ODQ and those of the transformational scores. This indicates a strong difference between the school culture profile and transactional leadership. The lack of transactional characteristics in the culture profile hints at a less formalized culture in which the organization may lack some of the processes and contractual agreements. According to Bass and Avolio (1993), a culture of predominantly Four I's is likely to emphasize employee individuality and potential (1993). In addition, organizations of this nature the individuals are likely to exercise creativity and tend to be highly adaptive (Bass and Avolio, 1993). 
Conversely, the results of the study show that the predominant culture profile according to the participants is overwhelmingly transformational in nature. There is no statistically significant difference between the transformational sections of the ODQ. This demonstrates a likeness in the characteristics of the participants that scored high transformational scores on the ODQ. The participants' opinion of their organizational culture is that their schools demonstrate a strong personal and organizational purpose in their organization and in their own roles within the organization. In these instances, the participants are likely to feel that they have the right to express their needs freely; and therefore, these participants are likely to feel valued within their organization. The fact that there is no statistical significance demonstrates a synchrony between the two ideologies of transformational organizational culture and transformational leadership.

So, when the study turns to research question 3, establishing whether there is a connection between the leadership style of educational administrators and teacher-leaders and school culture as determined by and analysis of variance between leader and follower scores on the MLQ-5X and the ODQ, the research takes on a different meaning. While there was no statistical significance between the predominant leadership characteristics and the school culture profile, it becomes apparent that this is because these transformational activities are already happening.

The results of the study demonstrated no statistical significance between the ODQ Culture profile as the dependent variable and the MLQ leadership style as the independent variable, we see that they seem to be synchronous as well. The significance value was $\alpha=.782(F=0.593, p<0.05)$, demonstrating that the leadership style that was predominant was transformational in nature, as was the ODQ. Therefore, we would 
expect to see no statistical difference between them. In this instance, administrative leaders are indicating transformational practices within their schools and are, in fact, leading their schools to be transformational in culture as well.

The same does not hold precisely true in instances of teacher-leadership where the predominant characteristic was less transformational. Those teacher-leaders are charged with the daily activities of running their departments, leading their teachers, and working within the confines of their own classrooms. Therefore, their activities could be construed as more transactional by their very nature. This could be a reason for the perception that teacher-leaders are not as transformational in their leadership style and bears further examination.

The results of this three-phase study have demonstrated a wealth of opportunity for the research to understand the connection between the different levels of leadership, leadership style, and school culture within the context of the schools in Miami Dade County Public Schools. It is apparent that there is a strong significance in administrative leaders transformational practices, while teacher leaders do not necessarily show such a strong practice. Additionally, school culture has shown itself to be transformational, which is indicative of a strong culture of independence, growth, and adaptation.

\section{Discussion and Limitations of Results}

Educational leadership is the cornerstone of educational practices within the schools themselves. It is imperative that we work towards a greater understanding of how the style of leadership practiced within each organization impacts those within that school. This study sought to shed light on the style of leadership within the frame of transformational and transactional leadership. It also sought to elucidate the connection 
between the particular leadership style of administrators themselves, and their direct subordinates- the teacher-leaders. One of the findings of this study was that there is a significant difference between administrative leaders' and teacher leaders' leadership style.

The implications of this finding are many, but the main takeaway from this study is that there is a need for increased attention to the leadership styles of teacher leaders. Their activities are often in direct contact with the teachers and students in their department, therefore it is imperative that leadership training and understanding extend to those teachers in that role (Shelton, 2014). The research is lacking in teacher-leadership practices and there has been a lack of focus on how these teachers can help administrators to solidify the vision of their schools (Angelle \& Schmid, 2007). For instance, Mangin (2007) demonstrated that administrators who understood the importance of teacherleaders were better able to bridge the gaps in education and attainment while working to improve school initiatives. Therefore, this study demonstrates that there is a gap between either the training that administrative leaders and teacher-leaders receive, or there is a difference in natural leadership abilities.

This difference is one of the limitations of this study. The study does not evaluate whether these leadership styles are innate, or learned. Therefore, the study lends itself to a natural progression of research, in that finding out the origin of leadership styles and their development could help us to further understand exactly why some leaders are better at creating success, and why some leaders naturally exhibit transformational or transactional tendencies. This in turn, could help us to better train those teacher-leaders that are so very imperative to a school's success. 
In addition, one of the main facets of the research was the connection made between leaders and their followers. This study demonstrates that the predominant characteristic of the leadership is significantly skewed towards transformational leadership. One of the more interesting conversations revolves around the leaders' perceptions versus those of their followers. The research results demonstrated that the predominant culture profile was Moderately Four I's, which is a tendency towards transformational leadership tempered with transactional formalized agreements. It is this formalization that maintains the ordered paradigm of the education system.

It has also become increasingly apparent that a school's culture is one of the key determining factors in the success and achievement of the school as a whole. Bolman \& Deal (2006) highlighted the essential qualities of culture that make for success at a school and Arifin (2014) uncovered the connection between culture and job satisfaction. This study reveals that a transformational school culture is tantamount to transformational leadership in that both of these types of activities are critical to success. The activities that take place at the school are more or less successful depending on the amount of buyin, engagement, and dedication of those whose job it is to fulfill those functions. School culture plays an important role in that capacity. Those who operate in the culture influence the culture in and of themselves by their very interactions within the school.

Therefore, it is the leadership and the followers that both help to guide the culture of the school and also operate within that culture. One of the implications of this study is that there is an obvious accord between leadership style and school culture. The results demonstrated that there was a significant difference between transactional culture and the 
school's culture, which demonstrates that the schools have shifted away from the codified practices of transactional culture and towards those of flexible and collaborative practice.

One of the limitations of this study is that school culture has several other influencing factors. Issues such as socio-economic standing, community relations, and parent involvement all influence those who operate within the school. This study does not differentiate out those factors in the examination of school culture. It may be that one or more of these other factors have a greater influence on the schools' culture than leadership.

However, it was precisely this connection that this study sought to highlight; the connection between administrative leadership, teacher-leadership, and school culture. The research has already shown that leadership and culture are connected, but it is unclear why or just how (Aspen Institute, 2014). While the results of this research demonstrated statistical significance, it is of note here that the predominant leadership style was transformational, just as the predominant school culture profile was transformational. The end result is that the reasons for the correlation, while apparent, remains elusive. As previously pointed out, there are many mitigating factors in school culture and also in leadership styles (Veiseh et al., 2014). It may be that any one of those factors has an influence that is more significant.

However, the connection is still clear. Transformational leadership is a chief factor in these schools' leaders, just as it is in school culture. Therefore, the discussion turns to more a minute examination of the precise practices that make up both of these factors between leadership and culture. This leads to more questions that could further guide researchers in forging a better understanding of leadership and school culture. Are 
there particular things that transformational leaders do that create transformational culture? Conversely, are leaders more transformational because of the culture? Each of these questions open up a new avenue of inquiry which could help researchers to better understand this connection between leadership and culture.

This study contributes to the body of research by connecting leadership, teacherleadership, and school culture. The era of purely transactional leadership is past, but this study shows that effective schools still have some component of those formalized agreements that make for effective processes and efficient organizations. Indeed, the schools surveyed in this research demonstrated components of transactional culture as well as those of transformation. It is this middle ground that will enable real change to take place in that while we understand the need to change the processes and to collaborate and encourage individualistic thinking, we often fall back on the pedagogies that have always been the cornerstone of education. By understanding the school culture, the leaders and followers alike can use the school's strengths and weaknesses in order to make real change.

One of the main findings in this study demonstrated that there was a significant difference between teacher leaders and followers. Additionally, the teacher leader group demonstrated more transactional characteristics than those of the administrative leadership. This demonstrates a need to focus on teacher leaders' contributions to the school in order to ascertain the true impact that teacher leaders have on their followers and on the culture of the school. While it is important to note the differing roles that teacher leaders play in the context of the daily activities that they fulfill in terms of the hands on management of those in their department, it is also crucial for us to understand 
how teacher leaders obtain their leadership skills. By understanding whether teacher leaders are trained leaders or rather those that display innate leadership characteristics, we will be able to target training practices in which we can leverage these leadership abilities to create a more thoughtful leadership program. By pairing administrative leaders with teacher leaders in a deliberate manner, we can potentially influence the culture of the school.

The relationship between leadership styles and school culture is apparent and bears further scrutiny, and this study opens the door to a wider understanding of this connection. The results of this study demonstrate that transformational practices are alive and well within these schools, and that the symbiosis that exist between teachers and leaders creates a culture that encourages challenge, originality, and capacity building rather than rewarding compliance, assimilation, and passivity. This study is important because it demonstrates that leadership and culture are coexistent and interdependent upon one another. This study shows us that leadership styles help to build a culture; where we find leadership characteristics, we also find culture.

\section{Suggestions for Further Research}

The research completed within this study sought to fill a gap in the research and create a connection between administrative leadership and teacher-leadership and school culture. The study contributes to a growing body of research that demonstrates that there is a need to broaden the scope of the research being conducted in terms of education and leadership. While studies abound regarding teaching, students, pedagogy, and curriculum, we are beginning to understand the importance of educational leadership and its impact on systemic efforts to educate our youth. 
Leadership within the education system is multifaceted with some challenges that are completely unique to leadership. While the results of this study demonstrated a strong transformational connection between administrative leaders and teacher leaders, there may be a need to understand the leadership characteristics of followers. Further study into the followers' innate or trained characteristics may prove to be beneficial in that it may assist formalized leaders in using leadership practices that are effective and differentiated to the needs of the followers.

In addition, further study may be warranted into effective transactional practices. While transformational leadership is critical to a modern organization, it is also clear that some transactional practices are necessary to maintain roles, obligations, and contractual formalized agreements between leaders and followers. While there is some research that elucidates the benefits of transactional leadership (Moujaes et al, 2012), it may prove useful to research specific best transactional practices that lend themselves to improved transformational leadership and the characteristics of transformational leadership. So, further research into how each of these practices works within the symbiosis between leadership styles and culture may be beneficial for the use of purposeful training and cultivation of characteristics that show themselves to be the most relevant to productivity and motivation.

Interestingly, the thinking portion of Intellectual Stimulation is ingrained within education and is the cornerstone of educational attainment, and so it raises questions about why our leadership would not seek this in followers. Further research could help to elucidate the reasoning behind a paradigm that seeks inventive problem solving in students but not in those whose primary purpose is to teach those same students. 
Challenging the paradigm of traditional education is the cornerstone of educational reform practices; therefore, it is the very idea of non-traditional problem solving that will eventually lead to innovative change and practices in a system which is becoming increasingly antiquated for our society and our youth. Examining the means through which we can encourage and implement new, unique, and non-traditional answers to questions and asks that those within a paradigm to reexamine and question previous assumptions may lead to a greater understanding of initial suppositions. By investigating these beliefs, researchers may find a way in which leaders can gain new perspectives and answers to problems within education.

One suggestion for further research into organizational culture is the means through which specific transformational cultures develop and can be nurtured within an organization. Purposeful means through which leaders can build organizations whose culture focuses on those transformational practices would be valuable. Researchers are only now beginning to understand that culture may be purposefully cultivated and teacher-leadership may play an important role in those activities that help promote transformational culture. Practical applications for developing and implementing transformational practices will be essential in creating a purposefully transformational culture.

This research can lead to a "best practices" approach in which we work to research the specific activities of transformational leaders in order to be able to find a best fit for schools that are suffering from a strong transactional culture in which there is little collaboration and little symbiosis between leaders and followers. By placing transformational leaders within a school that is highly transactional, the leader will be 
able to introduce some of these best practices for transformational leadership. This in turn will enable the collaborative growth and processes that will unlock innovative ideas leading to transformation.

Conversely, this research demonstrates that an organization that is too transformational can lack formalized agreements and processes necessary for the day to day running of the organization. An organization that lacks these processes tends to focus on the theoretical solution rather than the practical application of the solution. Therefore, a leader that proves themselves to be more transactional in nature can assist in clarifying and implementing the agreements, rules, and roles needed for these visions to become a reality. This research can help to elucidate the needs of the schools by examining the culture profile and then examining the leaders within the school to see whether they are the best fit for the needs of the school environment.

Further, this research was limited to the scope of the schools within Miami Dade County Public Schools that were surveyed. A wider study that encompasses many schools within Miami Dade may yield differing results. Replication of this research may be beneficial in more traditional school systems in which we may be able to understand the implications of smaller paradigms. The question of whether more conservative school districts are more or less likely to practice transformational leadership or transformational culture. In addition, widening the scope of this research to other large districts may elucidate whether the schools within Miami Dade are unique in their leadership practices and components of culture. 


\section{Conclusion}

Throughout this study, it has become clear that there are many avenues that can be further explored in the connection between school leadership and school culture. By using this research as a keystone research, school systems can adapt their leadership styles to the needs of the specific schools and can select leaders that exhibit the needed characteristics of the school to maximize the potential for achievement and to improve the culture of the school. In addition, they can target training practices within the district in order to deliberately train and place leaders in positions in which they will achieve the greatest improvement results.

This study follows a body of research that seeks to understand leadership and school culture so that educators and educational systems can better address the needs of leaders, teachers, students, and the educational organization. There are a myriad of concerns surrounding the current state of education. The paradigms under which we operate are complicated, confounded, and often comingled in a manner that makes it difficult to gauge the best means through which improvements can be made.

One thing is clear, in the increasingly turbulent systems that govern education, leadership and the roles that all leaders play is ever more important. Understanding how effective administrative leaders and teacher-leaders guide others and their organizations has been the cornerstone of this study. These leaders are the foundation upon which the organization rests; it is their duty to lead teachers and students into achieving their highest potential. The practices that they inhabit influence the future of those they touch, and their example is what makes a school effective. 
The habits, visions, and functions of the school dictate on many levels the successes of the school and its students. This basis for shared mission brings together the village that seeks to educate the youth of our society. It is this culture within which these organizations and its people operate, and is truly a microcosm of the societies from which they are borne. And so it is imperative that we continually seek to comprehend the relationships that exist between administrators, teacher-leaders, and school culture. 


\section{REFERENCES}

Amar, A. D. (2001). Leading for innovation through symbiosis. European Journal of Innovation Management, 4(3), 126-132.

Anderson, K. D. (2008). Transformational teacher leadership in rural schools. Rural Educator, 29(3), 8-17.

Angelle, P. S., \& DeHart, C. A. (2011). Teacher perceptions of teacher leadership: Examining differences by experience, degree, and position. NASSP Bulletin, 95(2), 141-160.

Angelle, P. S., \& Schmid, J. B. (2007). School structure and the identity of teacher leaders: Perspectives of principals and teachers. Journal of School Leadership, 17(6), 771-799.

Antonakis, J., Avolio, B.J., \& Sivasubramaniam, N. (2003). Context and leadership: An examination of the nine-factor full-range leadership theory using the Multifactor Leadership Questionnaire [electronic version]. The Leadership Quarterly, 14, 261-295.

Aspen Institute. A culture of high expectations: Teacher leadership at Pritzker College prep. (2014).

Arifin, H. M. (2015). The influence of competence, motivation, and organisational culture to high school teacher job satisfaction and performance. International Education Studies, 8(1), 38-45.

Avolio, B.J. (2007). Promoting more integrative strategies for leadership theory-building. American Psychologist, 62(1), 25-33.

Avolio, B.J. \& Bass, B.M. (2004). Multifactor leadership questionnaire: Third edition manual and sampler set. Menio Park, CA: Mind Garden.

Avolio, B.J., Bass, B.M., \& Jung, D.I. (1999). Re-examining the components of transformational and transactional leadership using the Multifactor leadership questionnaire. Journal of Occupational and Organizational Psychologyx, 72, 441462.

Barnett, K., \& McCormick, J. (2003). Vision, relationships and teacher motivation: A case study. Journal of Educational Administration, 41(1), 55-73.

Barnett, K., McCormick, J. \& Conners, R. (2001). Transformational leadership in schools: Panacea, placebo or problem? Journal of Educational Administration, 39(1), 24. 
Bass, B.M. (1985). Leadership and performance beyond expectations. New York, Free Press, Collier MacMillan.

Bass, B.M. (1997). Does the transactional-transformational leadership paradigm transcend organizational and national boundaries? American Psychologist, 52(2), 130-139.

Bass, B.M., \& Avolio, B.J. (1989). Potential biases in leadership measures: How prototypes, leniency, and general satisfaction relate to ratings and rankings of transformational and transactional leadership constructs. Educational and Psychological Measurement, 49(3), 509-527.

Bass, B.M., \& Avolio, B.J. (1993). Transformational Leadership and organizational culture. Public Administratoin Quarterly, 17(1), 112.

Bass, B.M., \& Avolio, B.J. (1992). Organizational description questionnaire: Manual and sampler set. Menio Park, CA: Mind Garden.

Bass, B. M., \& Avolio, B. J. (2006). Leadership Culture: The Organisation Description Questionnaire. MLQ, Leadership Assessment and Development Services.

Bass, B.M., Avolio, B.J., Jung, D.I., and Berson, Y. (2003). Predicting unit performance by assessing transformational and transactional leadership [Electronic version]. Journal of Applied Psychology, 88(2), 207-218.

Bolman, L.G. \& Deal, T.E. (2006). The wizard and the warrior: Leading with passion and power. San Francisco, CA: Jossey-Bass.

Bowman, R. F. (2004). Teachers as leaders. The Clearing House, 77(5), 187-189.

Brosky, D. (2011). Micropolitics in the school: Teacher leaders' use of political skill and influence tactics. International Journal of Educational Leadership Preparation, $6(1), 11$.

Burns, J. M. (1978). Leadership. New York, New York: Harper \& Row.

Camburn, E. M. (2009). Allocating more experienced teachers to leadership positions in schools: A double-edged sword? Journal of School Leadership, 19(6), 680-696.

Cheng, J. (2012). An exploration and examination of the school culture of accumulated virtue and kind deeds: Using organizational commitment and teacher efficacy to examine its efficacy. The Journal of Human Resource and Adult Learning, 8(1), 16-29. 
Davis, H., \& Macauley, P. (2011). Taking library leadership personally. Australian Library Journal, 60(1), 41-53.

DeGroot, T., Kiker, D. S., \& Cross, T. C. (2000). A meta-analysis to review organizational outcomes related to charismatic leadership. Canadian Journal of Administrative Sciences, 17(4), 356-371.

Den Hartog, D., Van Muijen, J., \& Koopman, P. (1997). Transactional versus transformational leadership: An analysis of the MLQ [Electronic version]. Journal of Occupational and Organizational Psychology, 70, 19-34.

Dininno, M. A. (2012). A multiple-case study examining promoters and inhibitors of teacher transformational leadership (Ed.D.). ProQuest Dissertations \& Theses A\&I: Social Sciences, ProQuest Dissertations \& Theses Global: Social Sciences. (1197649165)

Downton, J.V. (1973). Rebel Leadership: Commitment and Charisma in the Revolutionary process, Free Press, New York

Edwards, M. R. (1992). Symbiotic leadership: A creative partnership for managing organizational effectiveness. Business Horizons, 35(3), 28.

Eshbach, E. C. (2008). The symbiotic relationship between new principals and the climate of the schools in which they lead. (Ed.D., Duquesne University). ProQuest Dissertations and Theses. (304639261).

Fu, P. P., \& Yukl, G. (2000). Perceived effectiveness of influence tactics in the united states and china. Leadership Quarterly, 11(2), 251-266.

Giese, T. H., Slate, J. R., Brown, M. S., \& Tejeda-Delgado, C. (2009). Female high school principals: Leadership practices and individual traits. Advancing Women in Leadership, 29, 1-10.

Griffith, J. (2004). Relation of principal transfornational leadership to school staff job satisfaction, staff turnover, and school performance. Journal of Educational Administration, 42(3), 333-356.

Hampton, K. (2010). Transforming school and society: Examining the theoretical foundations of scholar-practitioner leadership. Scholar-Practitioner Quarterly, 4(2), 185-193.

Hinde, E.R. (2004). School culture and change: An examination of the effects of school culture on the process of change. Journal of Geography, 104(4), 95-103. 
Hinkin, T. \& Tracey, J. (1999). The relevance of charisma for transformational leadership in stable organizations [Electronic version]. Journal of Organizational Change Management, 12 (2), 105.

Inabinett, Jean M, \& Ballaro, J. M. (2014). Developing an organization by predicting employee retention by matching corporate culture with employee's values: A correlation study. Organization Development Journal, 32(1), 55-74.

Jackson, K. M., \& Marriott, C. (2012). The interaction of principal and teacher instructional influence as a measure of leadership as an organizational quality. Educational Administration Quarterly, 48(2), 230-258.

Judge, T. A., \& Piccolo, R. F. (2004). Transformational and transactional leadership: A meta-analytic test of their relative validity. Journal of Applied Psychology, 89(5), 755-768.

Lahtero, T. J., \& Risku, M. (2014). Symbolic leadership culture and its subcultures in one unified comprehensive school in Finland. The International Journal of Educational Management, 28(5), 560-577.

Leithwood, K. A. (1992). The move toward transformational leadership. Educational Leadership, 49(5), 8-12.

Leithwood, K. and Jantzi, D. (1997), Explaining variation in teachers' perceptions of principals' leadership: A replication, Journal of Educational Administration, Vol. 35 No. 4, pp. 312-31.

Leithwood, K.; Louis, K.,Anderson, S. \& Wahlstrom, K. (2011) How Leadership Influences Student Learning: Final Report, The Wallace Foundation: New York,

Leithwood, K., and Patrician, P. (2015). Changing the educational culture of the home to increase student success at school. Societies, 5(3), 664-685.

Mangin, Melinda M. (2007), Facilitating elementary principals' support for instructional teacher leadership. Educational Administration Quarterly, 43(3), 319-357.

Moujaes, C., Hoteit, L., Hiltunen, J. \& Sahlberg, P. (2012). Transformation leadership in education, three key imperatives for lasting change. Abu Dhabi: Booz \& Co.

Nader, M., Perugini, M. L. L., \& Solano, A. C. (2006). Adaptation and validation of the organizationl description questinnaire: A civil and military study. Revista De Psicología, 24(2), 152-173. 
National Commission on Excellence in Education. (1983). A Nation at risk: The Imperative for educational reform.

Northouse, P. G. (2018). Leadership: Theory and practice. (8th ed.). Sage Publishing.

Parry, K.W., \& Proctor-Thomson, S.B. (2001). Testing the validity and reliability of the Organisational Description Questionnaire, International Journal of Organisational Behaviour, 4(3), 111-124.

Parry, K., and Proctor-Thompson, S. (2007). Perceived integrity of transformational leaders in organizational settings. Journal of Business Ethics, 35(2), 75-96.

Peterson, K. and Deal T. (1998). How leaders influence the culture of schools. Educational Leadership 56 (1), 28-30.

Quantz, R.A., Rogers, J., \& Dantley, M (1991). Rethinking transformative leadership: Toward democratic reform of schools. Journal of Education. 172(3). 96-117.

Sergiovanni, T. J. (1996). Building community in schools. Jossey-Bass Inc., Publishers, Maxwell Macmillan International Publishing Group.

Shelton, M. P. (2014). Teacher leadership: Development and research based on teacher leader model standards (Ed.D.). Available from ProQuest Dissertations \& Theses A\&I, ProQuest Dissertations \& Theses Global. (1560248147).

Springer, P. J, Clark, C. M, Anef, F., Strohfus, P., \& Belcheir, M. (2012). Using transformational change to improve organizational culture and climate in a school of nursing. Journal of Nursing Education, 51(2), 81-88.

Tavares-Silva, \& Pessanha, E. C. (2012). Observations of school culture: From theorists to curriculum issues. International Education Studies, 5(4), 65-70.

Thoonen, E., Sleegers, P., Oort, F., Peetsma, T., \& Geijsel, F. (2011). How to improve teaching practices: The role of teacher motivation, organizational factors, and leadership practices. Educational Administration Quarterly. 47, 496-536.

Turan, S., \& Bektas, F. (2013). The relationship between school culture and leadership practices. Eurasian Journal of Educational Research, (52), 155-168.

Veiseh, S., Mohammadi, E., Pirzadian, M., \& Sharafi, V. (2014). The relation between transformational leadership and organizational culture (case study: Medical school of Ilam). Journal of Business Studies Quarterly, 5(3), 113-124. 
Wang, F., \& Zepeda, S. J. (2013). A comparative study of two schools: How school cultures interplay the development of teacher leadership in mainland china. Creative Education, 4(9B), 63-68.

Wilmore, E.L., \& Thomas, C. (2001). The new century: Is it too late for transformational leadership? Educational Horizaons, 79(3), 115-123.

Yu, H., Leithwood, K. \& Jantzi, D. (2002). The effects of transformational leadership on teachers' commitment to change in Hong Kong [Electronic version]. Journal of Educational Administration, 40(4), 368-389. 
APPENDIX A

FIU CITI IRB Research Certification

\section{MEMORANDUM}

To:

Dr. Peter Cistone, Principal Investigator

CC:

File

From:

Eliza Gomez, M.Ed., Coordinator, Research Integrity

Date:

September 29, 2016

Protocol Title: "Measuring the Relationship Between Educational Administrators' and Teacher-Leaders' Leadership Style and School Culture"

The Florida Intemational University Office of Research Integrity has reviewed your research study for the use of human subjects and deemed it Exempt via the Exempt Review process.

\section{IRB Protocol Exemption \#: IRB-16-0378 IRB Exemption Date: $\quad$ 09/29/16 \\ TOPAZ Reference \#: $\quad 105090$}

As a requirement of IRB Exemption you are required to:

1) Submit an Event Form and provide immediate notification of:

- Any additions or changes in the procedures involving human subjects.

- Every serious or unusual or unanticipated adverse event as well as problems with the rights or welfare of the human subjects.

2) Submit a Project Completion Report Form when the study is finished or discontinued.

Special In conducting research in the Miami-Dade County Public Schools Conditions: $\quad$ System (M-DCPS), upon receiving this FIU IRB Approval, the Investigator must submit her application to the M-DCPS Research Review Committee which must include a copy of the FIU IRB Approval letter. This application complies with the School Board rule 6Gx13-6A1.38 which states that "Any request from people outside the public school system, or from employees seeking university degrees, must be submitted to the Research Review Committee (RRC)." The application forms and contact information can be found at http://oer.dadeschools.net.

Upon approval from M-DCPS RRC, the investigator must submit a copy of the M-DCPS RRC approval letter to the FIU IRB Office (Office of Research Integrity) to complete the process.

For further information, you may visit the IRB website at http://research.fiu.edu/irb. 


\section{COLLABORATIVE INSTITUTIONAL TRAINING INITIATIVE (CITI PROGRAM)}

COURSEWORK REQUIREMENTS REPORT*

- NOTE: Soores on this Requirements Report reflect quiz completions at the time all requirements for the course were met. See list below for details. See separate Transcript Report for more recent quiz scores, including those on optional (supplemental) course elements.

- Name: Kristina Garcia (ID: 1402988)

- Email: $\quad$ kgarc030gfu.edu

- Institution Affiliation: Florida Imternational University (ID: 970 )

- Institution Unit: Engish

- Phone: 306-323-5249

- Curriculum Group: Responsible Conduct of Research

- Course Learner Group: Social and Behavioral Responsible Conduct of Research Course

- Stage: $\quad$ Stage 1-RCR

- Description: This course is for imvestigators, staff and students with an interest or focus in Social and Behavioral research. This course contains text, embedded case studies AND quizzes.

- Report ID:

Completion Date: $\quad$ 02/15/2016

- Expiration Date: N/A

- Minimum Passing:

- Reported Score*: $\quad 100$

REQUIRED AND ELECTIVE MODULES ONLY

Research Misconduct (RCR-Basic) (ID: 16604)

Data Management (RCR-Basic) (ID: 16600)

Authorship (RCR-Basic) (ID: 16597)

Peer Review (RCR-Basic) (ID: 16603)

Using Animal Subjects in Research (RCR-Basic) (ID: 13301)

Conflicts of Interest (RCR-Basic) (ID: 16599)

Collaborative Research (RCR-Basic) (ID: 16598)

Research Imvolving Human Subjects (RCR-Basic) (ID: 13566)

DATE COMPLETED

$02 / 09 / 16$

$02 / 09 / 16$

$02 / 10116$

$02 / 10 / 16$

$02 / 11 / 16$

$02 / 11 / 16$

$02 / 15 / 16$

$02 / 15 / 16$
SCORE

$5 / 5(100 \%)$

$5 / 5(100 \%)$

$5 / 5(100 \%)$

$5 / 5(100 \%)$

$5 / 5(100 \%)$

$5 / 5(100 \%)$

$5 / 5(100 \%)$

$5 / 5(100 \%)$

For this Report to be valid, the learner identified above must have had a valid affiliation with the CITI Program subscribing institution identified above or have been a paid Independent Learner.

ciTI Program

Email: clisupporistismismied

Phone: $305-243-7970$

Web: https:/lwwww. citiprogram arg 


\section{COLLABORATIVE INSTITUTIONAL TRAINING INITIATIVE (CITI PROGRAM)}

COURSEWORK TRANSCRIPT REPORT ${ }^{\text {t* }}$

NOTE: Scores on this Transcript Report reflect the most current quiz completions, including quizzes on optional (supplementa) elements of the
course. See list below for detais. See separate Requirements Report for the reported scores at the time all requirements for the course were met.

- Name: Kristina Garcia (ID: 1402988)

- Email: $\quad$ kgarc030Bfiu.edu

- Institution Affiliation: Florida International University (ID: 970)

- Institution Unit: English

- Phone: $\quad 306-323-5249$

- Curriculum Group: Responsible Conduct of Research

- Course Learner Group: Social and Behavioral Responsible Conduct of Research Course

- Stage: Stage 1 - RCR

- Description: This course is for imvestigators, staff and students with an interest or focus in Social and Behavioral research. This course contains text, embedded case studies AND quizzes.

- Report ID:

18672078

- Report Date:

$02 / 15 / 201$

- Current Score"*:

100

REQUIRED, ELECTIVE, AND SUPPLEMENTAL MODULES

Responsible Conduct of Research (RCR) Course Introduction (ID: 1522)

Using Animal Subjects in Research (RCR-Basic) (ID: 13301)

Research Imwolving Human Subjects (RCR-Basic) (ID: 13566)

Authorship (RCR-Basic) (ID: 16597)

Introduction to the Responsible Conduct of Research Archived 1248 (ID: 1248)

Collaborative Research (RCR-Basic) (ID: 16598)

Conflicts of Interest (RCR-Basic) (ID: 16599)

Data Management (RCR-Basic) (ID: 16600)

Peer Review (RCR-Basic) (ID: 16603)

Research Misconduct (RCR-Basic) (ID: 16604)

Responsible Conduct of Research (RCR) Caurse Conclusion (ID: 1043)

MOST RECENT SCORE

09/16/09 No Quiz

02/11/16 $\quad 5 / 5(100 \%)$

$02 / 15 / 16 \quad 5 / 5(100 \%)$

$02 / 10 / 16 \quad 5 / 5(100 \%)$

09/16/09 No Quiz

$02 / 15 / 16 \quad 5 / 5(100 \%)$

$02 / 11 / 16 \quad 5 / 5(100 \%)$

$02 / 11169 / 16 \quad 5 / 5(100 \%)$

$02 / 10 / 16 \quad 5 / 5(100 \%)$

$\begin{array}{ll}02 / 10 / 16 & 5 / 5(100 \%) \\ 02 / 09 / 16 & 5 / 5(100 \%)\end{array}$

For this Report to be valid, the learner identified above must have had a valid affiliation with the CITI Program subseribing institution identified above or have been a paid Independent Learner.

citi Program

Email: ctisupporiamiamied

Phone: 305-243-7970

Web: hllps:lihwow. ciliprogram arg 
Superintendent of Schools Alberto \%. Carvalino

Dctober 24, 2016

Mrs. Kristina Garcia

12233 SW I04 Lane

Miami, FL 33I86

Dear Mrs. Garcia:
Miami-Dade County School Board Dr. Domthy Rendrosabares Hantoman, Chair Susie V. Castilio Dr. Lawrence S. Foldman Or. Wibert "Tec' Hollowsy Dr. Martiv Karn Raquel A. Regalado Dr. Morta Pórez Wuriz

I am pleased to inform you that the Research Review Committee (RRC) of the Kiami-Dade County Public Schools (MDCPS) has granted you approval for your request to conduct the study: "Measuring the Relationship Between Educational Administrators' and Teacher Leaders' Leadership Style and School Culture" in order to fulfill the requirements of your dissertation at Florida International University.

This RRC approval is granted with the following conditions:

1. Participation in this study is at the discretion of the principal of each targeted school.

Please note that even with the approval of the RRC, it is still the responsibility of the Principal as the gatekeeper of the school to decide whether to participate or not. As stated in the Board rule, ".. the principa/ of the individual school has the privilege of deciding if RRC-approved research will be conducted within his/her school"

A copy of this appraval letter must be presented/and or shared with the Principal of each targeted school.

2. The participation of all subjects (such as students, faculty. or staff) is voluntary. The anonymity and/or confidentiality of all subjects must be assured

3. As you stated in section 23 of your application, participant consent forms must be secured for ALL targeted subjects prior to their participation in the study.

4. The purpose of this study is to demonstrate a comprehensive research model that leads to a better understanding of leadership style based on an enhanced use of the "Full Range Model" that includes an examination of the perceptions of follawers.

5. The study will involve the voluntary participation of approximately 15 principals and I,000 teachers in a paper and pencil survey of approximately 45 Likert-type questions. The Multifactor Leadership Duestionnaire has twa forms: a Leader Form and a Rater Form.

6. Disruption of the schaol's routine by the data collection activities of the study must be kept at a minimum. Data collection activities must not interfere with the district's testing schedule.

7. All research activities must be conducted with the knowledge and approval of the Principal of each targeted school. All efforts should be made to minimize any negative impact on the learning environment.

Assessment, Research, and Data Analysis * School Board Administration Building • 1450 N.E. 2nd Ave. * Suite 222 * Miami, FL 33132 305-995-7091 • 305-995-7512 * www.dadeschools.net 
It should be emphasized that the approval of the Research Review Committee does not constitute an endorsement of the study. It is simply a permission to request the voluntary cooperation in the study of individuals associated with MDCPS.

It is your responsibility to ensure that appropriate procedures are followed in requesting an individual's cooperation, and that all aspects of the study are conducted in a professional manner. With regard to the latter, make certain that all documents and instruments distributed within MDCPS as a part of the study are carefully edited.

The appraval number for your study is 2168. This number should be used in all communications to clearly identify the study as approved by the Research Review Committee. The approval expires on 06/30/2017. During the approval period, the study must adhere to the design, procedures and instruments which were submitted to the Research Review Committee. Finally. as indicated in your application, please submit to the RRC an abstract of the research findings by December 2017.

If there are any changes in the study as it relates to MDCPS, the RRC must be notified in writing. Substantial changes may necessitate resubmission of the request. Failure to notify me of such a change may result in the cancellation of the approval.

If you have any questions, please call me at 305-995-7091. Dn behalf of the Research Review Committee, I want to wish you every success with your study.

Sincerely.

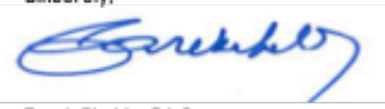

Tarek Chebbi, Ed. D.

Chairperson

Research Review Committee

\section{(*) F.IL. ARB - $16-13378$ (Exempt)}

Note: The researcher named in this letter of approval will be solely responsible and strictly accountable for any deviation from or failure to follow the research study as approved by the RRC. M-DCPS will NOT be held responsible for any claim and/or damage resulting from conducting this study. 


\section{APPENDIX C}

\section{Letter of Invitation to Participate}

\section{August 22, 2016}

Title of Study: Measuring the Relationship Between Educational Administrators' and TeacherLeaders' Leadership Style and School Culture

Principal Investigator: Peter J. Cistone, Major Professor, Leadership and Professional Studies, Florida International University

Student Principal Investigator: Kristina K. Garcia, Doctoral Candidate/ Dissertation Author, Leadership and Professional Studies, Florida International University

I, Kristina K. Garcia, student researcher and doctoral candidate, from the Department of Leadership and Professional Studies, Florida International University, invite you to participate in a research project entitled Measuring the Relationship Between Educational Administrators' and Teacher-Leaders' Leadership Style and School Culture.

The purpose of this research project is to examine the leadership styles of principals and teacherleaders in your school and to evaluate your school's culture. Participation in this research study is voluntary. Should you choose to participate, you and your faculty will be asked to complete two short surveys based on leadership styles and school culture.

The expected duration will be $25-35$ minutes for instructions and the completion of the surveys.

This research should benefit the school and its leaders by defining a relationship between school culture and the leadership styles of the principal and teacher-leaders within the school, which will assist leaders in decision-making and goal setting activities at the school.

This study consists of research conducted at multiple school sites and uses surveys that were developed by Bernard Bass and Bruce Avolio (1997). This research is conducted in partial fulfillment of the requirements for a doctoral degree in Education Administration and Supervision.

If you have any pertinent questions about your rights as a research participant, please contact the Florida International University Research Ethics Officer 305-348-2494, ori@fiu.edu)

If you have any questions, please feel free to contact me (see below for contact information).

Thank you,

[Insert Principal Investigator's Signature]

Kristina K. Garcia

Student Researcher, Doctoral Candidate 305-323-5249

kgarc030@fiu.edu
Peter J. Cistone

Major Professor, Faculty Supervisor 305-348-2665 cistonep@fiu.edu

This study has been reviewed and received ethics clearance through Florida International University's Research Ethics Board file number 105090 and Miami Dade County Public School Research Review Committee. 


\section{APPENDIX D}

\section{Oral Script for Instrument Administration}

Oral Script for Request for Participation

Good afternoon,

Thank you for having me. My name is Kristina Garcia. I am an Assistant Principal at Miami Palmetto Senior High and a doctoral candidate at Florida International University. My dissertation is on Educational Leadership styles and school and I am focusing on principals and teacher-leaders. The purpose of this study will be to evaluate the relationship between leadership styles and school culture. The outcome of this study may assist administrators and leaders in making decisions that will positively affect the culture of the school and will enable to them to set goals that will allow for the betterment of educational efforts.

I am requesting your participation in evaluating the school culture and one leader at this school. Participation in this study is voluntary. No names will be collected with the research. All research will be kept confidential and anonymous and all data will be kept in a secured location.

You will be evaluating your principal, your department or grade level chair, or another formal teacher-leader here at your school such as the test chair, or instructional coach. Each of you will be provided with and envelop containing an informed consent, a random leadership assignment, and two surveys, one for leadership styles and one for school culture. I am asking you to complete these surveys to the best of your ability. The expected total time for completion of both surveys will be $15-25$ minutes.

Thank you for your time and participation. Are there any questions? 
Appendix E

Adult Participant Consent Form

\section{FIU}

\section{ADULT CONSENT TO PARTICIPATE IN A RESEARCH STUDY}

Measuring the Relationship Between Educational Administrators' and Teacher-Leaders' Leadership Style and School Culture

\section{PURPOSE OF THE STUDY}

You are being asked to be in a research study. The purpose of this study is to examine the leadership style of current principals and teacher-leaders in order to assess the relationship between their leadership style and school culture.

\section{NUMBER OF STUDY PARTICIPANTS}

If you decide to be in this study, you will be one of 1000 people in this research study.

\section{DURATION OF THE STUDY}

Your participation will require $30-45$ minutes.

\section{PROCEDURES}

If you agree to be in the study, we will ask you to do the following things:

1. Evaluate the assigned leader or teacher-leader one time by answering 45 survey questions of the Multifactor Leadership Questionnaire Self or Rater ( $5 \mathrm{x}$ Short form) in a paper and pencil format.

2. Evaluate the current leadership culture of your school one time by answering 28 survey questions on the Organizational Description Questionnaire in a paper and pencil format.

\section{RISKS AND/OR DISCOMFORTS}

The following risks may be associated with your participation in this study: There are no known risks associated with this study.

\section{BENEFITS}

The following benefits may be associated with your participation in this study: Your school will receive a school culture profile and leadership profile which will allow the school leaders to make informed decisions about goal setting and improvements to educational leadership activities for the benefit of the school, teachers, and students.

\section{ALTERNATIVES}

There are no known alternatives available to you other than not taking part in this study. However, any significant new findings developed during the course of the research and which may relate to your willingness to continue participation will be provided to you.

\section{CONFIDENTIALITY}

The records of this study will be kept private and will be protected to the fullest extent provided by law. In any sort of report we might publish, we will not include any information that will 
make it possible to identify a subject. Research records will be stored securely and only the research team will have access to the records. However, your records may be reviewed for audit purposes by authorized university or other agents who will be bound by the same provisions of confidentiality.

\section{COMPENSATION \& COSTS}

You will receive no payment or monetary compensation for your participation. You will not be responsible for any costs to participate in this study.

\section{RIGHT TO DECLINE OR WITHDRAW}

Your participation in this study is voluntary. You are free to participate in the study or withdraw your consent at any time during the study. Your withdrawal or lack of participation will not affect any benefits to which you are otherwise entitled. The investigator reserves the right to remove you without your consent at such time that they feel it is in the best interest.

\section{RESEARCHER CONTACT INFORMATION}

If you have any questions about the purpose, procedures, or any other issues relating to this research study you may contact Kristina K. Garcia at $12233 \mathrm{SW} 104^{\text {th }}$ Lane Miami, Florida 33186, phone: 305-323-5249, email: kgarc030@fiu.edu.

\section{IRB CONTACT INFORMATION}

If you would like to talk with someone about your rights of being a subject in this research study or about ethical issues with this research study, you may contact the FIU Office of Research Integrity by phone at 305-348-2494 or by email at ori@fiu.edu.

\section{PARTICIPANT AGREEMENT}

I have read the information in this consent form and agree to participate in this study. I have had a chance to ask any questions I have about this study, and they have been answered for me. I understand that I will be given a copy of this form for my records.

Signature of Participant

Printed Name of Participant

$\overline{\text { Signature of Person Obtaining Consent }}$
Date

Date 


\section{Demographic Information Survey}

\section{a1 $\mid \begin{aligned} & \text { FLORIDA } \\ & \text { INTERNATIONAI }\end{aligned}$ \\ UNIVERSITY}

\section{Participant Demographic Information}

Location \#:

Dear Participant,

Thank you for your participation in this study. Please answer all questions in the Multi Factor Leadership Questionnaire Rater about the following leader:

\section{Your Principal}

Name of Principal:

\section{Demographic Information:}

These questions are about you, your education and the time you have spent in teaching. In responding to the questions, please mark the appropriate box.

1. What is your gender?

$\square_{\text {Female }} \quad \square$ Male

2. How old are you?

$\square_{21-29} \square_{30-39} \square_{40-49} \square_{50-59} \square_{60+}$

3. What is your employment status as a teacher?

Full -time $\quad \square_{\text {Part-time (50-90\% of full-time hours) }}$

4. What is your employment status as a teacher with MDCPS? Please do not consider the probationary period of a contract as a separate contract.

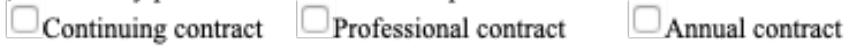

5. What is the highest level of formal education that you have completed? Please mark one choice.

$\square_{\text {Bachelor's }} \square_{\text {Master's }} \square_{\text {Specialist }} \square_{\text {Doctorate }}$

6. How many years have you been working as a teacher? Where possible exclude extended periods of absence (e.g. career breaks).

$\square_{1-5} \quad \square_{6-10} \quad \square_{11-15} \quad \square_{16-20} \quad \square_{21-30} \square_{31+}$

7. How many years have you been working as a teacher at this school? Where possible exclude extended periods of absence (e.g. career breaks).

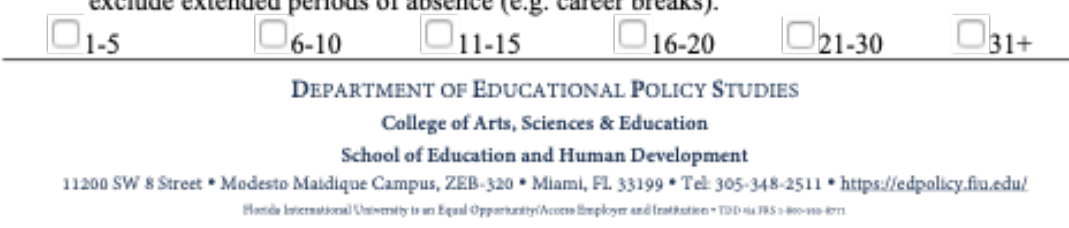




\title{
APPENDIX G
}

Multifactor Leadership Questionnaire Permission and Survey Sample

\author{
For use by Kristina Garcla only. Recelved from Mind Garden, Inc. on November 6, 2016 \\ Permission for Kristina Garcia to reproduce 501 copies \\ within one year of November 6, 2016

\begin{tabular}{|c|}
\hline $\begin{array}{c}\text { Multifactor Leadership Questionnaire } \\
{ }^{\mathrm{TM}}\end{array}$ \\
Instrument (Leader and Rater Form) \\
and Scoring Guide \\
(Form 5X-Short)
\end{tabular}

by Bruce Avolio and Bernard Bass

Published by Mind Garden, Inc.

info@mindgarden.com

www.mindgarden.com

IMPORTANT NOTE TO LICENSEE

If you have purchased a license to reproduce or administer a fixed number of copies of an existing Mind Garden instrument, manual, or workbook, you agree that it is your legal responsibility to compensate the copyright holder of this work -- via payment to Mind Garden for reproduction or administration in any medium. Reproduction includes all forms of physical or electronic administration including online survey, handheld survey devices, etc.

The copyright holder has agreed to grant a license to reproduce the specified number of copies of this document or instrument within one year from the date of purchase.

You agree that you or a person in your organization will be assigned to track the number of reproductions or administrations and will be responsible for compensating Mind Garden for any reproductions or administrations in excess of the number purchased.

This instrument is covered by U.S. and international copyright laws as well as various state and federal laws regarding data protection. Any use of this instrument, in whole or in part, is subject to such laws and is expressly prohibited by the copyright holder. If you would like to request permission to use or reproduce the instrument, in whole or in part, contact Mind Garden, Inc. 


\section{MLQ Multifactor Leadership Questionnaire ${ }^{\mathrm{TM}}$ Leader Form (5x-Short)}

My Name:

Date:

Organization ID \#: Leader ID \#:

This questionnaire is to describe your leadership style as you perceive it. Please answer all items on this answer sheet. If an item is irrelevant, or if you are unsure or do not know the answer, leave the answer blank.

Forty-five descriptive statements are listed on the following pages. Judge how frequently each statement fits you. The word "others" may mean your peers, clients, direct reports, supervisors, and/or all of these individuals.

Use the following rating scale:

\begin{tabular}{|ccccc|}
\hline Not at all & Once in a while & Sometimes & Fairly often & $\begin{array}{c}\text { Frequently, } \\
\text { if not always }\end{array}$ \\
0 & 1 & 2 & 3 & 4 \\
\hline
\end{tabular}

1. I provide others with assistance in exchange for their efforts.

2. I re-examine critical assumptions to question whether they are appropriate ................................... $0 \begin{array}{lllll}1 & 2 & 3 & 4\end{array}$

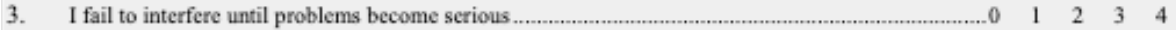

4. I focus attention on irregularities, mistakes, exceptions, and deviations from standards ................... $0 \begin{array}{lllll}1 & 2 & 3 & 4\end{array}$

5. I avoid getting involved when important issues arise _............................................................ $0 \begin{array}{lllll}1 & 2 & 3 & 4\end{array}$

6. I talk about my most important values and beliefs _......................................................................

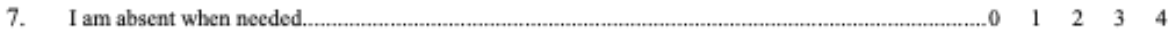

8. I seek differing perspectives when solving problems ...........................................................

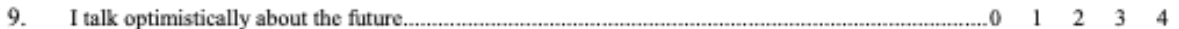

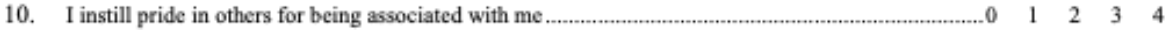

11. I discuss in specific terms who is responsible for achieving performance targets ............................... $0 \begin{array}{lllll}1 & 2 & 3 & 4\end{array}$

12. I wait for things to go wrong before taking action …............................................................ $0 \begin{array}{lllll} & 1 & 2 & 3\end{array}$

13. I talk enthusiastically about what needs to be accomplished................................................ $0 \begin{array}{llllll} & 2 & 3 & 4\end{array}$

14. I specify the importance of having a strong sense of purpose ........................................... $0 \begin{array}{lllll}1 & 2 & 3 & 4\end{array}$

15. I spend time teaching and coaching ............................................................................... $0 \begin{array}{lllll} & 1 & 2 & 3 & 4\end{array}$ 


\section{MLQ Multifactor Leadership Questionnaire Rater Form (5x-Short)}

Name of Leader: Date:

Organization ID \#: Leader ID \#:

This questionnaire is to describe the leadership style of the above-mentioned individual as you perceive it. Please answer all items on this answer sheet. If an item is irrelevant, or if you are unsure or do not know the answer, leave the answer blank. Please answer this questionnaire anonymously.

IMPORTANT (necessary for processing): Which best describes you?

I I am at a higher organizational level than the person I am rating.

The person I am rating is at my organizational level.

I am at a lower organizational level than the person I am rating.

I do not wish my organizational level to be known.

Forty-five descriptive statements are listed on the following pages. Judge how frequently each statement fits the person you are describing. Use the following rating scale:

\begin{tabular}{|ccccc|}
\hline Not at all & Once in a while & Sometimes & Fairly often & $\begin{array}{c}\text { Frequently, } \\
\text { if not always }\end{array}$ \\
0 & 1 & 2 & 3 & 4 \\
\hline
\end{tabular}

THE PERSON I AM RATING. .

1. Provides me with assistance in exchange for my efforts ......................................................... $0 \begin{array}{lllll}1 & 2 & 3 & 4\end{array}$

2. Re-examines critical assumptions to question whether they are appropriate.................................. $0 \begin{array}{llllll}1 & 2 & 3 & 4\end{array}$

3. Fails to interfere until problems become serious................................................................... $0 \begin{array}{llllll} & 2 & 3 & 4\end{array}$

4. Focuses attention on irregularities, mistakes, exceptions, and deviations from standards.................. $0 \begin{array}{llllll}1 & 2 & 3 & 4\end{array}$

5. Avoids getting involved when important issues arise _........................................................ $0 \begin{array}{llllll}1 & 2 & 3 & 4\end{array}$

6. Talks about their most important values and beliefs ............................................................

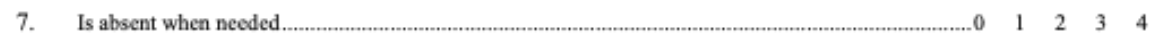

8. Seeks differing perspectives when solving problems ........................................................... $0 \begin{array}{lllll}0 & 1 & 2 & 3 & 4\end{array}$

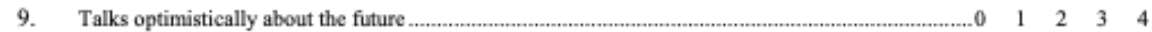

10. Instills pride in me for being associated with him/her ........................................................ $0 \begin{array}{llllll}1 & 2 & 3 & 4\end{array}$

11. Discusses in specific terms who is responsible for achieving performance targets ............................ $0 \begin{array}{lllll}1 & 2 & 3 & 4\end{array}$

12. Waits for things to go wrong before taking action ......................................................... $0 \begin{array}{llllll} & 1 & 2 & 3 & 4\end{array}$

13. Talks enthusiastically about what needs to be accomplished ........................................... $0 \begin{array}{llllll}1 & 2 & 3 & 4\end{array}$

14. Specifies the importance of having a strong sense of purpose ................................................. $0 \begin{array}{llllll}1 & 2 & 3 & 4\end{array}$

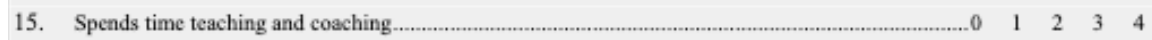

Continued $=$

1995 Bruce Avolio and Bernard Bass. All rights reserved in all media.

Published by Mind Garden, Inc., www.mindgarden.com 


\section{APPENDIX H}

Organizational Description Questionnaire Permissions and Survey Sample

For use by Kristina Garcla only. Recelved from Mind Garden, Inc. on November 6, 2016

Permission for Kristina Garcia to reproduce 501 copies

within one year of November 6, 2016

\section{Organizational Description Questionnaire Instrument and Scoring Guide}

\section{by Bernard M. Bass and Bruce J. Avolio}

Published by Mind Garden, Inc.

info@mindgarden.com

www.mindgarden.com

\section{IMPORTANT NOTE TO LICENSEE}

If you have purchased a license to reproduce or administer a fixed number of copies of an existing Mind Garden instrument, manual, or workbook, you agree that it is your legal responsibility to compensate the copyright holder of this work -- via payment to Mind Garden - for reproduction or administration in any medium. Reproduction includes all forms of physical or electronic administration including online survey, handheld survey devices, etc.

The copyright holder has agreed to grant a license to reproduce the specifled number of copies of this document or instrument within one year from the date of purchase.

You agree that you or a person in your organization will be assigned to track the number of reproductions or administrations and will be responsible for compensating Mind Garden for any reproductions or administrations in excess of the number purchased.

Copyright 1992 Bernard Bass and Bruce Avolio. All Rights Reserved. 
For use by Kristina Garcla only. Recelved from Mind Garden, Inc. on November 6, 2016

ORGANIZATIONAL DESCRIPTION QUESTIONNAIRE (ODQ) [FORM A]

Name of your organization

INSTRUCTONS For items 1 through 28, circle " $T$ " for a true statement, " $F$ " for a false statement, or "?" if you are undecided or cannot say about the team, department, or organization you are leading or representing.

IN MY TEAM, DEPARTMENT OR ORGANIZATION...

\begin{tabular}{ll|ll}
$T$ & F & W. We negotiate with each other for resources.
\end{tabular}

T F ? 2. People go out of their way for the good of the team, department and/or organization.

T F ? 3. Decisions are often based on precedents.

\begin{tabular}{ll|ll}
$T$ & $F$
\end{tabular} ? 4 There is continuous search for ways to improve operations.

\begin{tabular}{ll|ll}
$\mathrm{T}$ & $\mathrm{F}$ & ? & R. Rules and procedures limit discretionary behavior.
\end{tabular}

T F ? 6. Mistakes are treated as learning opportunities.

T F ? 7. You get what you earn - no more, no less.

T F ? 8. When you are unsure about what to do, you can get a lot of help from others.

\begin{tabular}{ll|ll}
$T$ & $F$
\end{tabular} ? $\quad$ There is strong resistance to changing the old ways of doing things.

T F ? 10. We trust each other to do what's right.

T F ? 11 . It's hard to find key people when you need them most.

$\begin{array}{llll}T & F\end{array}$ ? 12 . We are encouraged to consider tomorrow's possibilities.

\begin{tabular}{ll|ll}
$T$ & $\mathrm{~F}$
\end{tabular} ? 13 . Bypassing channels is not permitted.

T F ? 14. New ideas are greeted with enthusiasm.

T F ? 15. One or two mistakes can harm your career.

T F ? 16. Individual initiative is encouraged.

T F ? 17. Decisions often require several levels of authorization before action can be taken.

T F ? 18. We strive to be the best in whatever we do.

T F ? 19. Agreements are specified in advance on what each of us must do to complete the work.

T F ? 20. Stories are shared of the challenges that we have overcome.

\begin{tabular}{ll|ll}
$T$ & $\mathrm{~F}$ & 21. People are hesitant to say what they really think.
\end{tabular}

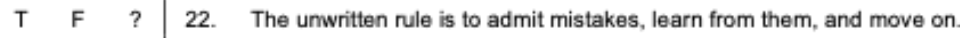

T F ? 23. We have to compete with each other to acquire resources.

$\begin{array}{llll}T & F\end{array}$ 24. You advance or achieve depending on your initiative and ability.

\begin{tabular}{ll|ll}
$\mathrm{T}$ & $\mathrm{F}$ & ? & 25. Deviating from standard operating procedures without authorization can get you into
\end{tabular} trouble.

T F ? 26. We share the common goal of working toward the team, department and/or organization's success.

T F ? 27. People often try to avoid responsibility for their actions.

T F ? 28. We encourage a strong feeling of belonging.

Thank you for your cooperation in completing this questionnaire. 
VITA

KRISTINA K. GARCIA

Born, Oakland, California

$1998-2002$

B.A., English

Florida International University

Miami, Florida

2003-2005

Teacher, Mater Academy Charter School

2005- 2014

Teacher, Felix Varela Senior High

2008- 2011

M.A., English

Florida International University

Miami, Florida

Thesis: Examining the Proximity of Power Structures in Dystopian and Anti-Utopian Literature

2015-2017

Assistant Principal of Curriculum, Palmetto Senior High

2018-2019

Teacher, Milton High School

$2011-2020$

Doctoral Candidate

Florida International University

Miami, Florida

2019-Current

Assistant Principal, Riverwood International Charter School 